Portland State University

PDXScholar

1994

\title{
The Schooling of Vietnamese-American High School Students in Oregon: Their Perspectives
}

Minh Van Tran

Portland State University

Follow this and additional works at: https://pdxscholar.library.pdx.edu/open_access_etds

Part of the Bilingual, Multilingual, and Multicultural Education Commons Let us know how access to this document benefits you.

\section{Recommended Citation}

Tran, Minh Van, "The Schooling of Vietnamese-American High School Students in Oregon: Their Perspectives" (1994). Dissertations and Theses. Paper 1314.

https://doi.org/10.15760/etd.1313

This Dissertation is brought to you for free and open access. It has been accepted for inclusion in Dissertations and Theses by an authorized administrator of PDXScholar. Please contact us if we can make this document more accessible: pdxscholar@pdx.edu. 


\title{
THE SCHOOLING OF VIETNAMESE-AMERICAN HIGH SCHOOL STUDENTS IN OREGON: \\ THEIR PERSPECTIVES
}

\author{
by \\ MINH VAN TRAN
}

A dissertation submitted in partial fulfillment of the requirements for the degree of

\author{
DOCTOR OF EDUCATION \\ in \\ EDUCATIONAL LEADERSHIP: \\ ADMINISTRATION AND SUPERVISION
}

Portland State University

1994 


\section{DISSERTATION APPROVAL}

The abstract and dissertation of Minh Van Tran for the Doctor of Education in Educational Leadership: Administration and Supervision were presented October 27, 1994, and accepted by the dissertation committee and the doctoral program.

COMMITTEE APPROVALS:

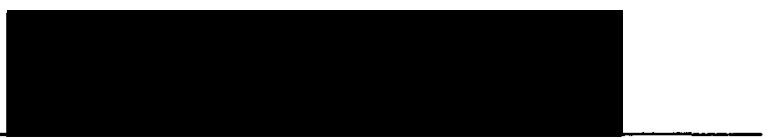

Kenneth Peterson, Chair

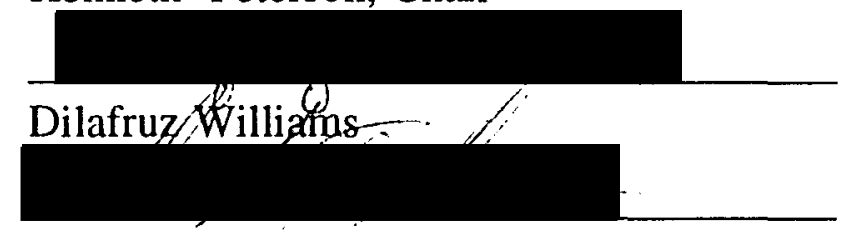

Douglas Sherman

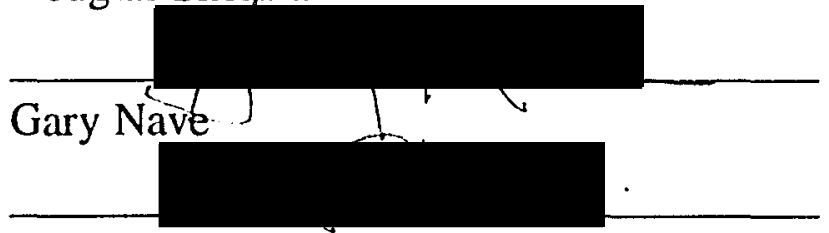

Ma-Ji Rhee

Representative of the Office of Graduate Studies

DOCTORAL PROGRAM APPROVAL:

Robert Everhart, Dean

School of Education

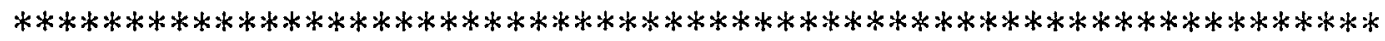

ACCEPTED FOR PORTLAND STATE UNIVERSITY BY THE LIBRARY

bys

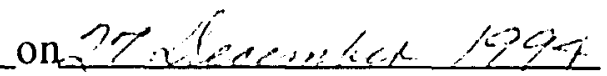




\begin{abstract}
An abstract of the dissertation of Minh Van Tran for the Doctor of Education in Educational Leadership: Administration and Supervision presented on October 27, 1994.
\end{abstract}

Title: The Schooling of Vietnamese-American High School Students in Oregon: Their Perspectives

Research on the education of Vietnamese-Americans is very limited, and mainstream media continue to project Vietnamese students either as high achievers or gang affiliated (Castro, 1983; Davis \& McDaid, 1992). This kind of projection can mask the real issues that Vietnamese students are facing.

Based on Cummins' (1979) Contextual Interaction Theory, this study examined the views of Vietnamese-American high school students in Oregon regarding their schooling under four major areas: Community Background Factors, Educational Input Factors, Instructional Treatment, and Student Input Factors. In particular, this study examined factors, within the above four areas, pertaining to the schooling of VietnameseAmerican high school students such as parental concerns, peer relationships, language use in the classroom, ESL learning, subject areas, teacher support, first language usage, discipline issues, home/school communication, teacher knowledge about culture, extracurricular activity, 
drug/alcohol issues, gang affiliation, dropping out, student effort in learning, homework, career planning, and future concerns.

A survey of 145 subjects was conducted in the Portland and surrounding high schools. The study was supplemented by two interviews of two unique students: a high-achiever and a high-risk case to illuminate the real life and school experiences they encountered in their schooling. The interviews added a holistic dimension to this study. The survey data were analyzed descriptively, statistically, and inferentially to provide answers for the research questions.

The overall conclusion was Vietnamese-American high school students in this sample came from large families with strong family support and value for education. They brought with them a strong motivation for learning. They were committed to school work and put much effort in learning. They reported doing well in mathematics and science. They reported difficulties in English language comprehension, but only one third of them perceived ESL as a strong treatment. Very few were participating in extracurricular activities. Their relationships with American peers were poor. They perceived a good level of staff welcome and support but were not sure about the staff's understanding of their culture. These students showed a respect for school rules, but reported little school/home communication. Many worried about their future.

Briefly, their perceptions regarding educational input factors and instructional programs were not as strong as community background factors and students' contributions. 


\section{DEDICATION}

In honor of King LY THAI TONG who instilled "tanh hieu hoc" (the love of learning) in the Vietnamese and in 1076, founded Quoc Tu Giam, the first Vietnamese University, located in the Temple of Literature in Hanoi, Vietnam. 


\section{ACKNOWLEDGEMENTS}

This study would not have been possible without the contributions, advice, guidance and support of Dr. Kenneth Peterson, chairperson of my committee. Professor Peterson spent countless hours walking with me through many rough roads and every corner of this study.

I would like also to thank Professors Dilafruz Williams, Douglas Sherman, Gary Nave, and Ma-Ji Rhee for their advice and support in this research. Thanks also goes to Professor Joan Strouse for her guidance in the conceptualization of this dissertation. I am grateful for the friendship of Drs. William Greenfield and Sorca O'Connor. I also want to express my appreciation to Dr. Don Leu, Dean Emeritus, for his encouragement and mentorship in my educational pursuit. I am also grateful to many friends and colleagues who assisted in this study: Gloria Muniz, Cong Phan, Chau Pham, Hung Tran, Marty McCall, Rhona Blackton, Pati Sluys, Sister Theresa, and Father Vincent. I also want to express my thanks to all the Vietnamese-American students who participated in this study.

Finally, I am deeply grateful to my family: Mary, Ailien, Michael and Andrew, for giving me unconditional love and support. 


\section{TABLE OF CONTENTS}

PAGE

ACKNOWLEDGEMENTS $\ldots \ldots \ldots \ldots \ldots \ldots \ldots \ldots$ ii

LIST OF TABLES $\ldots \ldots \ldots \ldots \ldots \ldots \ldots \ldots \ldots$ vii

LIST OF FIGURES . . . . . . . . . . . . . . . viii

CHAPTER

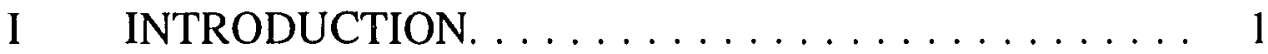

Background Information. . . . . . . . . . . 1

Southeast Asians in Oregon

Vietnamese-Americans

Issues Facing School Districts

Opposing Views on the Education of Language

Minority Students

Purpose of the Study . . . . . . . . . . 10

A Theoretical Framework . . . . . . . . . . . . 12

Research Questions ................ 14

The Study. . . . . . . . . . . . . . . . . . 15

Limitations of the Study. . . . . . . . . . . 18

Definitions of Terms . . . . . . . . . . . . . . 19

Summary. . . . . . . . . . . . . . . 21 
II REVIEW OF THE LITERATURE. . . . . . . . . . . 23

Theoretical Research . . . . . . . . . . . . . . 23

Basic Principles for the Education of

Language Minority Students

The Contextual Interaction Theory

The Language Acquisition Theory

Related Studies on the Education of Southeast

Asian Students . . . . . . . . . . . . . . . 38

The United States Educational Policies

Research on the Adaptation of Southeast

Asian Youth

Identifying Students' Needs: A Survey

of Vietnamese High School Students

Summary . . . . . . . . . . . . . . . . 44

III METHODOLOGY ................. 46

Data Gathering Methods. . . . . . . . . . . . 47

Survey

Interviews

Combined Survey and Interview

Methodology

Instruments for This Study. . . . . . . . . . . 51

Survey

Interviews

Use of Subjects' First Language in Study. . . . . . . 59

Sample . . . . . . . . . . . . . . . 60

Survey Sample

Interview Sample

The sample's representativeness 
Limitations of the Approach and Instruments . . . . 63

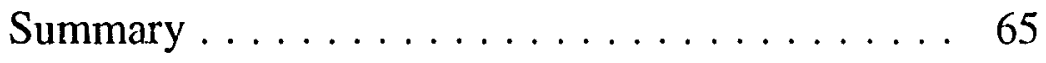

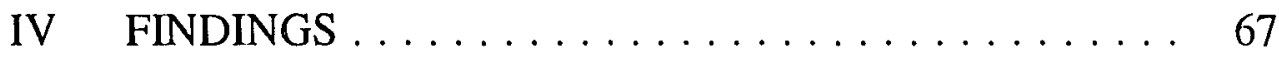

Part One: Survey Data Analysis. . . . . . . . . . 69

Section One: Descriptive Analysis of Survey Items

Section Two: Survey Findings Analyzed by

Research Questions

Section Three: Inferential Statistical Analysis

Part Two: Interview Descriptions. . . . . . . . . 120

Profile One: A High Achiever

Profile Two: A High Risk Case

Interview Content Analysis

Summary $\ldots \ldots \ldots \ldots \ldots \ldots \ldots \ldots . \ldots \ldots$

V CONCLUSION...................... 161

Part One: Discussion . . . . . . . . . . . . . 163

Part Two: Recommendations . . . . . . . . . . . 175

Recommendations for Parents

Recommendations for Schools and Teachers

Recommendations for Higher Education Institutions

Recommendations for Communities

Recommendations for Future Research

Part Three: Conclusion . . . . . . . . . . . . . 181 
REFERENCES. . . . . . . . . . . . . . . . . . . . . . . 190

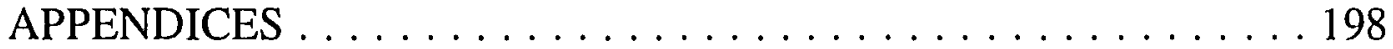

A Survey Questionnaire. . . . . . . . . . . . . . . . 199

B Ban Tham-Do Y-Kien: Vietnamese Version . . . . . . . . 203

C Interview Questions. . . . . . . . . . . . . 207

D Cau Hoi Phong-Van: Vietnamese Version. . . . . . . . 210

E Survey Results . . . . . . . . . . . . . . 213 


\section{LIST OF TABLES}

TABLE

PAGE

1. Survey Questions.................. 53

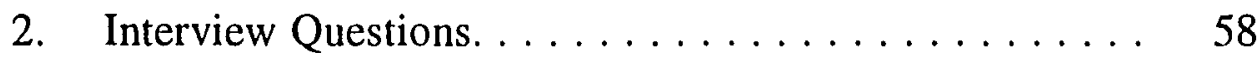

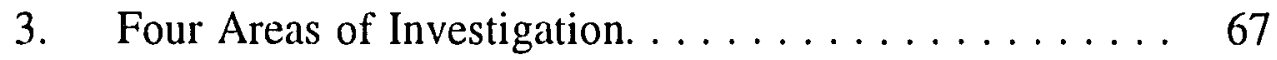

4. Descriptive Scale Analysis. . . . . . . . . . . . . 71

5. Pearson Product-Moment Inter-Item Correlation Matrix. . 105

6. Survey Questions - For Correlation Reference ....... 106

7. Correlations Among Four Areas of Investigation. . . . . 107

8. Correlations Between Variable "Years in U.S. Schools" and Survey Items $6-29$. . . . . . . . . . . . . . . . . 109

9. Tests of Significance of Observed Differences Between Variable "Living With Parents or Non-Parents" and Survey Items $6-29 . \ldots \ldots \ldots \ldots \ldots . \ldots \ldots 11$

10. Correlations Between Variable "Size of Household" and Survey Items 6-29. . . . . . . . . . . . . . . 114

11. Tests of Significance Between Variable "Working During Schooling" and Survey Items . . . . . . . . 115

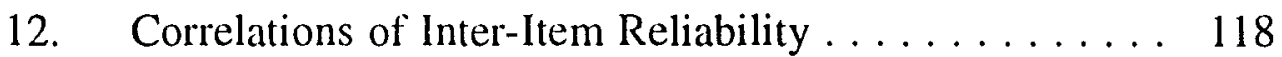




\section{LIST OF FIGURES}

FIGURE PAGE

1. Two Dimensions of Language Proficiency ......... 26

2. The Contextual Interaction Theory. . . . . . . . 31

3. How Long Have You Been in U.S. Schools? . . . . . . . 72

4. How Many People Live in Your House? . . . . . . . . 73

5. Who Do You Live With?. . . . . . . . . . . 74

6. Do You Have a Job Where You Earn Money? . . . . . . . 74

7. Subjects Vietnamese Students Do Well. .......... 75

8. I Prefer to Have Classes in Vietnamese . . . . . . . 76

9. I Have Close Vietnamese Friends. . . . . . . . . . 77

10. Teachers Make Me Feel Welcome .......... 78

11. My Parents Do not Care if I Do Well at School ..... . 79

12. Teachers, Counselors, Principal Visit Me at Home .... . 80

13. My Parents Want Very Much for Me To Do Well at

School ....................... 81

14. I Do Homework at Home. . . . . . . . . . . . 82

15. I Try Very Hard To Do Well in School. . . . . . . . . 83

16. I Do Not Belong to Any Clubs at School .......... 84 


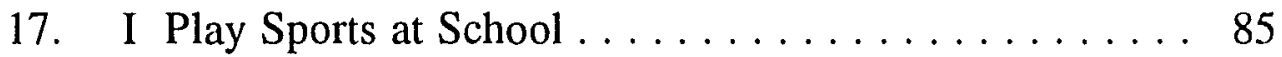

18. Vietnamese Students Do Not Belong to Gangs. . . . . . . 86

19. My School Makes Me Feel Welcome . . . . . . . . . 87

20. I Have Close American Friends at School. . . . . . . . . . 88

21. Vietnamese Students Do Not Smoke or Drink Alcohol . . . 89

22. I Learn a Lot From My ESL Teachers. . . . . . . . . . . 90

23. It is OK at My School to Use Vietnamese Language. .... 91

24. Vietnamese Students Do Not Drop Out of School ... . . . 92

25. I Have Plans for My Career After High School. . . . . . . 93

26. I Have Been Referred to Principal for Discipline ... . . . 94

27. I Am Not Worried About My Future . . . . . . . . . 95

28. I Understand the English Spoken in Classes . . . . . . . . 96

29. I Am Accepted and Treated Well by Other Students .... 97

30. School Counselors Help Me a Lot. . . . . . . . . . . . . 98

31. Principal, Teacher, Counselor Understand My Culture. . 99 


\section{CHAPTER I}

\section{INTRODUCTION}

\section{Background Information}

The Institute for Educational Leadership estimates that by the year 2000 the United States will have a school population in which one out of three students will be nonwhite (Hodgkinson, 1985). According to the 1980 U.S. census report (U.S. Department of Commerce, 1983), from 1970 to 1980 the U.S. population increased by $11.6 \%$, but the Asian-American population by $233 \%$. Many of these people were immigrants and refugees. The Refugee Resettlement Program of the U.S. Department of State (1990) stated that in the last 17 years more than one million Southeast Asians chose America as their new homeland. As Robinson (1990), an official of the U.S. Committee for Refugees, stated: "For better or worse, Indochinese migration to the United States is becoming routine" (p. 13). AsianAmericans are here and will continue to be a part of American society. The anthropologist Cortes (1986) observed that "the United States is becoming an increasingly multi-racial, multi-ethnic society" (p. 9). 


\section{Southeast Asians in Oregon}

Oregon has the tenth largest number of Southeast Asians in the country. A 1990 report to Congress indicated that about $80 \%$ of these people are Vietnamese (Refugee Resettlement Program, 1990, p. 5). Oregon has received more than 24,000 Southeast Asian immigrants and refugees (Oregon Department of Human Resources, 1988). According to this report, approximately $90 \%$ of Oregon refugee resettlement occurred in the Portland metropolitan area, which included Multnomah, Clackamas and Washington Counties. This is evidenced by the number of Southeast Asian students in many metropolitan schools, and by the number of Southeast Asian grocery stores, small businesses, and restaurants in the metropolitan Portland area.

The resettlement of immigrants and refugees will continue to grow due to the fact that after becoming citizens, refugees, in turn, often sponsor their relatives to be reunited with them in America. Based on the researcher's telephone conversation in 1989 with the Orderly Departure Program [ODP] in the U.S. Embassy in Bangkok, which handles reunification papers for Vietnamese-American citizens, there were more than 100,000 ODP cases backlogged in their files. That can be translated into about half a million Vietnamese in Vietnam waiting to be admitted to the United States. 


\section{Vietnamese-Americans}

Vietnamese are now one of the six largest Asian-American groups in the United States, together with Chinese, Japanese, Filipino, Asian Indian and Korean, according to the 1990 census (Waggoner, 1991). One important characteristic of this population is its youth. The Census Report of 1990 also indicated that the number of Vietnamese ages five or older increased $153 \%$ in the last decade. The average age of the Vietnamese American was 21 years (Rumbaut \& Ima, 1987). Overall, more than $40 \%$ of the Southeast Asians who have arrived since 1980 are less than 20 years old, and are school age (Haney, 1987). According to the 1989 report from the Oregon Department of Education, there were 5,869 Southeast Asian students attending school in the state.

\section{Issues Facing School Districts}

Many school districts, especially ones with a large concentration of language-minority children (e.g., Los Angeles, Houston, San Jose, Seattle, Portland, New York, Boston, Chicago), are faced with an ever-increasing population of Limited English Proficient (LEP) students, and have made considerable efforts to respond to the educational needs of this population. LEP students were enrolled in 6,400 of the nation's 15,000 school districts. Twenty-four states provided local state funding for LEP services, based on 
Development Associates' 1990 report. Oregon funding to local districts servicing these children is generous with a weighting formula of 1.5 (FTE), as indicated in Senate Bill 814: School funding (Oregon Department of Education, 1993).

One of the most important issues facing Southeast Asian newcomers is the educational needs of their children. The common thread that many of these persons bring with them to this country is a respect for education. To many Asian parents, and to most Vietnamese, education is the number one priority (Caplan, Whitmore, Bui, \& Choy, 1992). It is especially important to them in the United States where they know that without English language skills, training and education, it will be difficult to become self-sufficient and productive. In a study conducted on the adaptation of Southeast Asian Refugee Youth, Rumbaut and Ima (1987) emphasized that prospects for economic self-sufficiency and future productivity depend very much on their educational attainment.

In January 1993, the Superintendent of Portland Public Schools charted a new course for the English as a Second Language program in Portland Schools. He received the support of the school board to transition the present ESL program into a bilingual education program. "Bierwirth's proposal is to teach students core subjects in their native languages while also teaching them English" ("New Tack," 19y3). 
Opposing Views on the Education

of Language-Minority Students

How best to proceed with the education of all language minority students has generated numerous debates among educational professionals, school districts and policy makers (California Department of Education, 1981; Crawford, 1989; Cummins, 1989; First, 1989; Krashen, 1981a; Lambert, 1975). Some of these debates have been emotionally and politically charged. In 1985, after then Secretary of Education William Bennett criticized bilingual education as "a failed path," his office received much mail indicating approval of his stance (cited in Crawford, 1989). At the same time, the "English-Only Movement" had successfully mobilized politicians and educators alike in many states to make English the official language of the country. Senator Hayakawa of California, who headed the English-Only Movement effort, stated that: "Well-intentioned bilingual education programs have often inhibited immigrants' command of English and retarded their full citizenship" (cited in Crawford, 1989, p. 43).

President Reagan, shortly after taking office, strongly voiced his personal opinion about bilingual education:

...it is absolutely wrong and against American concepts to have a bilingual education program that is now openly, admittedly dedicated to preserving their native language and never getting them adequate in English so they can go out into the job market and participate. (cited in Crawford, 1989, p. 43) 
Many opponents of bilingual education have the view that knowing another language somehow prevents English acquisition, or that it suggests an absence of patriotism.

On the other side of the debate, Senator Simon argued that "we are foolhardy to discard the linguistic gifts of immigrants in our haste to Americanize their children" (cited in Crawford, 1989, p. 164).

As recently as at the July 1992 Democratic Convention in New York, presidential candidate Clinton's (1992) position paper stated:

The U.S. Department of Education has failed to guarantee the equal rights of Asian Pacific American students established by the 1964 Civil Rights Act,..the system should work to incorporate diverse racial groups into the curriculum, moving away from the Eurocentric focus of the status quo in order to educate all students on the diverse cultures which make up society. Educational programs should enable students to achieve proficiency in English through special programs and access to bilingual teachers. (p. 19)

Regardless of which side is taken in the emotionally and politically charged debates in the schooling of language-minority children, the challenges facing this country are not only the demographic changes in the next century, but also the values posed by American ideals such as equality, equity, diversity and inclusion (California DOE, 1982; First, 1989). It is increasingly complicated and difficult for school districts and policymakers to balance the above challenges with the reality of budget constraints, immigration issues and political conflicts. 
The California Department of Education (1981) acknowledged that:

As a group, language-minority students tend to do poorly in regular school programs. They do not acquire the language, academic, and sociocultural skills necessary to meet the challenges of vocational and higher education pursuits. (p. ix)

Many noted researchers such as Lambert (1975), Hakuta (1986), and

Krashen (1981a) take the position that U.S. public schools have not done an adequate job of addressing the needs of minority students. As Cummins (1981) stated "schools have contributed directly to minority children's academic difficulties by undermining their cultural identity, attempting to eradicate their first language" (p. 36).

In an attempt to provide equal educational treatment to all students, many schools opt to mainstream language-minority students as quickly as possible. For example the average length-of-service that language minority students receive English as a Second Language/Bilingual instruction in Portland Public Schools, Oregon, was 2.5 years (Portland Public Schools, 1992). This amount of time is just enough for limited English proficient students to acquire basic English to communicate in daily social conversation, what Cummins (1989) termed Basic Interpersonal Communicative Skills (BICS), or what Crawford (1989) called "playground English." 
When school districts mainstream limited-English-proficient students as quickly as possible, students are shortchanged and deprived of the full benefit of learning all subject matters through their native language while they acquire English.

"People are in such a hurry to get kids into English, thinking they're doing the right thing," says Bonnie Rubio, Eastman's principal "we were cutting off [native-language instruction] before they developed the thinking process, even the reading comprehension skills, at about 1st grade." (cited in Crawford, 1989, p. 130)

Also in this process, students are made to feel that their languages and cultures are not relevant or functional. Swain (1984) commented that "To be told, whether directly or indirectly, explicitly or implicitly, that your language and the language of your parents, of your home and of your friends is non-functional in school is to negate your sense of self" (p. 104). Many language-minority children change their names to "American" ones, or feel ashamed to be seen with their parents.

The preservation of the mother tongue and first culture is important because of the connection between language and identity. As Gee (1986) explained: "The cultures of immigrant children are embedded in their mother tongue. Each language holds a world view, and the identity of the speaker" (p. 16). Thus, language and culture are related to one's sense of identity, sense of self-esteem and self-worth. Sherman (1983) speculated 
on the connection between the students' world, their schooling and their future: "How do they perceive and make sense of their world? ...How do the young people view the relationship between their present involvement in school and their own futures?" (p. 1).

McGroarty (1986) observed "that schools reflect, in part, the values of the society at large...and often do not accommodate the experiences of students from cultural, class, or ethnic minority groups" (p. 303). From the anthropologist's point of view, Spindler (1982) asserted that "we must study cultural transmission if we are to study education" (p. 312).

The educational attainment of language minority students should, therefore, be based not only on test scores, GPAs and English language learning and acquisition but they should also consider social cultural factors affecting these children in their schooling. Holt (1986) acknowledged that:

Educational success and failure should be understood as a product of the interaction among such factors as the student's cultural background, the educational setting, and wider social forces. For example, educational success depends in part on how students have learned to solve problems, use language, form relationships, work with peers, and regard themselves. (p. iv)

Sue and Padilla (1986) also questioned the public schools' policies in the education of ethnic minorities in the United States where they noticed that the focus relied heavily on English instruction: 
How can the education and achievement of ethnic minority students, particularly those with limited-English-proficiency, be enhanced? In addressing this question, a great deal of attention has been placed upon English language acquisition. (p. 35)

These issues have generated many discussions among educators and policymakers around the country, especially between bilingual and English as Second Language educators.

\section{Purpose of the Study}

Vietnamese students in the United States have a unique set of cultural values, educational expectations and problems. Some of these students are considered high achievers.

Media reports told of some major achievements by students who had arrived from Indochina, with little English, only a few years earlier. Chi Luu was valedictorian of the City University of New York with straight A's in electrical engineering. Anh Tuan Nguyen Huynh was one of the five top winners of the Westinghouse Science Award. Hoang Nhu Tran was valedictorian at the Air Force Academy and a Rhodes scholar. (Caplan, Whitmore, Bui, \& Choy, 1990, p. 4)

This phenomenon of high achieving among the Vietnamese students was also mentioned in a study by Rumbaut and Ima (1987). They reported that $25 \%$ of the valedictorians in the San Diego area were Vietnamese, while they disproportionately made up only $7 \%$ of senior student population in the district. Also, from the Orange County area in Los 
Angeles, in a newly-established Vietnamese community called "Little Saigon," where the Vietnamese population made up less than $20 \%$ of the school population, 12 of the 14 valedictorians had Southeast Asian backgrounds ("Refugee Issues," 1985).

On the other hand, many Vietnamese students just barely make it through the system and some of them are at risk of failure. A report from a Vietnamese Refugee Center in New York indicated that:

The fact that there are a few number of Asian students who are quite visible in their academic achievement does not mean that the rest of the new immigrant students are highly successful. It is the opposite. Many of the new Vietnamese refugees do face a lot of problems in school. Some drop out. Some are unable to complete high school. Some are doing very poorly, especially in English and social [studies] and history classes. (First, 1989, p. 65)

This also concurred with what Peterson, Deyle, and Watkins (1988), mentioned that:

Some groups of minority students have not fared well in schools in this country... a number of reasons have been offered for low achievement... (p. 141)

Nationally, the number of Vietnamese-American children in school is increasing, but how are they doing educationally (U.S. Department of Commerce, 1990)? The media report Vietnamese students either as high achievers or gang members. The education of Vietnamese-American students has not been examined separately and thoroughly. There has not 
been any study exploring the educational, social, cultural and student input factors from the Vietnamese student perspective (Castro, 1983; Davis \& McDaid, 1992; Kim, 1979). This study explores the factors affecting the schooling of Vietnamese-American students.

\section{A Theoretical Framework}

California Department of Education (1982) summarized the state-ofthe-art in theoretical works and the body of knowledge in the area of education for language-minority students in five principles that describe the thenretical basis for ESL and bilingual education (Bain \& Yu, 1980; Cummins, 1979, 1981, 1989; Hakuta, 1986; Krashen, 1981a; Lambert, 1975; Oregon Department of Education, 1989; Swain \& Lapkin, 1981; U.S. Commission on Civil Rights, 1973).

These principles are:

1. Language proficiency in the first and second language is related to the academic achievement.

2. Language proficiency is important for both social and academic communication needs.

3. Proficiency in the first language is needed for proficiency in English academic language. 
4. Proficiency in English is the result of teaching in English that is understandable to students, and a supportive emotional climate.

5. The perceived status (importance/acceptance) of student effort, and the way students and teachers interact. Student status and interpersonal interactions affect student learning.

The basis for the five principles for the education of language minority students was derived from The Contextual Interaction Theory, hypothesized by Cummins (1979). In this theory, Cummins postulated that the student learning outcomes were the results of the interactions among four major factors: Community Background, Educational Input Educational Treatment, and Student Input.

Community Background variables include the nature of student linguistic interaction, and community and parental attitudes toward English and the mother tongue. Student Input variables include motivation to learn English and first language, and student's conceptual/linguistic knowledge. Instructional Treatment factors cover teacher attitude and expectation, and pattern of program language usage. Educational Input factors include fiscal resource, staff knowledge, skills, experience, expectations, and attitudes. In this study, the terms "educational treatment," "instructional treatment," and "instructional programs" are interchangeable. 
The five principles for the education of language-minority students as well as the three goals for bilingual education are in congruence with the Contextual Interaction Theory (Cummins, 1979). This theory is reviewed in Chapter II. This study adopts the Contextual Interaction Theory as its theoretical framework due to its potential in analyzing the variables investigated by this study's research questions on the schooling of Vietnamese students.

\section{Research Questions}

This study examines the views of Vietnamese students about their schooling. In particular this study examines factors pertaining to educational topics, sociocultural aspects, student input factors, and how students see themselves functioning in high school settings in Oregon. The emphasis of the study centers around four major areas of interest for this investigation:

- Community background factors

- Educational input factors

- Instructional input factors

- Student input factors

These factors were incorporated in the survey questionnaire and interview protocol as the study's variables. 
This study attempts to answer these five research questions:

1. How do Vietnamese-American high school students in Oregon perceive the community background for their schooling, including friendships, parental concern, and trends for completing schooling?

2. How do Vietnamese-American high school students in Oregon perceive the educational input for their schooling, including such factors as language used in the classroom, teacher support, discipline programs, and educator knowledge about their culture?

3. How do Vietnamese-American high school students in Oregon perceive the instructional treatment for their schooling, including ESL teaching, understanding English, and school counselors?

4. How do Vietnamese-American high school students in Oregon perceive their own student input for their schooling, including such factors as language preferences, homework, effort, participation in extracurricular activity, dropping out, friendship, and future plans?

5. How do the student perceptions of specific expressions of the four contextual factors relate to each other?

The Study

Based on the Language Acquisition, the Contextual Interaction theories, and principles of effective bilingual education, this study explores 
and examines the research questions through two activities: survey and interview (California DOE, 1982; Cummins, 1989; Hakuta, 1986; Krashen, 1981a; Lambert, 1975). The survey questionnaire and interview protocol were developed based on the four major research interest areas on the schooling and sociocultural factors related to the student's education. The survey was intended to assess student perceptions of factors affecting their schooling. The interview was intended to illuminate the real life successes or problems that some Vietnamese-American students lived through in their school experiences. To study the schooling of these students, it is important to consider their life and school experiences, as Peterson (1976) rationalized that: "...the learner as an individual subject who interacts with his or her environment to construct knowledge out of experience" (p. 13).

This study, using survey and interview approaches in the investigation, was conducted by an educator in the field of ESL/Bilingual education. With that perspective, this study presents the examination of the schooling of Vietnamese students from the vantage point of a bilingual, bicultural person, focusing upon the socio-cultural dimensions of their school adaptation to their new life in America. This study uses the student views to make recommendations for the improvement of schooling for this group of students. 
Since the research literature on the schooling and sociocultural adjustment of Vietnamese students is rather limited, this study would be of interest to educators and school districts in helping design sound and meaningful educational programs to meet the needs of these children and possibly that of other linguistically and culturally different students (Castro, 1983; Caplan et al., 1990; Davis \& McDaid, 1992). The kind of research that provides explanations and understandings to the academic failure or the adjustment problems of language minority students in school systems is needed to improve their schooling (Minaya-Rowe, 1992).

This study was conducted in the respondents' first language Vietnamese. Communication in the student's first language was intended to avoid translation distortion and to accurately reveal feelings and perceptions on the part of the respondents. Intercultural insights that could be overlooked, or even unknown to non-Vietnamese speakers, would be better understood. Cultural subtleties could be discovered and noted.

This research investigates the educational issues in the schooling of Vietnamese-American high school students, their perspectives on education, students' and parents' expectations, cultural, social, and at-risk issues (e.g., drug/alcohol use, dropping out) in this group of students. This study examines the educational and affective issues of the Vietnamese-American students as a separate group rather than as a subgroup of Southeast Asians. 


\section{Limitations of the Study}

This study is limited in its scope and the kinds of conclusions that can be drawn from it.

1. There is an advantage of being a native speaker in this kind of study, but it may also present the researcher's bias. The use of Vietnamese shows a value for it.

2. Even though the focus of this study was on students' schooling and social-cultural perspectives, it was not to evaluate the quality of any particular educational programs or services provided to these respondents.

3. It was not intended that this study explore all educational conditions of all Vietnamese students in the United States.

4. It should not be generalized to larger populations, as it was limited to Vietnamese students in a metropolitan area in Northwestern United States.

5. The sample size of this study was limited due to the unavailability of any complete database on the Vietnamese students in Oregon. It was, therefore, not at all representative for all Vietnamese students in America.

6. Since the sample of this study was at the high school level, some issues and factors were only pertinent to that population. The study does not cover Vietnamese students at all levels. 


\section{Definitions of Terms}

Following is a list of some of the terms used and their definitions as applicable in this study.

Basic Interpersonal Communicative Skills (BICS): The ability to use language as a social language or basic communicative language (Cummins, 1989). According to Cummins, it takes only two years or less for a second language learner to acquire the language skills of this level. Crawford (1989) refers to this as "playground English."

Bilingual Programs: Instructional services that use both the student's first language (mother tongue) and a second language more or less equally as the media of instruction. There are many varieties of bilingual programs such as Transitional Bilingual Programs, Maintenance Bilingual Programs, Two-way Bilingual, or Dual Immersion Programs.

Bilingual Students: Students who have the ability to communicate in two languages. Full bilinguals are persons who can speak, read and write two languages with equal ability. Partial bilinguals have a better mastery of one language over the other one.

Cognitive Academic Language Proficiency (CALP): The term was first used by Cummins (1989) to describe a student's language ability in cognitive domain in order to comprehend and function successfully in all 
cognitive development areas (e.g., school work) and academic courses. According to Cummins (1989), it takes a second language learner five to seven years to acquire language skills at the level which is needed for academic pursuit.

Dropout: A pupil who leaves school before graduation or completion of a program of studies and not attending any other school.

ESL Programs: Instructional services designed to teach English as a Second Language to non-native speakers of English students.

ESL Students: Students who speak a language other than English as their mother tongue, and are in the process of learning English as a second language.

Language-Minority Students: Persons in the United States whose first language is not English and who belong to an identifiable minority group (U.S. Commission on Civil Rights, 1973).

LEP Students: Limited-English Proficient learners who are in the process of acquiring English language skills.

Refugee: Any person who is outside any country of such person's nationality or, in the case of a person having no nationality, is outside any country in which such person last habitually resided, and who is unable or unwilling to return to, and is unable or unwilling to avail himself or herself of the protection of, that country because of persecution or a well 
founded fear of persecution on account of race, religion, nationality, membership in a particular social group, or political opinion (The Immigration and Nationality Act as amended by the Refugee Act of 1980 establishes the framework for selecting refugees for admission to the United States, Section 101(a)(42) U.S. Department of Health and Human Services, 1990).

Southeast Asians: People from Vietnam, Cambodia and Laos who came to the U.S. as refugees or immigrants. Sometimes they are referred to as Indochinese due to the term used by the French, who colonized these three countries from the 1850s until the mid-1950s.

Vietnamese-Americans: People from Vietnam who now reside in the United States. Their status can be refugee, immigrant or citizen. For the purpose of this study, the terms Vietnamese and Vietnamese-American are interchangeable.

\section{Summary}

The demographic changes have made Southeast Asians one of the largest Asian-American groups in which Vietnamese-Americans constitute a substantial percentage. The increase in the number of Vietnamese students, as well as the language minorities in American schools, has created many debates on how to best meet the educational needs of these 
children. School districts, policy makers and educators have made some progress in the delivery of services to these minority students.

The current body of knowledge on the issues of schooling for language. minority children is adequate. Educational, social and cultural issues pertaining to specific language groups such as the Vietnamese, have been modest and are in need of more exploration.

This study attempts to respond to the research needs in exploring factors affecting the schooling of Vietnamese-American students through a set of research questions presented in this chapter. The nature of this study allows an exploration of the issues through the respondent's perspective and through the respondent's first language. Due to the sampling approach, as well as the small number of factors investigated, this study has many limitations which should be further studied by researchers in the field of education for language-minority students. A review of research literature in the next chapter pertaining the education for these minority students as well as the theoretical framework guiding this study lays the foundation for this study. 


\section{CHAPTER II}

\section{REVIEW OF THE LITERATURE}

This chapter is divided into two sections. The first part includes the theoretical research which focuses on the effectiveness of the education of language-minority students. In particular, literature is reviewed that addresses their educational outcomes, their sociocultural adjustment in their new world as well as the research on language acquisition. This presents a theoretical framework for the present study. The second section consists of related studies on the education of Southeast Asian students since research on the Vietnamese students as a separate group has been scantily minimal (Caplan et al., 1990; Davis \& McDaid, 1992). The purpose of this chapter is to present a background of literature that further defines the issues of this study of Vietnamese-American schooling and that reviews the research done on this topic.

\section{Theoretical Research}

The central problem of this study was to obtain information on the views of one group of recent immigrant minorities of their schooling. A 
large body of knowledge is available for application and exploration in the area of theoretical studies on the education of all language-minority students. For the purposes of this study, literature was sought related to first and second language acquisition, content-based cognitive development, at-risk issues, psychological and emotional needs such as self-identity, selfconcept, positive relationships with majority and minority peers, counseling services and positive role models, and parent perspectives. A theory of language acquisition was also reviewed.

Since, according to the Oregon Department of Education (1989), "much of the research is illustrated within the five basic principles from the State of California document: 'Basic Principles for the Education of Language-Minority Students: An Overview'" (p. 2), this chapter begins with a review of these principles.

Basic Principles for the Education of Language-Minority Students

The Basic Principles are a synthesis of theoretical research and the current body of knowledge on the education of language-minority students (Oregon Department of Education, 1989; California Department of Education, 1982). A brief summary of these five principles is presented here to give the background for the theoretical framework (presented in the next section) which underpins this study. 
These principles are research-based and related to the three major educational goals for language-minority students as announced by the U.S. Department of Education (1994). They are: (a) English language proficiency, (b) academic achievement and access to the curriculum, and (c) psychological adjustment (California Department of Education, 1982, p. 1; Garcia, 1994). These three goals form a basis for the research questions of this study.

The first principle: For bilingual students, the degree to which proficiencies in both first and second language are developed, is positively associated with academic achievement. (California Department of Education, 1982, p. 7)

This simply means that academic achievement of language-minority students is correlated to student proficiency in both languages. Hakuta (1986) asserted that the use of two languages had a strong positive effect on cognitive functioning. This principle could be explained by Cummins' (1981) "Threshold Hypothesis," which holds that if the second language is developed at the expense of the first language, then negative cognitive effects are more likely to occur. Lambert (1975) called this "subtractive bilingualism." If the second language was acquired in parallel with the first language, it is called "additive bilingualism" (Cummins, 1989).

The second principle: Language proficiency is the ability to use language for both academic purposes and basic communication tasks. (California Department of Education, 1982, p. 9) 
The most prominent authority in this area is Cummins (1989) who postulated that there are two dimensions of language proficiency. The first is the Basic Interpersonal Communications Skills (BICS), which is daily social language, or what Crawford (1989) called "playground English." Cummins maintained that it takes less than two years to acquire this level. However, it takes up to seven years to develop Cognitive Academic Language Proficiency (CALP). This level of language skill is strongly related to cognitive and overall academic skills, and is necessary to achieve academic success.

The third principle: For language minority students, the development of the primary language skills necessary to complete academic tasks forms basis for similar proficiency in English. (California DOE, 1982, p. 11)

This principle explains that language skills are transferable. "Concepts learned in the first language will readily transfer to the second language once a certain level of proficiency in the second language is acquired" (Oregon DOE, 1989, p. 2). Students who read best in language $\mathrm{X}$ will probably read best in language $Y$ (California DOE, 1982, p. 11). Once they learn math concepts in their first language, they transfer skills to the second language. Therefore, an effort to develop the first language skills eventually promotes and enhances the student's ability to succeed in the mainstream English-only instruction (California DOE, 1982). 
Figure 1 depicts the differences between the two dimensions of language proficiency.

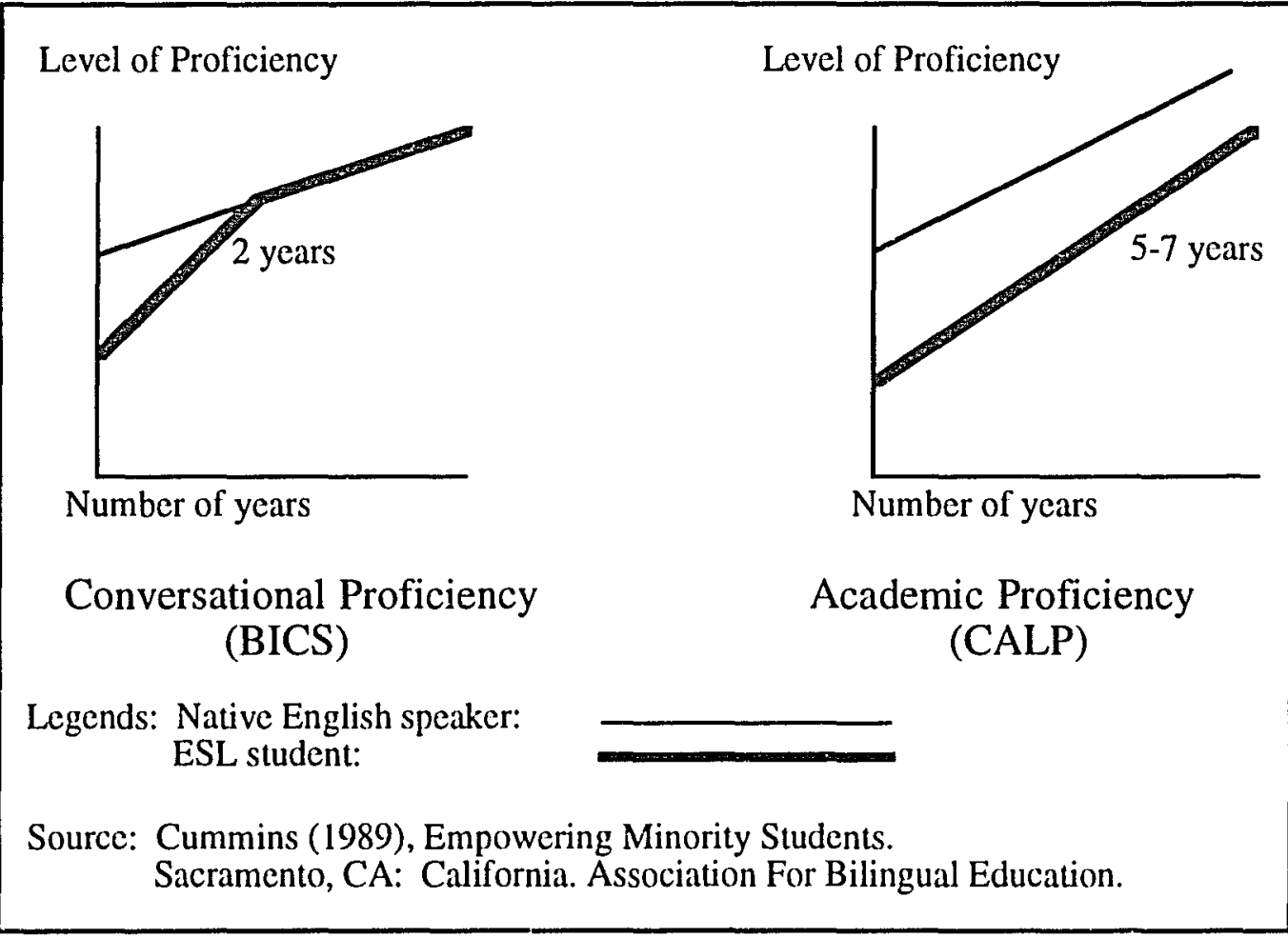

Figure 1. Two dimensions of language proficiency.

The fourth principle: Acquisition of basic communicative competency in a second language is a function of comprehensible second language input and a supportive affective environment. (California DOE, 1982, p. 13)

This principle emphasizes that the exposure to the new language has to be understandable to the student, or "Comprehensible Input" (Krashen, 198la). Students cannot learn a new language when they do not understand. The second part of this principle maintains that the 
environment of the second language learning has to meet certain affective conditions, such as the learner's low anxiety level, self-esteem, positive motivation, self-confidence and personality. Teachers need to consider affective factors in organizing lessons, diagnosing and grouping students, and responding to their learning needs (California DOE, 1982, p. 13).

The fifth principle: The perceived status of students affects the interactions between teachers and students and among students themselves. In turn, student outcomes are affected. (California DOE, 1982, p.14)

This principle stresses the importance of the context in which language acquisition and academic learning take place. Smith (1987) explained that the perception of the student's first language status in the school and community affects the student's learning. The way teachers, as members of the majority culture, perceive a student's language status has an effect on the student's learning. Briefly, it is the teacher's attitude and expectations have an important effect on student achievement. The status of the language-minority groups in the community also is a relevant factor in the educational treatment of minority students. If the community, through its school board members, does not feel positive about a certain languageminority group, then the educational programs for these children will not be top priority to the district. "In that schools are products of society, it is not unusual that society's values, social priorities, and status rankings are 
transmitted through the schools" (Smith, 1987, p. 69). The California DOE (1982) document stated that "Individuals with perceived high status receive qualitatively and quantitatively different types of interactions. This differential treatment, of course, contributes to differential outcomes" (p. 16).

The Contextual Interaction Theory

Cummins (1989) introduced many major concepts in language acquisition research, such as BICS (Basic Interpersonal Communication Skills) and CALP (Cognitive Academic Language Proficiency). Cummins also postulated that the outcomes of bilingual students' learning were affected by the interaction among many factors or variables including Community Background, Student Input, and Educational Input as well as Program Treatments. His theory was the basis for the five principles for the education of language-minority children formulated by the California DOE (1982) and presented in the preceding section of this chapter.

Cummins (1979) observed that:

Much of the controversy surrounding bilingual education has centered around the relative merits of transitional versus maintenance programs versus ESL-only program, with little attempt to relate the program impact to the diversity of student input. (p. 41) 
In his Contextual Interaction theory, he articulated that the Student Input variables interacted with other factors, such as Community Background variables, as well as the Educational Treatment. He rationalized that there were differences in students' motivation to learn and the conceptual/ linguistic knowledge of learners; "these dimensions are important determinants of academic outcomes" (p. 41).

Establishment of some programs for language-minority students is often a result of many social factors, such as the influx of new political refugees and immigrants, academic needs of mainstream students, and linguistic, social, and financial impact on the society placed by bilingual children (Paulston, 1976). These factors also influence the community's attitudes and behaviors regarding linguistic issues, such as the student's first language maintenance (Cummins, 1979). Peterson, Deyle, and Watkins (1988) maintained that many issues relate to educational achievement, such as teacher provisions (e.g., minority language and culture incorporating into school programs), community participation, teaching approaches that maximize student language to generate knowledge, and educators acting as advocates for minority students effectively benefit minority students.

Student input variables are characteristics of students such as conceptual-linguistic knowledge, motivation to learn English and first language, as well as competence in these languages. These variables likely 
would interact with other factors such as educational treatment, the school

language usage, teacher attitudes and expectations.

In this model, community background factors, such as language use patterns in the home and community attitudes towards the student's home language and second language contribute to student input factors which the child brings to the educational setting. These student input factors, such as first and second languages proficiency, self-esteem, levels of academic achievement, and motivation to acquire second language and maintain first language are in constant interaction with instructional treatments, resulting in various cognitive and affective student outcomes. The instructional treatments are primarily determined by such educational input factors as fiscal resources available to the school; staff knowledge, skills, experience, expectations, and attitudes; and underlying educational assumptions/theories. (California DOE, 1982, p. 4)

Figure 2 presents a schematic presentation of Cummins' (1979) theory.

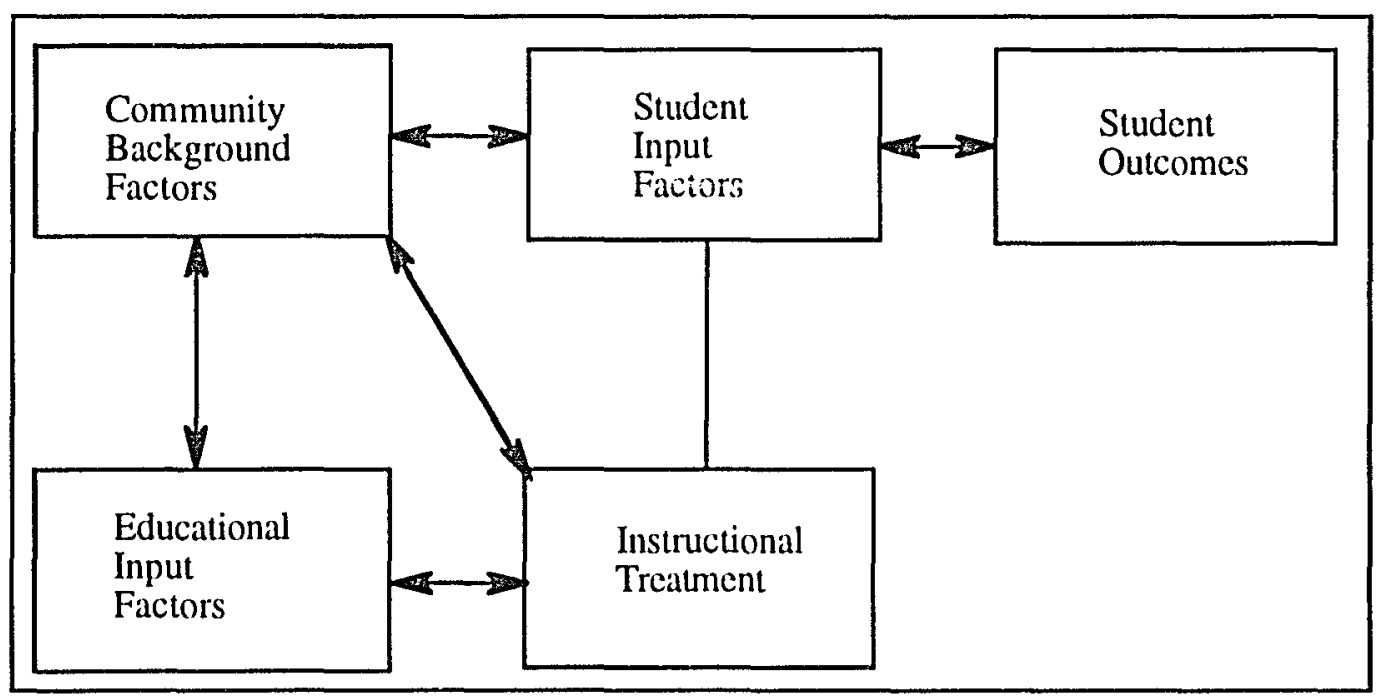

Source: Cummins (1979). Linguistic interdependence and the educational development of bilingual children. (California Department of Education, 1982, p. 4)

Figure 2. The contextual interaction theory. 
Some of community background variables include the nature of student's linguistic interaction and community, and parental attitudes toward English and the mother tongue. Student input variables include motivation to learn English and first language, and student's conceptuallinguistic knowledge. Instructional treatment factors cover teacher attitude and expectation and pattern of program language usage. Educational input factors include fiscal resources, and staff knowledge, skills, experience, expectations, and attitudes.

The educational outcomes of a student's schooling are determined by interaction with the educational environment. This would include academic and cognitive outcomes, as well as affective outcomes such as student identity and attitude toward first and second languages.

\section{The Language Acquisition Theory}

The United States Office of Civil Rights (U.S. Department of Health, Education, and Welfare, 1975) stated that the lack of English proficiency is detrimental to the schooling of language-minority students:

Lack of English proficiency is the major reason for language minority students' academic failure. Bilingual education is intended to ensure that students do not fall behind in subject matter content while they are learning English, as they would likely do in an all-English program. (Cummins, 1981, p. 4) 
Most educators, policy makers and language-minority parents and students agree to the importance of the English learning.

In the last 20 years, English as a second language and bilingual education have been the focus of many debates and controversies, as well as a topic for research on how to design the best approach and program in the schooling for language-minority children. The most-known theory on the second language acquisition was postulated by Krashen (1981a).

Complimentary to Krashen's work was the research done by Cummins (1989) in the field of bilingual education. This theoretical work also plays an important role in this present study.

Krashen (1981a) provided some important differentiation between the two concepts "learning and acquisition." He postulated that in order to master a second language, one must acquire it, just the same way as people acquire their first language. He pointed out that babies acquire language without any grammar or textbooks, and that learning grammar and vocabulary does not prepare for full language proficiency. Krashen theorized that "we acquire language when we understand it" (p. 62); he called this "comprehensive input."

Krashen (1981a) included five important hypotheses in his second language acquisition theory. These are summarized below. 
The Acquisition-Learning Hypothesis. This hypothesis focuses on the differences between Learning and Acquisition. Krashen (1981a) theorized that the acquisition for a new language was similar to the way children acquire the first language competence. He defined that language acquisition is a subconscious process that learners are often not aware that they are acquiring a language while they are doing so (p. 56). Krashen also postulated that language learning is different. It is when a learner receives formal knowledge of a language.

The Natural Order Hypothesis. In this hypothesis, Krashen (1981a) speculated that students acquire the grammatical structures of a language in a predictable order and innately. Certain grammatical structures are acquired early, while other complex ones are acquired later. "For grammatical morphemes in English, children's first language order is similar to adult second language order. There is thus a 'first language order' and a 'second language order"' (p. 57).

The Monitor Hypothesis. Krashen (1981a) described the relationship between acquisition and learning in this hypothesis. He believed that language acquisition is more important than language learning. Acquisition produces language fluency and ability to use it easily and comfortably, while "conscious learning is not at all responsible for our fluency but has only one function: it can be used as an editor or monitor" (p. 57). 
The Input Hypothesis. This hypothesis presents the idea that people can only acquire a second language when they receive "comprehensible input," or messages that make sense to them. In all-English, or "sink or swim" classrooms, Krashen (1981a) suggested that non-English students receive little or no comprehensible input. He advocated that LEP students be taught in the native language to gain background knowledge. Then the English instruction becomes more comprehensible. Krashen cited that: "The first rationale for bilingual education, is that information, knowledge that you get through your first language, makes English input much more comprehensible" (p. 57).

The Affective Filter Hypothesis. This hypothesis focuses on the affective domain and includes such factors as motivation, anxiety, personality and others affecting acquisition of a second language. These factors include: (a) Anxiety: Students who display low anxiety in a second language setting acquire more language; (b) Motivation: Students with high motivation have more second language acquisition; and (c) Selfconfidence: The acquirer with more self-esteem and self-confidence tends to do better in second language acquisition (Krashen, 1981b, p. 31). These factors have strong effects on second language acquisition. Krashen (1981a) speculated that the learner's anxiety, lack of self-confidence, and lack of motivation to speak the second language can inhibit language 
acquisition. Young children, on the contrary, are less self-conscious about learning or acquiring a second language. Therefore, they have less anxiety and more confidence in interacting with native speakers of a second language and are likely to acquire more language. Students from a low status language often display high anxiety, and sometimes hostility toward learning a language considered by teachers as superior, such as English. These students' "affective filter" likely interferes with second language acquisition. Krashen (1981a) suggested that a bilingual/bicuitural curriculum, recognizing the value of a minority language and culture, enhances a child's self-esteem and provides a good environment for English acquisition.

One of the major implications of Krashen's (1981a) theory was the concept of "Comprehensible Input." English as a Second Language (ESL) is an important component in any good bilingual program. A "good" ESL component is one that provides students with plenty of "comprehensible input." As Krashen (1981a) stated:

There is a tremendous difference between receiving comprehensible, meaningful input and simply hearing a language one does not understand. The former will help second language acquisition, while the latter is just noise. It remains noise no matter how much exposure is provided. (p. 66) 
He also suggested that interaction with other children on the playground or outside of school is a rich source of meaningful input. He speculated that this source of input was "responsible for the success of many people who succeeded without ESL or bilingual education" (p. 67). Another source of comprehensible input is subject matter taught in the first language. In a bilingual program where students do not have enough English language skills to function successfully in subject areas (social studies, science, etc.), then these subjects need to be taught in the students' first language.

Contrary to the view of critics, this (learning subject matters in first language) does not necessarily mean less acquisition of English as a second language. In fact, it may mean more acquisition of English. (Krashen, 1981a, p. 67)

Krashen also articulated that: "subject matter knowledge and the cognitive and academic proficiency it encourages, will help second language acquisition" (p. 68). He also mentioned that students who were behind in subject matier fail to acquire the second language; "Children who are behind in subject matter and weak in the second language face double trouble" (p. 68). Krashen stated that: "submersion" or "sink or swim" might not meet the requirement of comprehensible input. Children in such settings are "in danger of not getting the input needed to acquire English" (p. 70). 


\section{Related Studies on the Education of Southeast Asian Students}

Two other research studies are also relevant to the research questions of this investigation. The Studies focus on the United States educational policies and adaptation of Southeast Asian refugees, and a recent study on the Vietnamese students. A review of some significant concepts in these two studies is included.

\section{The United States Educational Policies}

In a policy study of the Hmong refugees and immigrants, Strouse (1985) reviewed three theories of assimilation: (a) Anglo-Conformity, (b) The Melting Pot, and (c) Cultural Pluralism. She analyzed the effects of these policies on the education of refugee children. In the AngloConformity policy, refugee and immigrant students are required to be assimilated to "become an American" (p. 44). In the Melting Pot theory, refugee students' culture changes and adapts with the native culture to become a homogeneous one, that of the American culture. On the contrary, in the Cultural Pluralism paradigm the immigrant students maintain their culture, and at the same time adapt the new one or the American culture. Public schools, as Strouse observed, view themselves as the main agents in the task of cultural change. "In school, students 
encountered one culture only, that of the American mainstream" (p. 65). Americanization remains an important part of the mission of the public schools. The educational policies based on Anglo-Conformity or the Melting Pot hypothesis might succeed in making the refugee and immigrant Americans, but at the expense of their native language and culture, according to Strouse. These policies might, in effect, cause conflicts inside the family. The value conflicts between school and home often result in traumatization and estrangement between many generations (p. 69). Strouse suggested that schools should "train staff to see the local community through the eyes of the immigrants" (p. 180). Educational policies in many public schools today regarding refugees and immigrants remain the same as "in the bad old days" (p. 75).

Research on the Adaption of Southeast Asian Youth

In a study conducted by Rumbaut and Ima (1987), the Southeast Asian refugee youths in San Diego schools were assessed on their adaptation to the new society. This was the first comprehensive study on Southeast Asian students in such a large school district in California. This study compared Southeast Asians academic achievements (GPAs), occupational aspirations and educational problems against other ethnic groups (including nonAsians). 
The study also explores the cultural and structural patterns of family organization, with special emphasis on the orientations toward authority and in discipline and control over the young; the coping strategies, attitudes and approaches to problem solving; the nature of the "fit" between these cultural and structural characteristics at school and work in the United States (Rumbaut \& Ima, 1987). Based on their analyses, the authors concluded that they were optimistic about the adjustment progress of these refugee youths who would become contributing citizens of the society. They also warned that there were "pockets" of at-risk youth that needed further study. Following is the summary of the study's findings:

The Southeast Asians had above average GPAs with average standardized math test scores and below average standardized verbal test scores. The factors that influenced their performance were: social class resources (eg., the educational level of parents and the income and employment levels of parents) and cultural resources (e.g., discipline and respect for education). Rumbaut and Ima (1987) found that the mother's socio-emotional characteristics were highly associated with student's performance; female students did better than boys, except for the Hmong. The length of stay was an important factor; the longer their U.S. residency, the more likely they would do well in school. Younger students did better than older ones. Intact family children were likely to do better. Parents 
with more "ethnic resilience" had children who had better educational achievement than those with parents who were more "Americanized." In other words, the less they were Americanized, the better they did at school (Rumbaut \& Ima, 1987).

Additional findings concerned future views. Occupational aspirations and their future: the Vietnamese, Chinese and Hmong sought higher status jobs and likely concentrated on math/science based careers while the Lao and Khmer sought lower status jobs. Vietnamese youths tended to have future planning than other groups. Vietnamese students were most likely to continue with schooling in higher education (Rumbaut \& Ima, 1987).

Suspensions and expulsions were often the result of responses to "racial baiting" by non-Asian students. Generally, the Southeast Asians had a lower rate of delinquency than other groups. Delinquents were almost all males and likely to be detached youths in one-parent homes.

Southeast Asians experienced barriers in family instability, broken families, early family formation (Hmong), emotional problems (Khmer with Pol Pot experience), lack of access to knowledge of work careers, prejudice, racism, name calling, physical confrontations, low levels of English language skills and the lack of bicultural strategies (Rumbaut \& Ima, 1987). 
"Southeast Asian Refugee Youth Study," authored by Rumbaut and Ima (1987), was the only comprehensive research conducted on the cultural and social adaptation of Southeast Asian refugee youths. The authors also suggested some interventions for federal agencies, sponsors, local and state governments, school districts, higher education institutions, and communities in order to positively impact the services provided to Southeast Asian youths.

\section{Identifying Student Needs: A Survey} of Vietnamese High School Students

This survey research on the Vietnamese high school students investigated by Davis and McDaid (1992) was conducted in three high schools in San Diego with large concentrations of Vietnamese-Americans. The study attempted to search for information related to student needs: background information, school environment and perceptions, home life and habits, language skills, future concerns and beliefs. Following is a summary of some of the major findings from their study. The study results show that $38 \%$ of the respondents had been in the U.S. less than three years. More than two thirds of these students had been in an ESL class from 1 to 4 years. Fifty-one percent of the Vietnamese students reported speaking English in class, but only one fifth said they spoke English with friends outside the classroom. More than one third spoke 
Vietnamese with their friends outside of class. The authors found a significant level of probability for length of time spent in the U.S. compared with both their level of ESL and language spoken with friends. Their data suggested that students who had shorter U.S. residency would likely retain their use of Vietnamese both in and out of the classroom (p. 35). About two thirds of these students felt a need to learn about their history and culture. In regard to home background, $61 \%$ of these students lived with their parents at home, while $12 \%$ indicated they lived with nonparent adults or unrelated persons. The majority $(87 \%)$ of these students perceived their school experience as positive. They reported that their grades in mathematics were above average to excellent. In regard to the relationship between school and parents, $72 \%$ gave a negative response. The authors also found that $94.2 \%$ of the Vietnamese students planned to go to college. These students (83\%) also believed that not doing well in high school restricted their job opportunities (p. 37). The authors also found that "nearly all students reported that they had experienced some cultural discrimination at school from students and teachers, and, to a lesser extent, from counselors" (p. 39). One fifth of these students expressed worries about their families and money issues. One third of these students reported having a job outside of the home. Up to $6 \%$ of the Vietnamese students in this study indicated experience with smoking and drinking. 
The authors also concluded that these students perceived that their parents were interested in their education and grades, but did not attend any school meetings or participate in any school activities.

\section{Summary}

Even though the education for language-minority students is still in an infantile stage, the research literature shows an impressive body of knowledge in this area. Many studies conducted on bilingual education programs have focused heavily on the education of Hispanic students. Research conducted on the schooling of other ethnic groups such as Vietnamese-Americans has been minimal. Davis and McDaid (1992) commented that "existing research often fail to capture the needs of the specific subpopulations" (p. 33).

A review of the literature for this chapter focuses on two areas: theoretical research and related studies. The theoretical research emphasizes the well-known "Five Basic Principles for the Education of Language-Minority Students," the "Contextual Interaction Theory," and the "Language Acquisition Theory." These theories and principles form the foundation for first and second language learning and teaching, cognitive and affective development for language-minority students. The Five Principles, the Language Acquisition Theory and the Interaction Theory 
with major hypotheses such as BICS, CALP, Comprehensible Input, and the Perceived Language Status are the most significant concepts in the field of education for language minority students.

As mentioned earlier, Vietnamese students were lumped together with either Southeast Asians or Asian-Americans. There has been little research done on the Vietnamese as a separate language minority group, even though demographic statistics show that Vietnamese-Americans are one of the fastest growing Asian-American groups. There have been reports by the mainstream media projecting opposite views on the schooling of Vietnamese-American students. This chapter also includes a summary of a recent study on Vietnamese students in three high schools in San Diego, which supports the rationale and purpose of this present study.

This study adopts Cummins' (1979) Contextual Interaction Theory as its theoretical framework due to the interaction among various factors (e.g., Community Background, Educational Input, Instruction, and Student Outcomes) which are of interest to this study's research perimeter. However, this study investigates those factors pertaining to the Vietnamese students as a culture-specific group. A review of the theoretical research, related studies, and the study's theoretical framework helps pave the road for the research design of this study which is discussed in Chapter III. 


\section{CHAPTER III}

\section{METHODOLOGY}

This study is an investigation into the views of Vietnamese-American high school students concerning their schooling. As described in Chapter II, the need for quality schooling for these citizens, their strong potential to contribute to this society, and the social costs of inadequate schooling combine to make this topic a valuable one for inquiry. There is a lack in the literature of information specifically focused on Vietnamese students.

The guiding theoretical model for this study is based on Cummins' (1979) Contextual Interaction Theory, presented in Chapter II. Cummins theorized that high quality schooling for ESL students can best be understood in terms of the five components of community, student input, educational input, instruction, and student outcomes. This present study investigates the views of Vietnamese high school students on these five components of their educational experience. The purpose for determining these views is to create recommendations for educational policy makers and other educators to better serve these students. 
This chapter describes the data gathering methods and instruments, and the analysis used to organize and report the findings of Chapter IV. This chapter discusses survey and interview methodology, development of the survey instrument and interview protocol, the study sample, and limitations of these methods.

\section{Data Gathering Methods}

The following section describes the rationale for this study's research approaches, which combine a survey of 152 respondents and interviews of two unique individuals.

\section{Survey}

Based on the purpose and scope of this study, survey research methods were selected. Borg and Gall (1983), Ary and Jacobs (1985) and Converse and Presser (1986) concurred that in educational research, survey methods were a common practice and a valuable tool. Questionnaire and interview are the most common instruments for data collection in survey research (Borg \& Gall, 1983). This study design combines two approaches in data gathering: a survey of 152 respondents and one-on-one interviews of two unique individuals from the sample. Data collected from the survey questionnaire could be quantified and analyzed statistically for hypotheses 
and possible relationships among factors investigated by this study. Special care was taken in constructing the questionnaire, as Converse and Presser recommended that "surveys must be custom built to the specification of given research purposes" (p. 7). Borg and Gall (1983) noted that "each item on the questionnaire must be developed to measure a specific aspect of one of [the] objectives or hypotheses" (p. 418). They also warned that researchers needed to be sensitive to the issue of invasion of privacy. As Fink and Kosecoff (1985) pointed out also that "any single survey can encompass hundreds of ideas (or more). Deciding on a survey's contents means setting the survey's boundaries..."(p. 23). Ary and Jacobs (1985) advised that the researcher must make every effort to eliminate unnecessary (items). They also warned that people resent questions about age, income, and status (p. 345). Indeed, within the study's boundary and the scope of the research questions, many personal or demographic questions were not included. Issues pertaining to confidentiality and anonymity need special care when investigating respondents from different cultures. In general, Vietnamese subjects are acutely sensitive to inquiry regarding their personal backgrounds due to their experience as war-torn political refugees. Fortunately, this study's scope of the investigation was only concerned about Vietnamese-American students as a whole group regardless of gender, ethnic backgrounds, grades or immigration status. 
Even though survey questionnaires are feasible to manage and data can be gathered uniformly and quantitatively, they are often shallow and fail to dig deeply enough to provide a true picture of opinions and feelings, (Borg \& Gall, 1983). Survey questionnaires are more efficient, reliable and easy for analysis due to their uniform data and scales (e.g., agree, disagree, etc.). However, a survey questionnaire would not provide a respondent's insights on the issue. Also, there was a possibility of misinterpretation of the questions by the respondents (Ary \& Jacobs, 1985). To compensate for that, this study also includes two personal interviews.

\section{Interviews}

Merriam (1988) indicated that interviewing could illuminate our understanding of the phenomenon under study. It would help us to study "how people make sense of their lives, what they experience, how they interpret these experiences, how they structure their social worlds" (p. 19). Patton (1980) described that "the purpose of interviewing is to allow us to enter into the other person's perspective" (p. 196).

The unique aspect of interviewing is its flexibility. Researchers and respondents are free to communicate directly. Respondents can ask for explanation and clarification. Additional information can be obtained. 
Both the researcher and respondent have the control of this process. As Sherman (1983) articulated that "since language has a primary role in the development, maintenance and communication of symbolic worlds, the issue of who control language during the research is crucial" (p. 55). The benefits of collecting data and insights from respondents make interviewing a more humanistic and holistic means to survey questionnaires.

The disadvantage of interviewing is that they are expensive and timeconsuming due to the fact that the researcher interacts with the respondents on a one-on-one basis. Also, interviewing can be very subjective and possible bias can occur. In regard to the number of subjects to be interviewed, Merriam (1988) commented that

Unlike survey where the number and representativeness of the sample are major considerations, in the interviewing the crucial factor is not the number of respondents but rather the potential of each person to contribute to the development of insight and understanding of the phenomenon. (p. 77)

The interview activity of this study was constructed on that premise. Indeed, the two unique youths interviewed for this study, a high achiever and a failing student, had given the study the needed insights as well as the understanding of how they made sense of their worlds and how they encountered their educational experiences in their schooling in Oregon. 


\section{Combined Survey and Interview}

Methodology

The methods used in this study combine the approaches of interviews and surveys in order to increase validity as suggested by Mathison (1988). Denzin (1970) recommended that by combining methods, observers could achieve the best of each, while overcoming their unique deficiencies. Sherman (1983) also rationalized on the relationship of school and work among high school juniors "...it is best to use a variety of techniques to develop data; different tools can complement each other, allowing greater confidence in interpretations" (p. 154). Minaya-Rowe (1992) believed that quantification provides a type of credibility, but often remains unconvincing unless supported by adequate qualitative, descriptive statements (p. 281). Caplan et al. (1992) supported the use of both survey and interview approaches in their research using many data sources and approaches to gain insights into the factors responsible for their achievements.

\section{Instruments for this Study}

This study employed two approaches in data gathering. The survey questionnaire and the interview protocol were developed and based on the variables adopted from Cummins' (1979) Contextual Interaction Theory. 
Survey

The first activity of the study was the survey, which was developed based on factors related to experience, opinion, value, knowledge, feeling and educational backgrounds, and the theoretical framework stated in Chapter I. There has been little empirical social research to measure the social/cultural dimensions in the education of the "Southeast Asian" refugee population (Castro, 1983). Some descriptive accounts written by the Southeast Asian refugee scholars living in America were available (Caplan et al., 1992). The survey questionnaire and interview questions, therefore, were constructed based on factors related to the educational, socio-cultural and at risk factors pertaining to all ethnic and language minorities in the current body of research.

The 29-item survey (see Table 1) and the interview questions were developed and centered around the four major areas of investigation of this study. These areas are in congruence with the components in the Contextual Interaction Theory postulated by Cummins (1979).

- Community background: Questions \# 1, 2, 3, 4, 7, 9, 11, 16, 19, 22

- Educational Input: Questions \# 6, 8, 10, 17, 18, 21, 24, 26, 27, 29

- Instructional Treatment: Questions \# 5, 20, 26, 28

- Student Input: Questions \# 12, 13, 14, 15, 23, 25 
Table 1

Survey Questions

Item \# Questions/Variables

1. How long have you been in U.S. schools?

2. How many people live in your house?

3. Who do you live with?

4. Do you have a job where you earn money?

5. Check the school subjects you do well.

6. I prefer to have these above classes taught in Vietnamese.

7. I have close Vietnamese friends.

8. Teachers make me feel welcome.

9. My parents do not care if I do well at school.

10. Teachers, counselors, principal visit me at home.

11. My parents want very much for me to do well at school.

12. I do homework at home.

13. I try very hard to do well in school.

14. I do not belong to any clubs at school.

15. I play sports at school.

16. Vietnamese students do not belong to gangs.

17. My school makes me feel welcome.

18. I have close American friends at school.

19. Vietnamese students do not smoke or drink alcohol.

20. I learn a lot from my ESL teachers.

21. It is $\mathrm{OK}$ at my school to use Vietnamese language.

22. Vietnamese students do not dropout of school.

23. I have plans for my career after high school.

24. I have been referred to the principal for discipline problems.

25. I am not worried about my future.

26. I understand the English spoken in my classes.

27. I am accepted and treated well by other students.

28. School counselors help me a lot.

29. Principal, teachers, counselors understand about my culture. 
Ten questions of the survey regard community background factors, 10 questions pertain to the educational input, 4 questions relate to the instructional treatment factors, and 6 questions regard the student input in the survey instrument. There are some overlapping questions which relate to more than one area of the four above areas of investigation. Survey items were rated by respondents on a five-point scale. Anchors for the scale were "agree" $=1$ and "disagree" $=5$.

Social and cultural factors assessed in this study (peer relationships, teacher/school welcome, home visit, parental support, the respect for home culture and first language, student acceptance and treatment) are well documented and supported by many studies as significant factors affecting minority schooling in America (Ambert, 1991; California DOE, 1982; Cummins, 1989; Zanger, 1991). However, it is assumed that there are many other social/cultural aspects pertaining to the education of Vietnamese students in America. This study is by no means a coverage of the whole spectrum of the educational, social and cultural factors pertaining to Vietnamese students.

The survey included two opposite questions asking about the same variable (parental support) in separate orders (items \#9 and 11) to help assess the accuracy and understanding of respondents. Also, six items of 
the survey were stated in negative form to challenge respondent's seriousness in their responses, (items \#9, 14, 16, 19, 22 and 25). The above measures were built-in to the study to help ensure better validity and reliability.

The survey was field tested by a class of Vietnamese students at a high school in Portland. Revisions were made to increase understanding, clarity of item statements, and to improve directions. As outside experts, a Vietnamese high school teacher and a cultural specialist assisted in this process, as recommended by Converse and Presser (1983, p. 48). A revised final edition of the survey was administered at three high schools in Portland Public Schools, Parkrose High School, David Douglas High School, Beaverton High School, and Gresham High School and also at a Vietnamese Sunday School. The survey was administered with the assistance of two Vietnamese teachers, one cultural specialist, one youth outreach coordinator, one Catholic father and a nun at Sunday classes. These assistants were briefed about the purposes of the study and were trained to proctor the survey. The survey results were used as quantitative data pertaining to the educational, social, and cultural issues and the respondent's perception of their schooling in Oregon high schools.

Respondents were told about the anonymity and confidentiality of the study. All written survey questionnaires and interviews were conducted 
on an anonymous basis to fully insure respondents' confidentiality and privacy. The survey was administered to 152 students. Out of this number, seven surveys were considered invalid due to incompleteness or dishonest/contradictory answers on variables \#9 and \#11, and were omitted from analysis. The response rate was $95 \%$.

The 145 completed surveys were analyzed statistically to obtain descriptive analysis, percentages, standard deviations, correlations, and $t$ tests for significance of observed group differences were performed. Major findings and relationships from these analyses are discussed and interpreted in later chapters along with possible implications and recommendations.

\section{Interviews}

The second activity of this study was the interviews. Out of this group of 145 surveyed respondents, 2 individuals were referred by their teachers for personal interviews due to their uniqueness: one was a high achiever and the other was a failing case. The interviews were conducted individually. These students volunteered to participate in the interviews audio-recorded by the researcher. The purpose of the interviews was to explicate and illuminate the real school life experiences of these two students. 
The interview questions were basically the same as the survey instrument except that some questions were collapsed and the total number of questions were reduced to 20 . The interviews took four hours, were semi-structured and open-ended allowing room for explanation, clarification, and paraphrasing. The interviews took place at a local Vietnamese restaurant long before the lunch guests crowded the facility. This kind of arrangement served well by providing a relaxed atmosphere, away from friends and staff. It created a good environment to build trust and openness.

Interview transcripts were content analyzed in terms of topics developed for the questionnaire (e.g., "I learn a lot from ESL" and "I try very hard to do well at school," etc.). Direct student quotes were obtained to portray the language, perspective and emphasis of two youth in order to put more meaning and realistic subtlety into the survey findings.

The interview questions are also developed around Cummins' (1979) Contextual Interaction Theory (see Table 2).

Interview questions 1, 2, 8, 14, 16, 18, 19: Community Background Interview questions 10,11, 12: Instructional Input Interview questions 4, 5, 6, 13, 15, 17: Educational Input Interview questions 3, 7, 9, 10, 20: Student Input 
Table 2

Interview Questions

1. How long have you been in the country?

2. Were there any special experiences you had in American schools?

3. Name some of your educational achievements so far.

4. What problems have you had in school since coming to America?

5. Are you a member of a club or participating in any after-school activities? What do you do in your spare time?

6. Can you share with me some of the things that you like about American schools and some of the things you dislike about them?

7. What are your educational/career goals? Do you have a plan to achieve these goals? Do you feel you are prepared for your future?

8. Do you have somebody that you see as a role model or who has influenced or helped you in your education?

9. What do you see as your strong characteristics in helping you in your education? And what do you consider as your weaknesses?

10. Is learning English important to you? Are you satisfied with what you have learned?

11. Do you think you need to learn your native language? Why/Why not? Do you have an opportunity to learn your native language now?

12. Besides English, how are you doing with other subjects such as Math, Science, Health, History, Social Studies, Government, etc.? Are you satisfied with your progress in these areas? Why/Why not?

13. Do school staff communicate with you or your family? In what way and what is the purpose of their communication?

14. Have there been any changes or problems in your family in adjusting to the new society? What is your role in your family?

15. Do you have American friends at school? Do you have Vietnamese friends at school? How is your relationship with them?

16. Have your values and attitudes changed since coming to America?

17. Do you know of any friends who dropped out of school? If yes, why?

18. Do you see yourself as a Vietnamese or as an American? Why?

19. There are many publicized stories of Asian gangs and drug/alcohol use among Asian students, what is your opinion on these issues?

20. If you had a wish about your education, what would it be and why? 


\section{Use of Subjects' First Language in Study}

The written survey and the interviews were conducted in the respondents' first language. Even though respondents were given the choice of the survey in either Vietnamese or English, they all chose Vietnamese. Native language competency is important in a minorityfocused study where the flow of communication between the investigator and respondents should be as spontaneous and natural as possible, and not distorted via translation.

Important factors such as revelation of feelings, perceptions and cultural insights could be valuable. In some cases, language-minority respondents may be hesitant responding truthfully or frankly to investigators who are from the host society, unless a personal relationship has been established. This is not to say that studies conducted via translators are not as valid. Ideally, the investigator of a second culture study needs to have the ability to speak the language, to understand the respondent's culture and to establish a good rapport. The author took full advantage of the language facility and also utilized previous knowledge, experience and relationship with this community and this group of respondents. The researcher and many of the respondents share the same experiences, since they have been in the same situation. 
The study was designed with the respondent's perspective, an advantage which Merriam (1988) commented that this perspective would "contribute to the knowledge base and practice of education" (p. 3). Many of the issues pertaining to these students' perceptions regarding their schooling are enmeshed in the socio-cultural contexts of American schools. This study also has a goal to understand the social cultural aspects regarding the schooling of Vietnamese students.

\section{Sample}

The sample of this study is limited to the number of Vietnamese students in several Portland high schools and the surrounding districts. The interview sample was drawn from the survey sample of 152 respondents.

\section{Survey Sample}

There have not been any tabulated records of Vietnamese student enrollments in Oregon. The cluster sampling approach was therefore employed. Three high schools in Portland with a good concentration of Vietnamese students, David Douglas, Parkrose, Beaverton, Gresham high schools and the Vietnamese Vicariate Sunday school were included in this study. 
The bilingual teachers and specialists at these schools were precontacted for participation in this study. The purpose and scope of the study were discussed and explained to these professionals. A Vietnamese teacher and a cultural specialist, as outside experts, volunteered to field test the survey as well as to assess the appropriateness, the meaning and clarity of the questionnaire to ensure better content validity (Ary \& Jacobs, 1985, p. 357). Accordingly, revisions were made based on their feedback. Questions regarding personal backgrounds were discussed in length due to the issues of anonymity and confidentiality of respondents. Many demographic questions were intentionally not inquired, fearing that they were too culturally intrusive, which in turn could affect the outcomes of the survey.

One hundred fifty-two Vietnamese students in these seven high schools and a Sunday school volunteered to participate in the survey. The surveys were administered during their normal class time of 45 minutes. Respondents were given a choice of either a Vietnamese or English version of the survey. All respondents chose the Vietnamese version.

\section{Interview Sample}

As designed in this study, some "most unique" respondents would be sought for the personal interviews. It was hoping that these unique 
individuals would shed some light on the successes and problems that Vietnamese students encountered. Two most unique individuals were referred by their teachers to voluntarily participate in the audio-recorded interviews. These two youths were interviewed for four hours, which included two hours of initial interviews and two hours of follow-up interviews. They were most unique due to their opposite extremity in their educational experience: one was a high achiever and the other one was a failing student.

The purpose of the interviews was to illustrate some real life situations of these students. It was not intended for generalizations or inferences. The interview activity was only a subsidiary effort to add a holistic view to the quantification of the survey.

\section{The Sample's Representativeness}

Comparing this sample with the data from Portland Public School's enrollment report of June 1992 showed a good level of representativeness. Based on that report, there were 377 Vietnamese high school students enrolled in the ESL/Bilingual Program (p. 9). Out of the 377 Vietnamese students, 176 were enrolled at three Portland high schools participated in this study. In other words, a great percentage of Vietnamese high school students in these Portland schools were included in the survey $(\underline{N}=152)$. 
Comparing the results of this study with Davis and McDaid's (1992) research on the Vietnamese high school students in San Diego confirmed many compatible demographic findings. For example:

- $38 \%$ of the respondents of the San Diego's study had arrived in the United States within the past 3 years (p. 34), compared with the average 2.8 years of United States school residency in this study.

- $12 \%$ of the San Diego's respondents indicated that they lived with unrelated adults (p. 36). This study's findings show $15.9 \%$ of the respondents living with nonparent adults.

- The San Diego findings showed that one third of respondents held a job for pay outside of the home (p. 38), compared with $26.9 \%$ of the respondents of this study who reported having a job while in school.

The above comparisons show that even though the cluster sampling approach has limitations, this study demonstrates a good level of representativeness of the Vietnamese-American high school student population.

Limitations of the Approach and Instruments

The survey did not intend to measure a student's academic achievement since this research was not an evaluative study. Most survey items were constructed to assess a student's own perception regarding their 
schooling and some social/cultural factors within the context of Oregon high schools. This study did not cover "all" aspects pertaining to the schooling of Vietnamese students in America. Due to the scope of this study and the issues of anonymity, many demographic questions were not included. The survey was also designed short enough so that respondents could finish in a class period (45 minutes).

Many factors might affect the validity and reliability of this study:

- the cluster sampling approach;

- factors pertaining to educational, social, and cultural aspects of schooling limited only in the survey questionnaire;

- student's honesty, interest and understanding in survey questions;

- the interviews were not representative.

It was extremely difficult to secure a pure random sampling for this study due to the lack of any recorded data on the number of Vietnamese students in Oregon. Vietnamese students are classified as Asian-Americans, Indochinese or Southeast Asians in all school districts in Oregon. There was no existence of any tabulated record from rural districts in regard to Vietnamese students. Therefore, no rural school was included. Also, the majority $(95 \%)$ of Vietnamese settled in urban areas (Oregon Department of Human Services, 1988). However, in these urban school districts, not many high schools had any considerable concentration of Vietnamese 
students. Therefore, the only sensible sampling approach for this study was "clustering," although this approach had its limitations.

\section{Summary}

In order to thoroughly examine the factors affecting the schooling of Vietnamese-American high school students in Oregon, the guiding theoretical framework of this study placed the major focus on four areas of investigation: Community Background, Educational Input, Instructional Treatment, and Student Input (contributions). The literature in the preceding chapter provides a review of some research studies as well as the state-of-the-art knowledge on the schooling of language-minority students.

This chapter describes the instruments and the road map designed for this investigation. The chapter includes: data gathering methods, instruments for the study, the language used, the sample, and their limitations.

This study combines the survey and interview methods due to the quantification benefits of the survey in performing many statistical analyses needed for this research, and due to the holistic illustration of the real life experiences the two unique respondents brought to this study.

The instruments were custom-made for both the survey questionnaire and the interview protocol. They cover a wide range of issues pertaining 
to the four areas of this investigation, and based on the current research knowledge. Special care was taken in designing the instruments to protect the respondents' privacy, confidentiality, and cultural concerns. Limitations were unavoidable. Reliability and internal validity were seriously considered. The instruments were also field tested by outside specialists to insure the quality and high standards in this research.

Even though instruments were designed bilingually, all respondents chose the Vietnamese version. The use of the subject's first language was also designed to maximize the benefits of respondent's language and culture skills and to accurately project their perspectives. This also alleviates the distortion of translation and the use of non-researcher translators.

One major issue that concerned this study was the availability of tabulated data on the subjects. Therefore, a pure random sampling approach was not feasible. Because of the limitations of the sampling approach and the instruments, this study forewarns readers of any generalizations. 


\section{CHAPTER IV}

\section{FINDINGS}

The theoretical framework guiding this present study, as presented in Chapter I, covers the research question topics under four major areas of investigation: Community Background, Educational Input, Instructional Treatment, and Student Input which were carried out through the survey questionnaires as well as the interview questions. Table 3 shows the variables studied within these four areas.

Table 3

Four Areas of Investigation

\begin{tabular}{ll}
\hline Item \# & Survey Question \\
\hline
\end{tabular}

\section{Community Background}

1. How long have you been in U.S. schools?

2. How many people live in your house?

3. Who do you live with?

4. Do you have a job where you earn money?

7. I have close Vietnamese friends.

9. My parents do not care if I do well at school.

11. My parents want very much for me to do well at school.

16. Vietnamese students do not belong to gangs.

19. Vietnamese students do not smoke or drink alcohol.

22. Vietnamese students do not dropout of school. 
Table 3

Four Areas of Investigation

(continued)

\begin{tabular}{ll}
\hline Item \# & Survey Question \\
\hline II. Educational Input
\end{tabular}

6. I prefer to have these above classes taught in Vietnamese.

8. Teachers make me feel welcome.

10. Teachers, counselors, principal visit me at home.

17. My school makes me feel welcome.

18. I have close American friends at school.

21. It is OK at my school to use Vietnamese language

24. I have been referred to the principal for discipline.

26. I understand the English spoken in my classes.

27. I am accepted and treated well by other students.

29. Principal, teachers, counselors understand about my culture.

\section{Instructional Treatment}

5. Check the school subjects you do well.

20. I learn a lot from my ESL teachers.

26. I understand the English spoken in my classes.

28. School counselors help me a lot.

\section{Student Input}

12. I do homework at home.

13. I try very hard to do well in school.

14. I do not belong to any clubs at school.

15. I play sports at school.

23. I have plans for my career after high school.

25. I am not worried about my future. 
The research design for this study uses two methods in gathering information: a survey of 145 subjects and interviews of two selected individuals. The survey questionnaires provide information about a sample of Vietnamese students while the interviews provide an illustration of how two students actually live through the issues and variables explored by this study.

Therefore, this chapter contains two parts: Survey Data Analysis and Interview Descriptions, which include two profiles and the content analysis.

\section{Part One: Survey Data Analysis}

The findings of the survey are presented in this chapter in three sections:

The first section is an item-by-item analysis. This provides descriptive findings concerning Vietnamese-American students' views of their schooling.

The second section summarizes these survey findings in terms of the first four research question topics introduced in Chapter I:

1. How do Vietnamese-American high school students in Oregon perceive the community background for their schooling? 
2. How do Vietnamese-American high school students in Oregon perceive the educational input for their schooling?

3. How do Vietnamese-American high school students in Oregon perceive the instructional treatment for their schooling?

4. How do Vietnamese-American high school students in Oregon perceive their own student input for their schooling? This provides findings organized in terms of the research questions which followed from the theoretical structure underlying this study.

The third section of survey data presents the inferential analysis (correlational and analysis of variance) that addresses the fifth research question:

5. How do the student perceptions of specific survey items concerning the four contextual factors relate to each other? This inferential analysis provides information about relationships among student views on individual items.

Section One: Descriptive Analysis of Survey Items

The results reported in this section are based on descriptive statistical analysis of the survey data. The descriptive analysis of this section is intended as a complete factor-by-factor result report. The results on each item are presented graphically and with descriptive highlights. 
Table 4 presents means and standard deviations on the survey items.

\section{Table 4}

\section{Descriptive Scale Analysis}

\begin{tabular}{llll}
\hline \multicolumn{1}{c}{ Survey Items } & $\underline{\mathrm{N}}$ & $\underline{\mathrm{M}}$ & $\underline{\text { SD }}$ \\
\hline How long have you been in U.S. schools? & 144 & 2.82 & 1.83 \\
How many people live in your house? & 141 & 5.60 & 2.31 \\
I prefer to have these above classes taught in Vietnamese. & 133 & 2.85 & 1.41 \\
I have close Vietnamese friends. & 144 & 1.41 & .93 \\
Teachers make me feel welcome. & 143 & 1.83 & .99 \\
My parents do not care if I do well at school. & 143 & 4.20 & 1.37 \\
Teachers, counselors, principal visit me at home. & 144 & 4.56 & .92 \\
My parents want very much for me to do well at school. & 145 & 1.23 & .63 \\
I do homework at home. & 145 & 1.72 & 1.05 \\
I try very hard to do well in school. & 142 & 1.52 & .79 \\
I do not belong to any clubs at school. & 143 & 3.37 & 1.32 \\
I play sports at school. & 142 & 3.19 & 1.61 \\
Vietnamese students do not belong to gangs. & 143 & 3.21 & 1.56 \\
My school makes me feel welcome. & 144 & 2.05 & 1.03 \\
I have close American friends at school. & 141 & 2.81 & 1.46 \\
Vietnamese students do not smoke or drink alcohol. & 143 & 3.27 & 1.49 \\
I learn a lot from my ESL teachers. & 138 & 2.75 & 1.67 \\
It is OK at my school to use Vietnamese language & 142 & 2.30 & 1.44 \\
Vietnamese students do not dropout of school. & 142 & 3.06 & 1.47 \\
I have plans for my career after high school. & 142 & 1.90 & 1.18 \\
I have been referred to the principal for discipline & 142 & 4.24 & 1.34 \\
I am not worried about my future. & 143 & 4.09 & 1.32 \\
I understand the English spoken in my classes. & 142 & 2.43 & 1.25 \\
I am accepted and treated well by other students. & 143 & 2.38 & 1.21 \\
School counselors help me a lot. & 143 & 2.44 & 1.2 .3 \\
Principal,teachers,counselors understand about my culture. & 142 & 2.53 & 1.21 \\
\hline
\end{tabular}

(5-point scale; $1=$ agree, $5=$ disagrec) 
Figures 3-31 are presented graphically with descriptive highlights as a complete result report of the study's descriptive analysis.

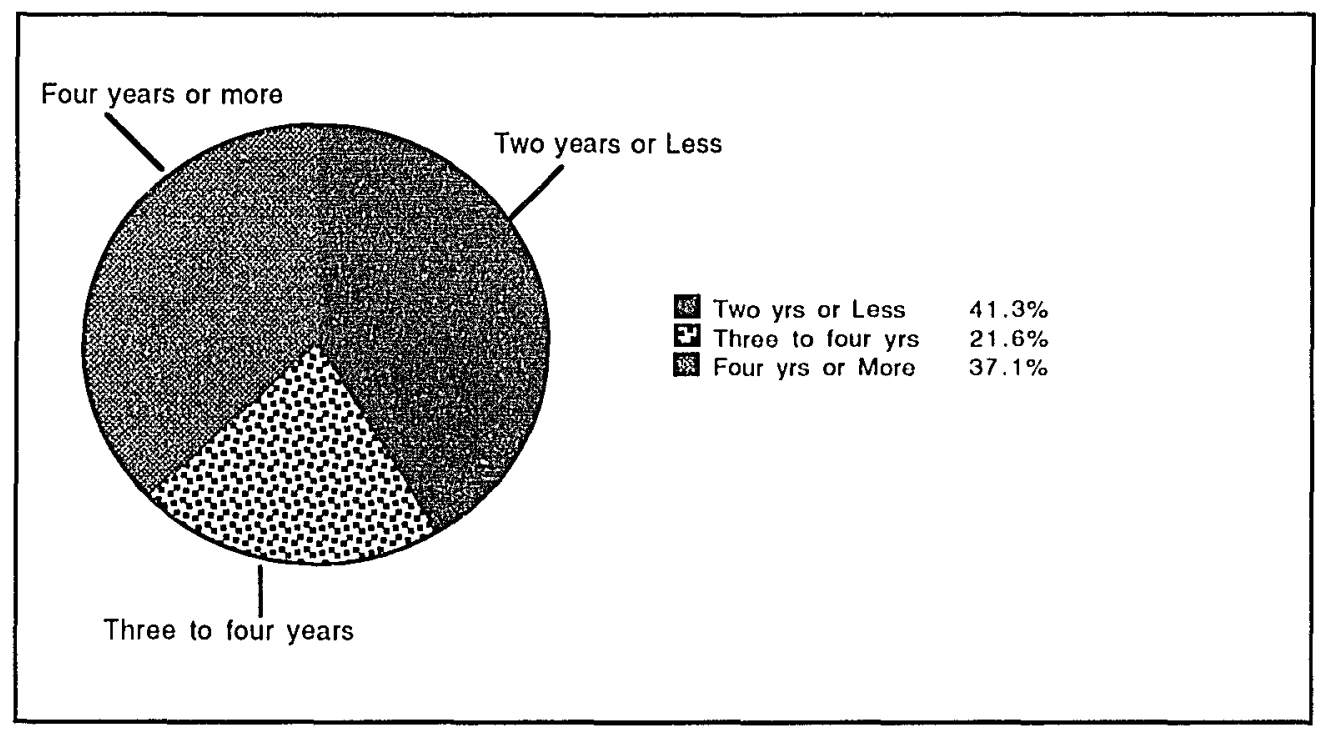

Figure 3. How long have you been in U.S. schools?

- Four out of 10 Vietnamese from this sample had been in U.S. schools less than two years, and were new to the country.

- Only a little more than a third of this group had been here in U.S. schools more than four years.

- Overall, two thirds of these students had only four years or less of American school experience.

- In comparision, American born high school students had at least eight years of schooling before entering their freshman year. 


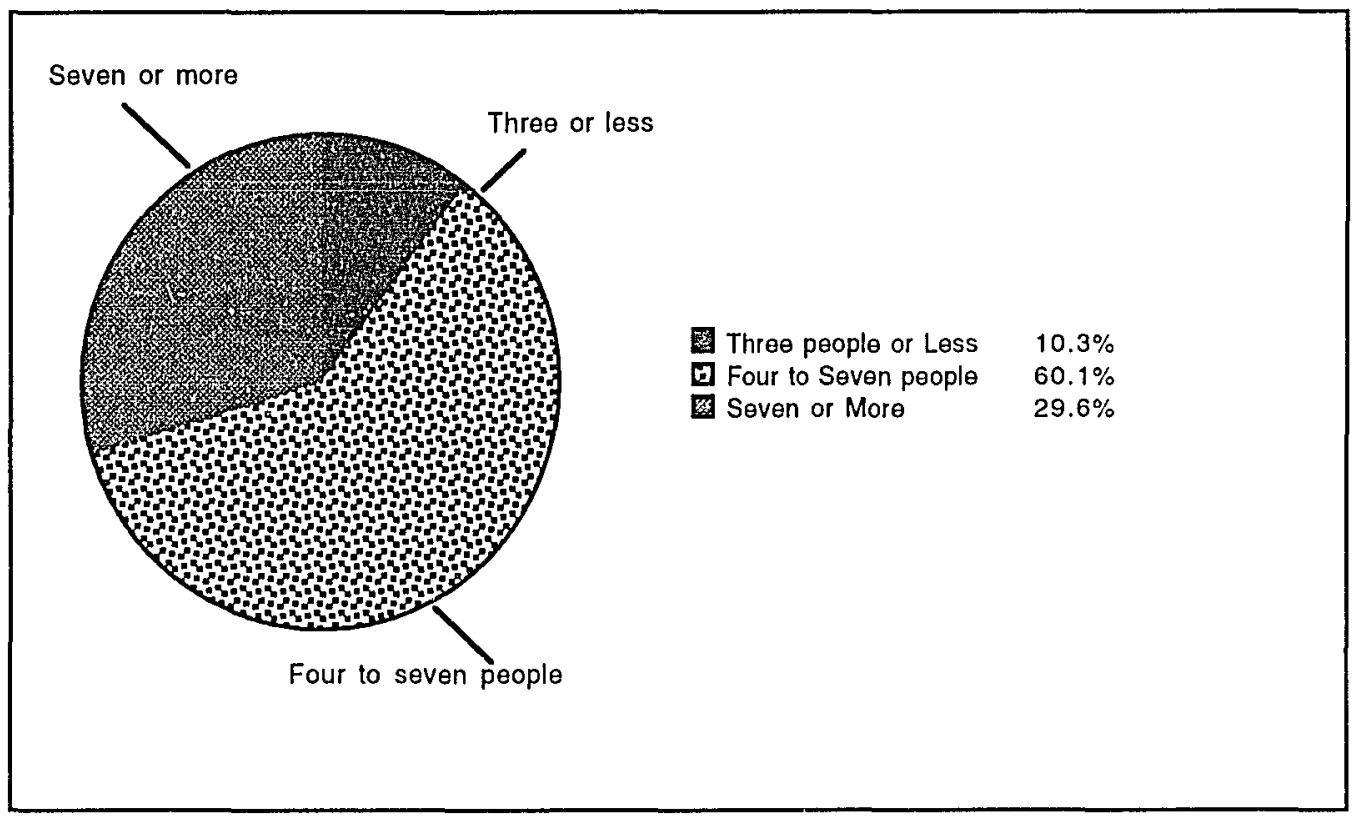

Figure 4. How many people live in your house?

- Two thirds of the subjects in this sample came from a large household made up of four to seven people.

- Three out of 10 students were from families of more than seven people.

- Only slightly more than $10 \%$ of the sample were from small households of three people or less. 


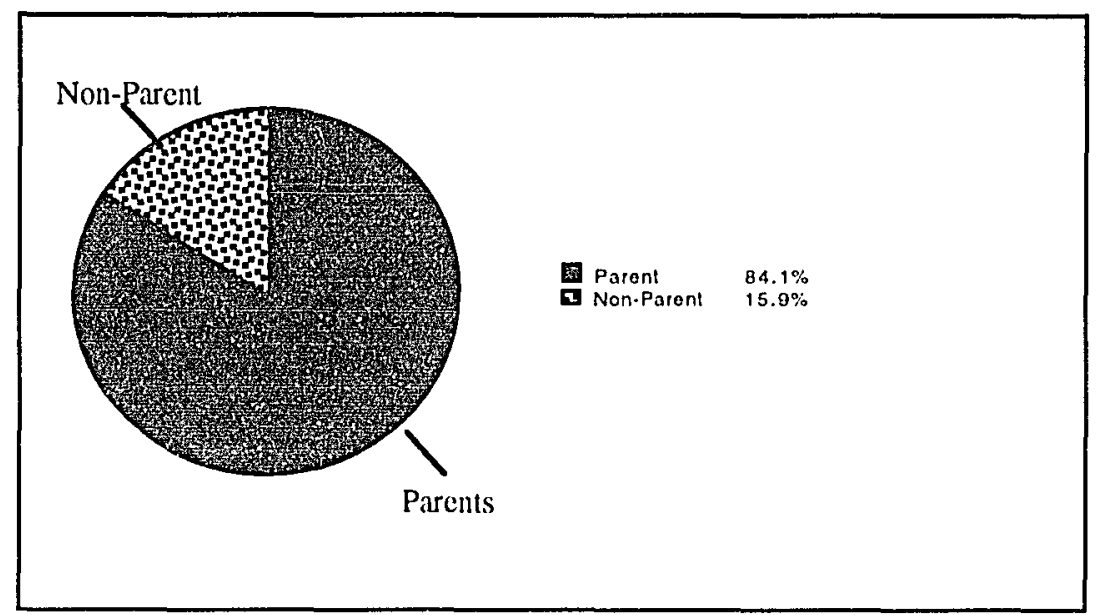

Figure 5. Who do you live with?

- The majority of these students indicated living with parents.

- A small percentage reported living with non-parent adults.

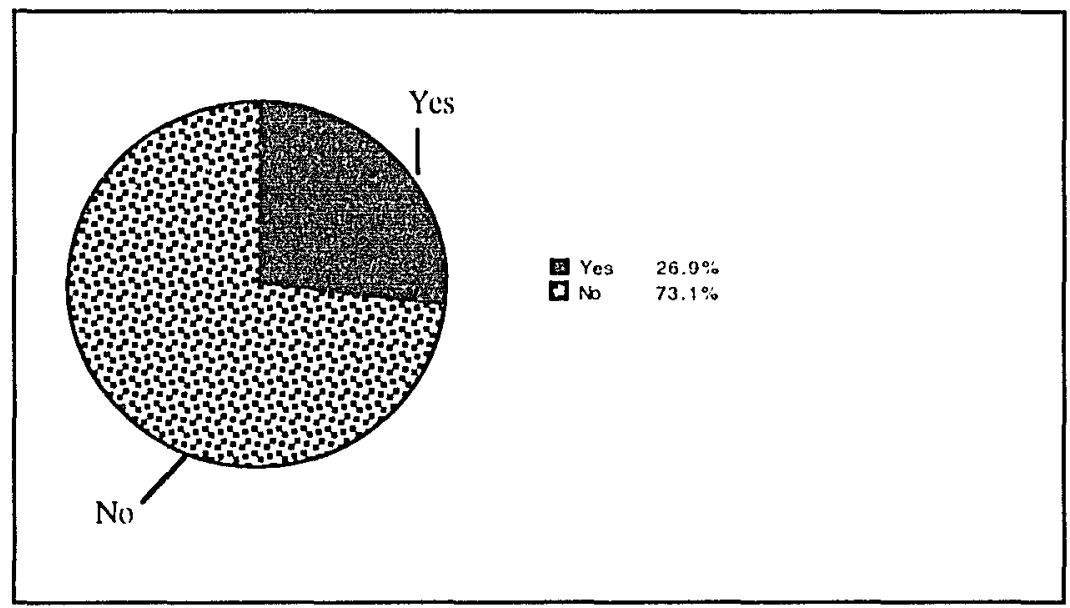

Figure 6. Do you have a job where you earn money?

- More than two thirds of these students do not have jobs.

- One out of four reported working on a job while schooling. 


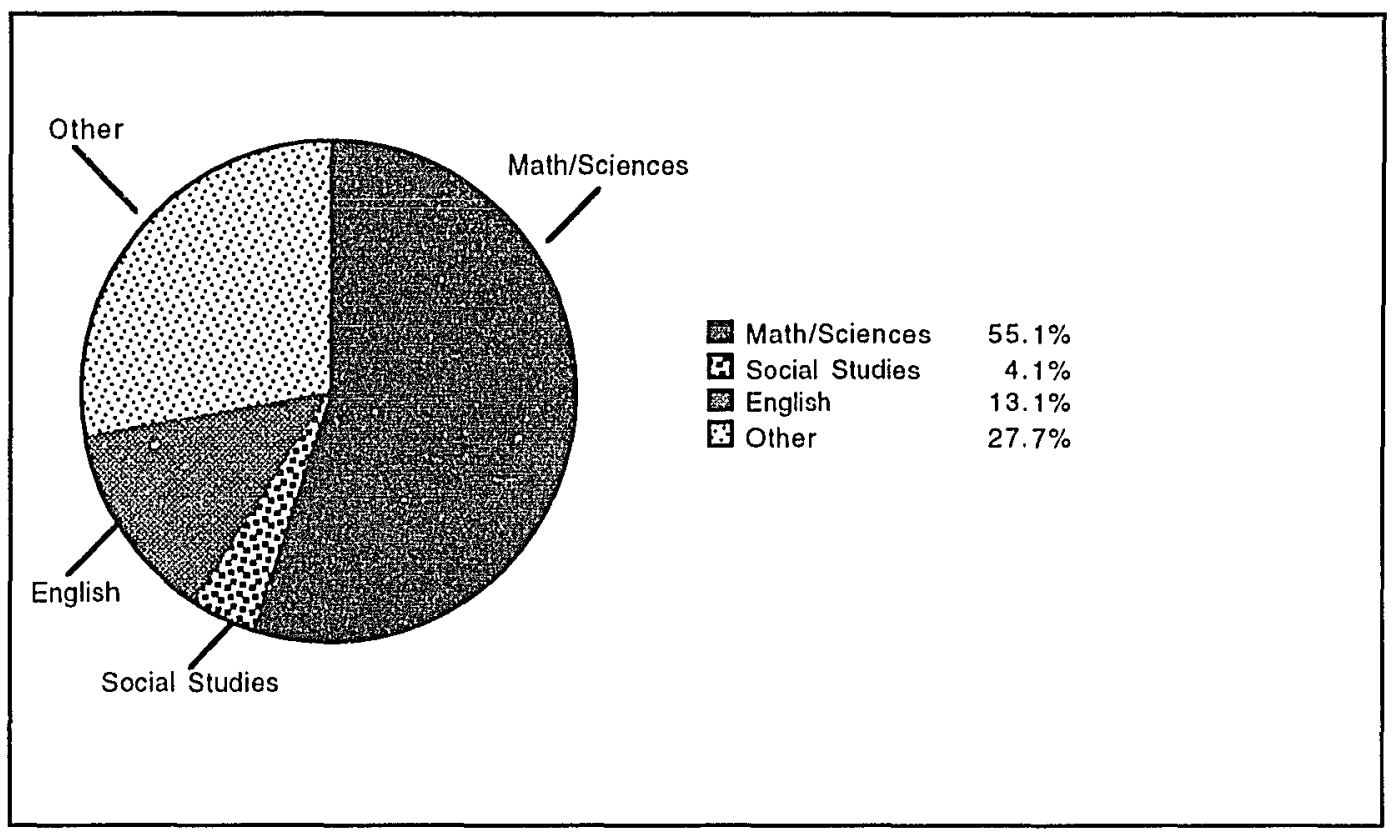

Figure 7. Subjects Vietnamese students do well.

- More than $55 \%$ of respondents indicated that they did well in mathematics and sciences: these subjects require less mastery of English language skills.

- In subject areas that require reading and language mastery, such as social studies, only $4.1 \%$ of the students responded positively.

- Only a little more than $10 \%$ of Vietnamese students in this sample thought that they were doing well in English. 


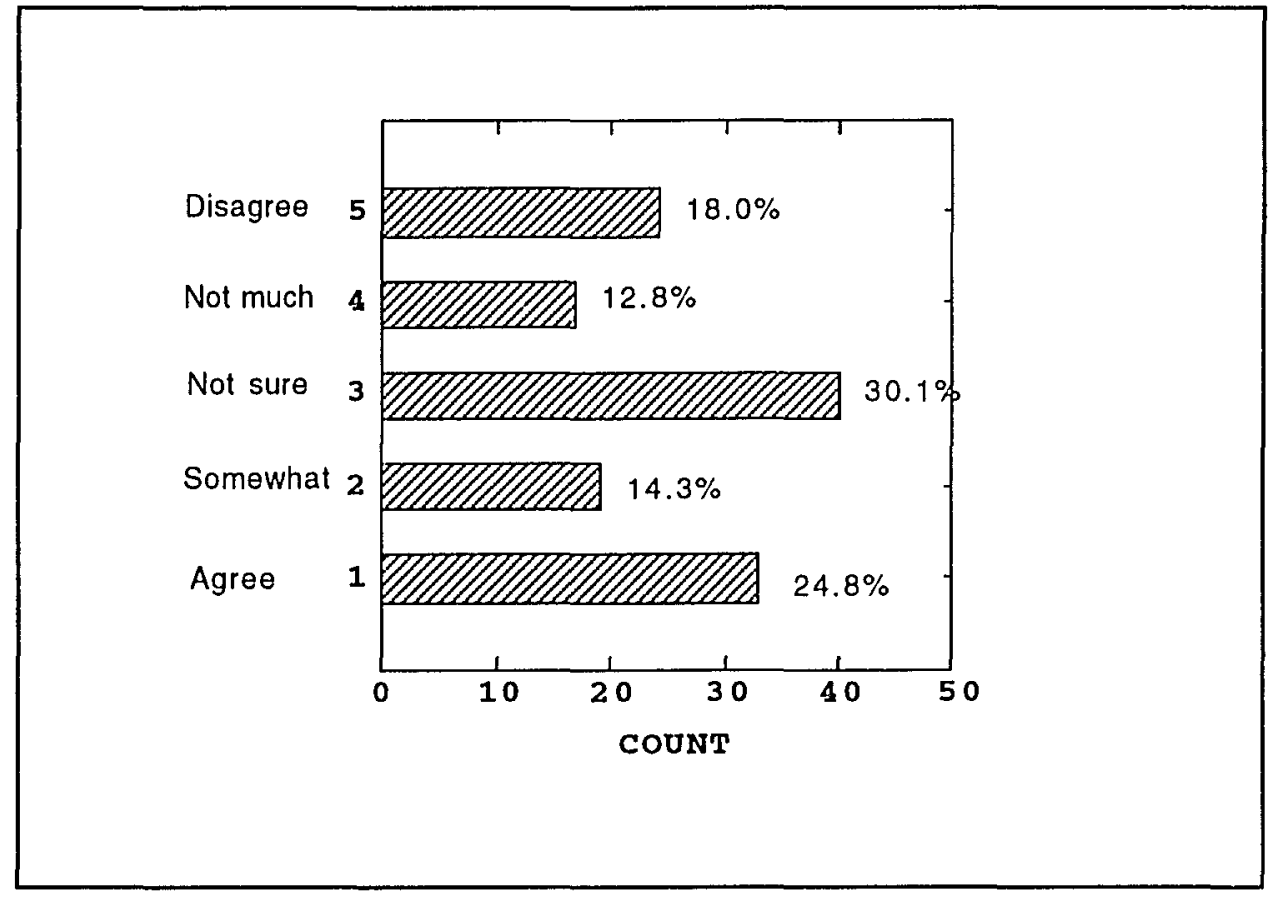

Figure 8. I prefer to have classes taught in Vietnamese.

- Students had mixed opinion about using Vietnamese as a language of instruction.

- Almost one third said they were "not sure" about using Vietnamese in teaching.

- About one out of five students did not agree with the idea.

- One out of four students responded favorably to use of Vietnamese in class.

- About the same percentage of students "somewhat" agreed and "not much" disagreed to have classes in Vietnamese. 


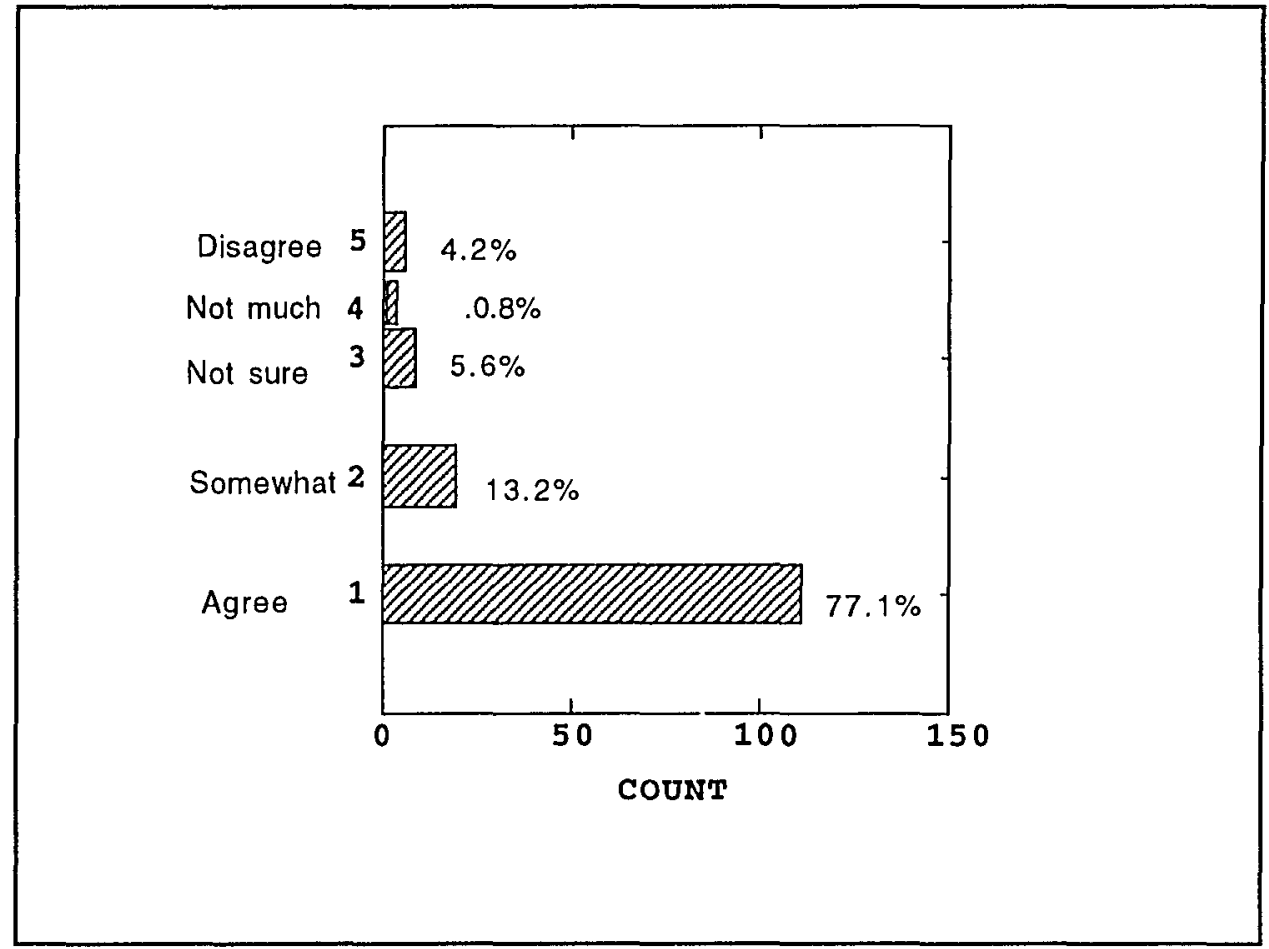

Figure 9. I have close Vietnamese friends.

- The majority of respondents reported to have close Vietnamese friends.

- A small percentage of the sample indicated that they do not have close Vietnamese friends.

- Another $13.2 \%$ of students indicated that they "somewhat" had close Vietnamese friends.

- About $5 \%$ of these students were "not sure" if they had close Vietnamese friends or not.

- This item had uniform agreement. 


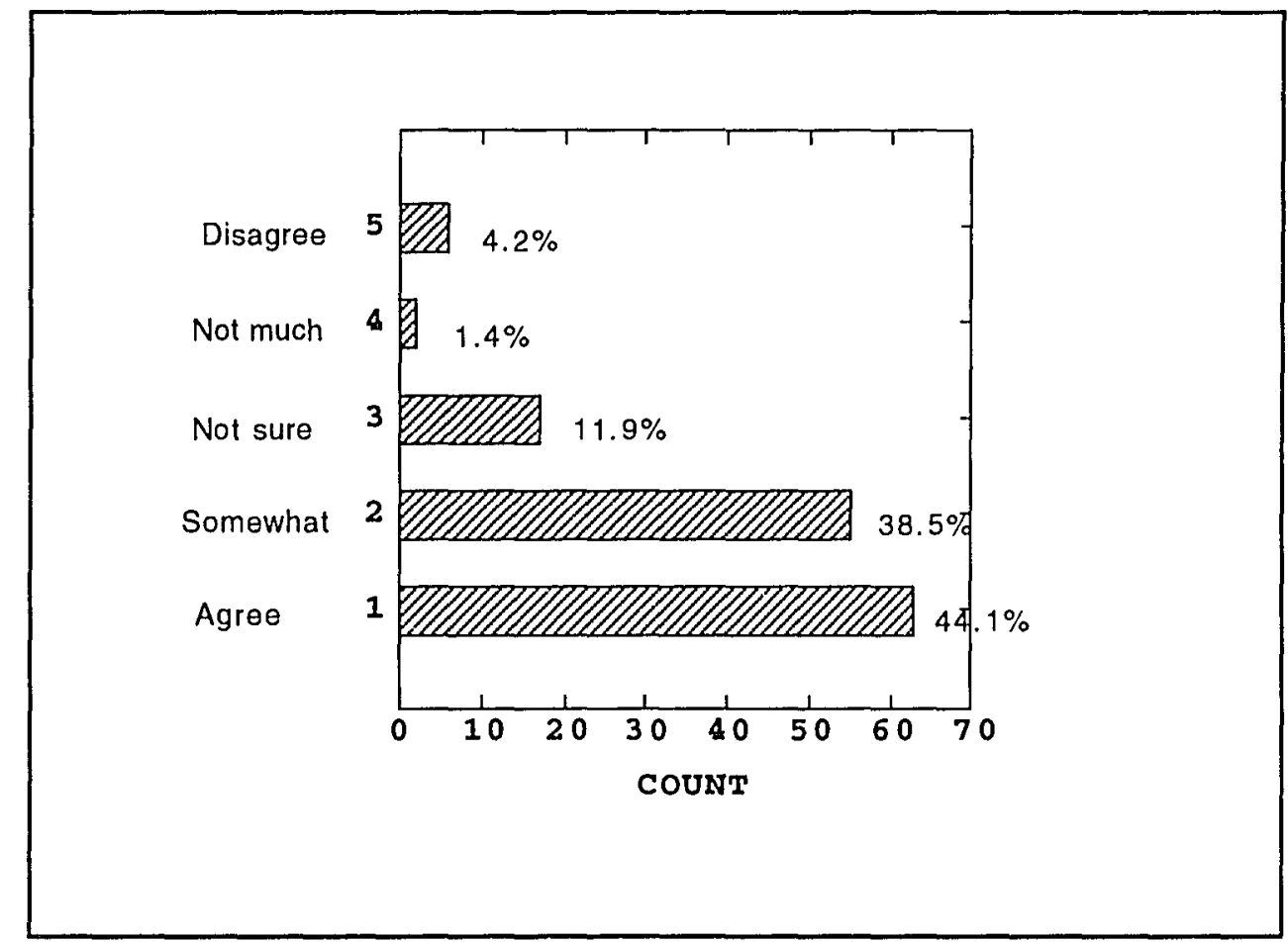

Figure 10. Teachers make me feel welcome.

- A large percentage (44\%) of this group of students believed that teachers made them feel welcome.

- Also, a little over one third agreed "somewhat" that teachers welcomed them.

- Overall, the majority of Vietnamese students in this sample perceived that their teachers made them feel welcome at school.

- One out of 10 students were "not sure" if they were welcomed.

- A small percentage of this sample believed that teachers did not make them feel welcome. 


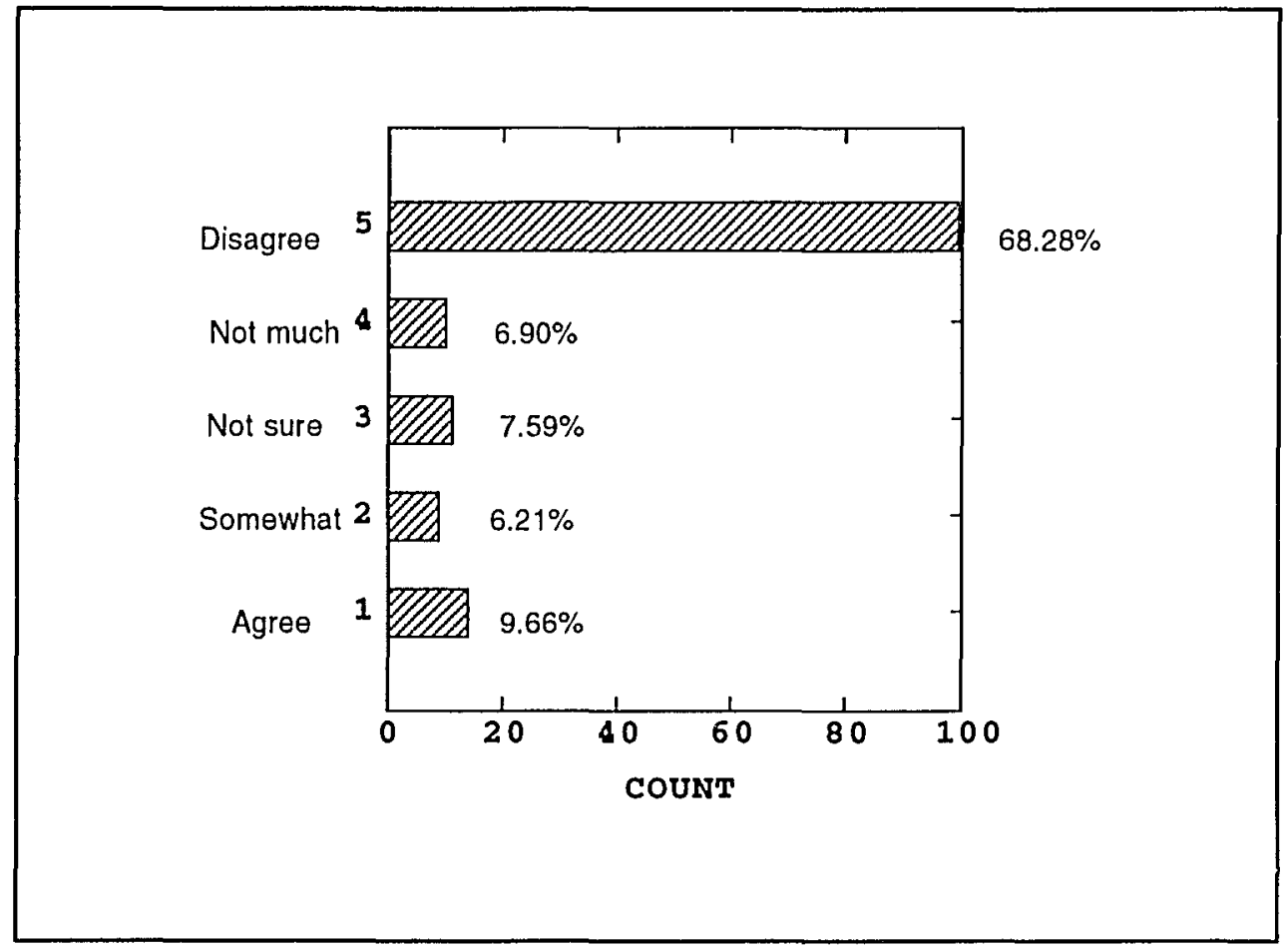

Figure 11. My parents do not care if I do well at school.

- The majority of respondents $(68 \%)$ disagreed with the question that their parents "do not care" if they were doing well at school.

- One out of 10 students perceived that their parents did not care about their schooling.

- Small percentages of students perceived this question as "not sure," "somewhat" or "not much."

- This item was uniformly high. 


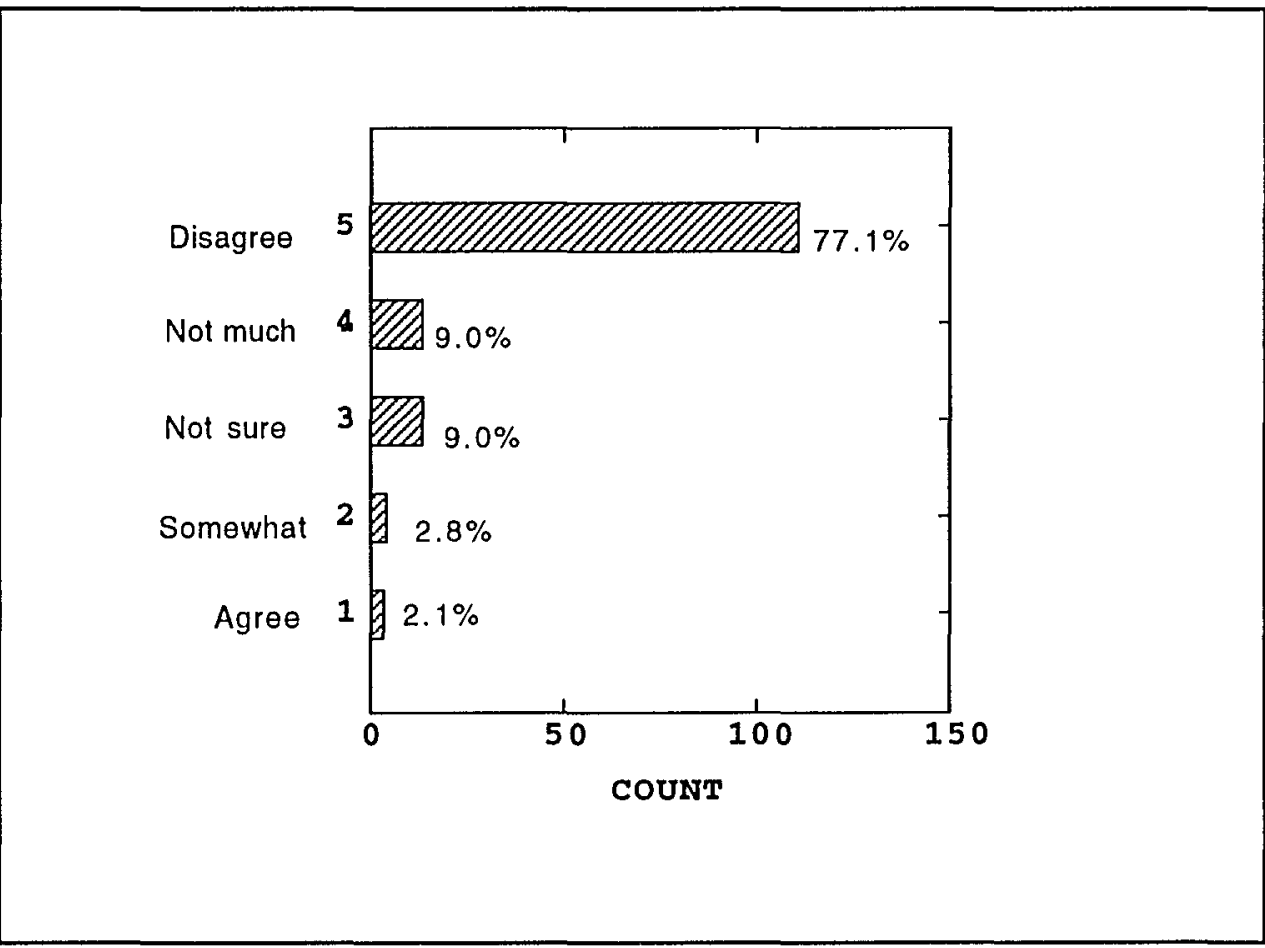

Figure 12. Teachers, counselors, principal visit me at home.

- Only a fraction of the students (4.9\%) in this sample indicated home visits.

- Approximately 1 out of 10 Vietnamese students in this sample were "not sure" or "not much" in agreement with this survey statement.

- Levels of disagreement were uniform on this item. 


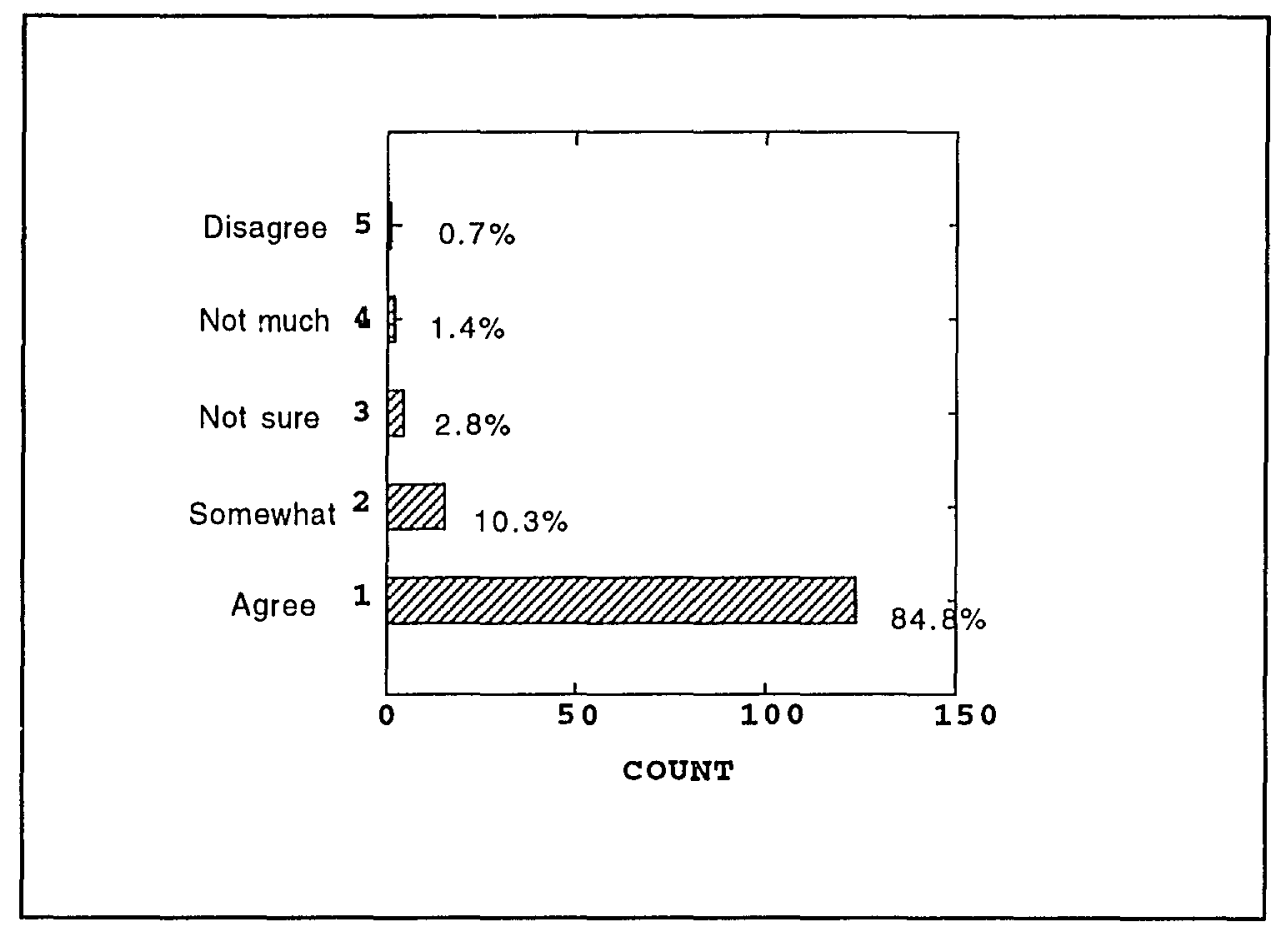

Figure 13. My parents want very much for me to do well at school.

- The majority of Vietnamese students $(85 \%)$ reported that their parents wanted them to do well at school.

- Ten percent indicated a "somewhat" lesser degree of the perception that their parents cared about education.

- Only a fraction perceived that their parents did not care if they were doing well at school or were "not sure."

- There was a high level of agreement on this item. 


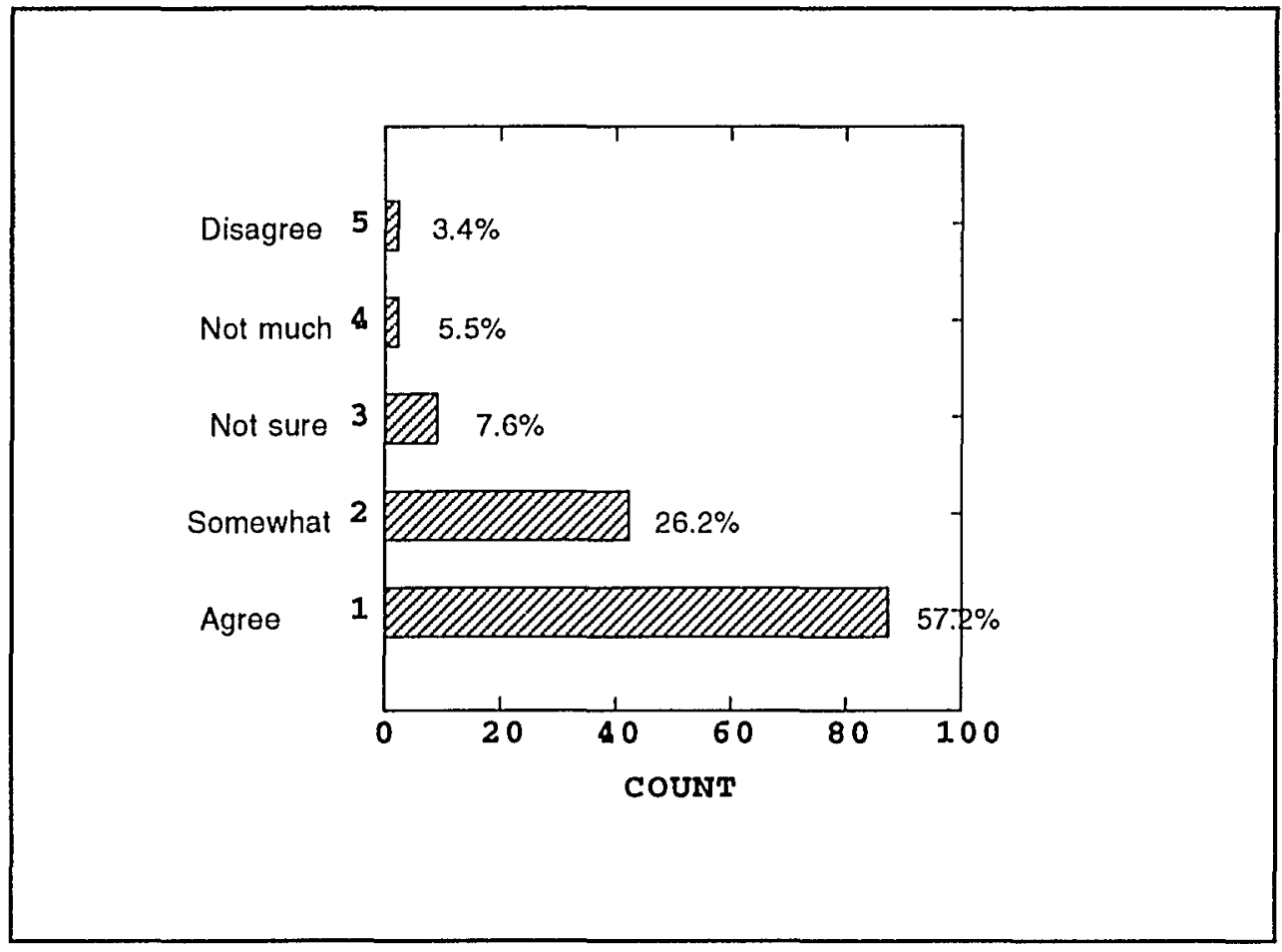

Figure 14. I do homework at home.

- Most students (57.2\%) reported that they "do homework at home."

- Almost one third agreed "somewhat" with this question about homework.

- The majority of these respondents $(83.4 \%)$ saw homework as a part of their schooling.

- A very low percentage reported not "doing homework." 


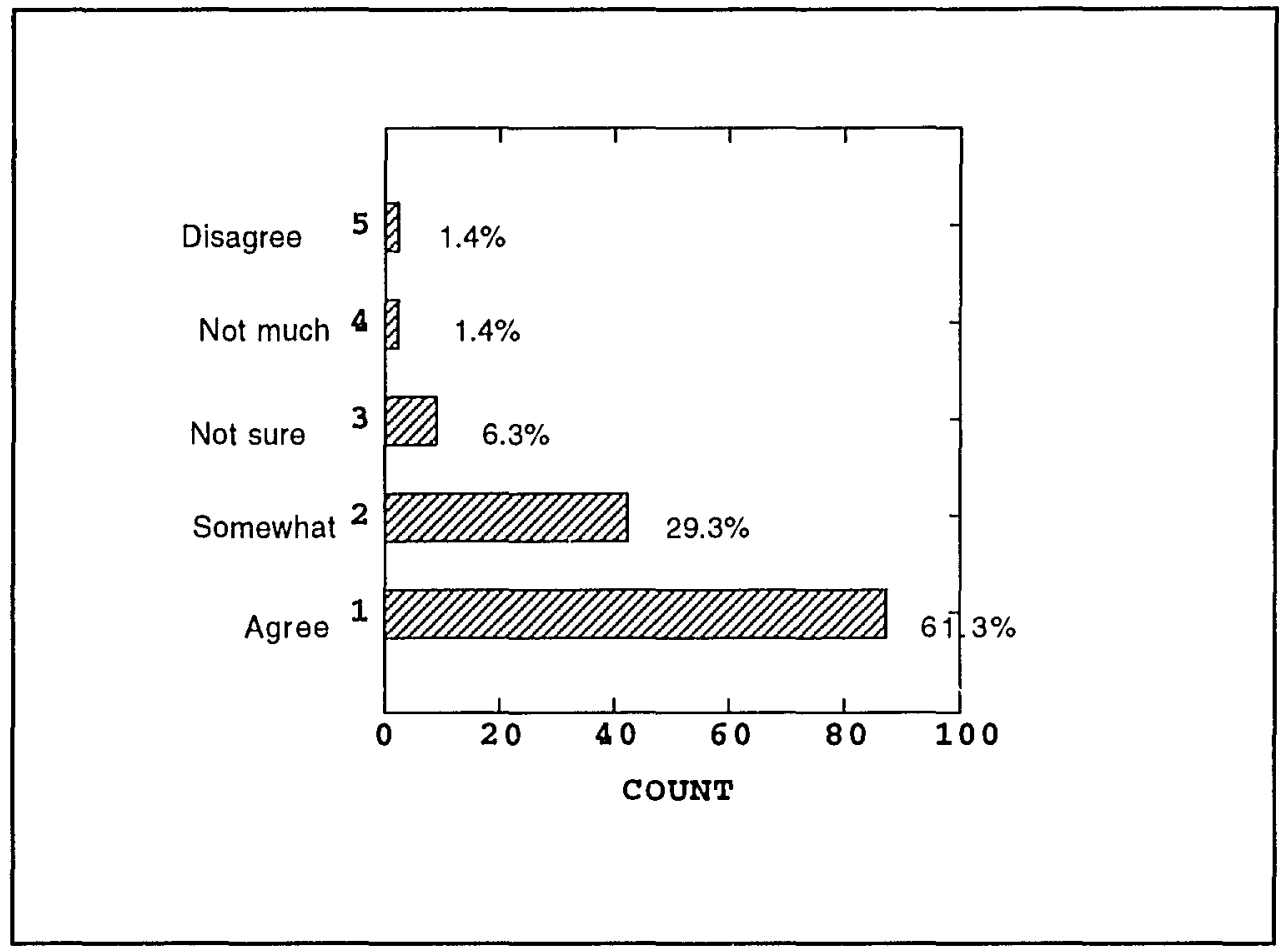

Figure 15. I try very hard to do well in school.

- Two thirds of the Vietnamese students indicated that they tried very hard to do well at school.

- Another third of the respondents also reported that they were "somewhat" trying hard at school.

- A very small percentage did not agree that they put some effort in their education.

- Respondents reported a high level of agreement on this question. 


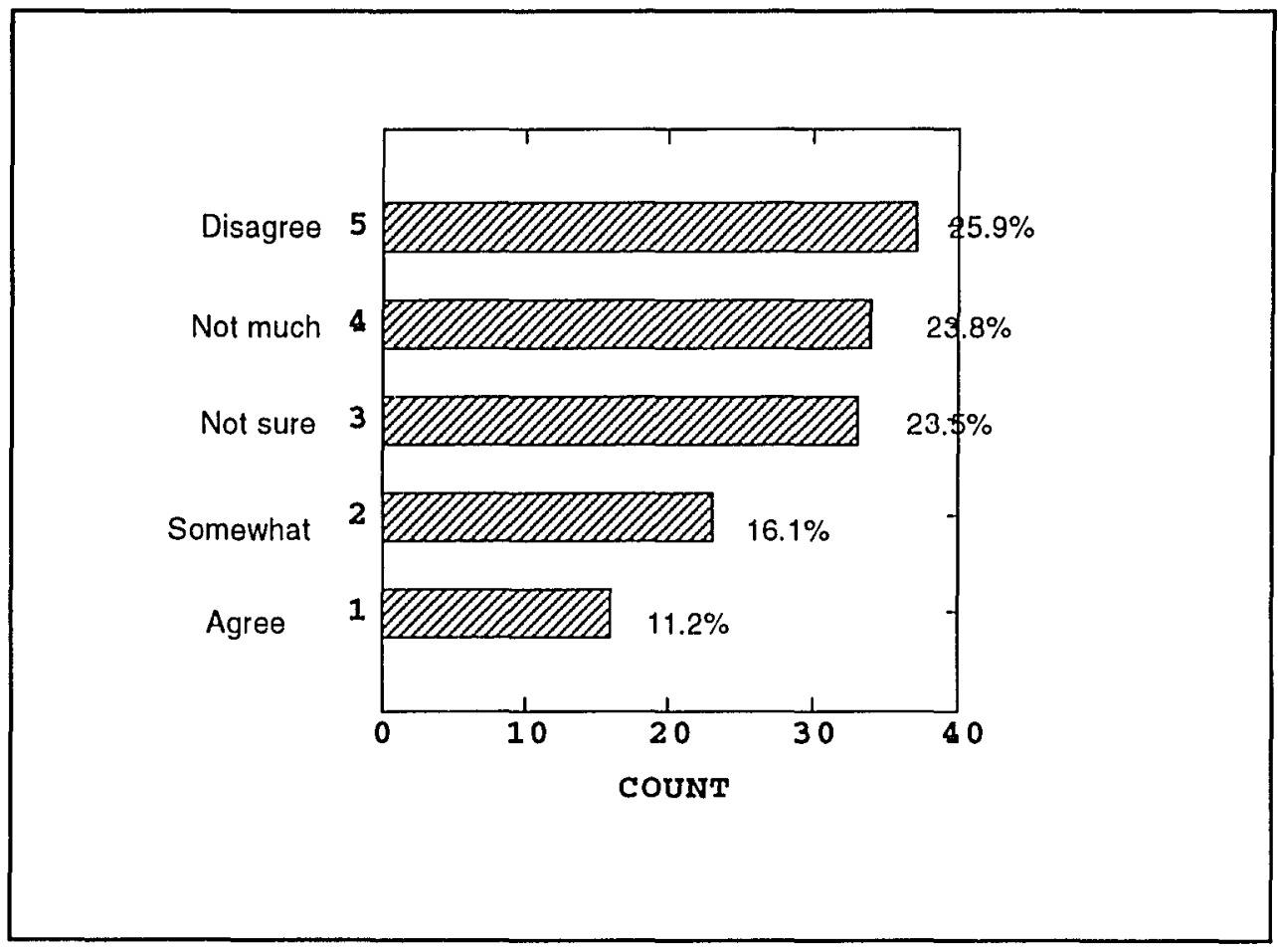

Figure 16. I do not belong to any clubs at school.

- One fourth of the Vietnamese students reported belonging to clubs at school.

- About the same percentage of respondents reported either "not sure" or "not much" in agreement with this item.

- Only one tenth said that they "do not belong to any clubs." 


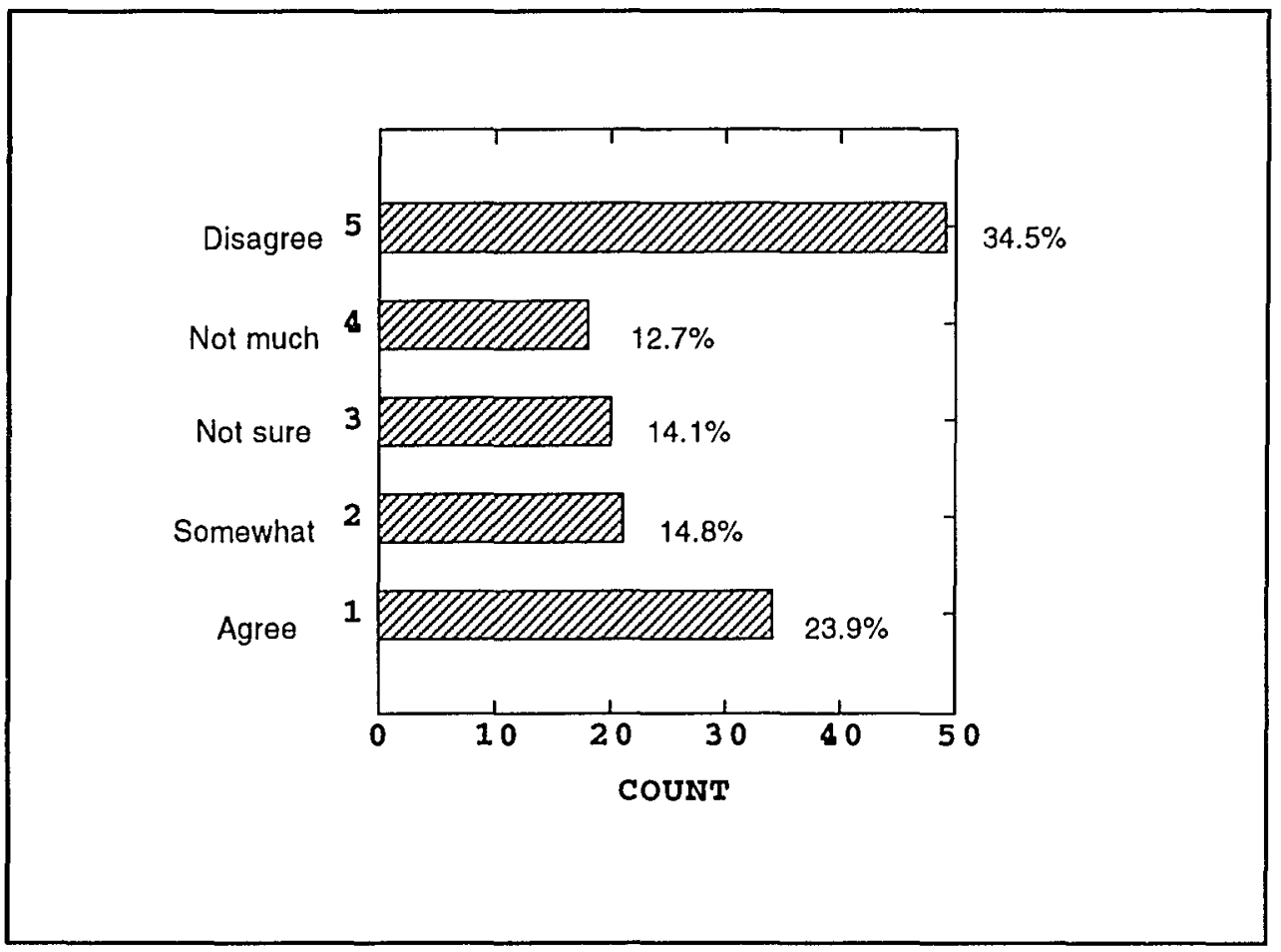

Figure 17. I play sports at school.

- Only one out of four Vietnamese students reported that they "play sports at school."

- One third reported that they did not play any sports at school.

- The percentages of students who reported that they either were "not sure" or "somewhat" are approximately the same.

- There was a high level of variance in perceptions on this item. 


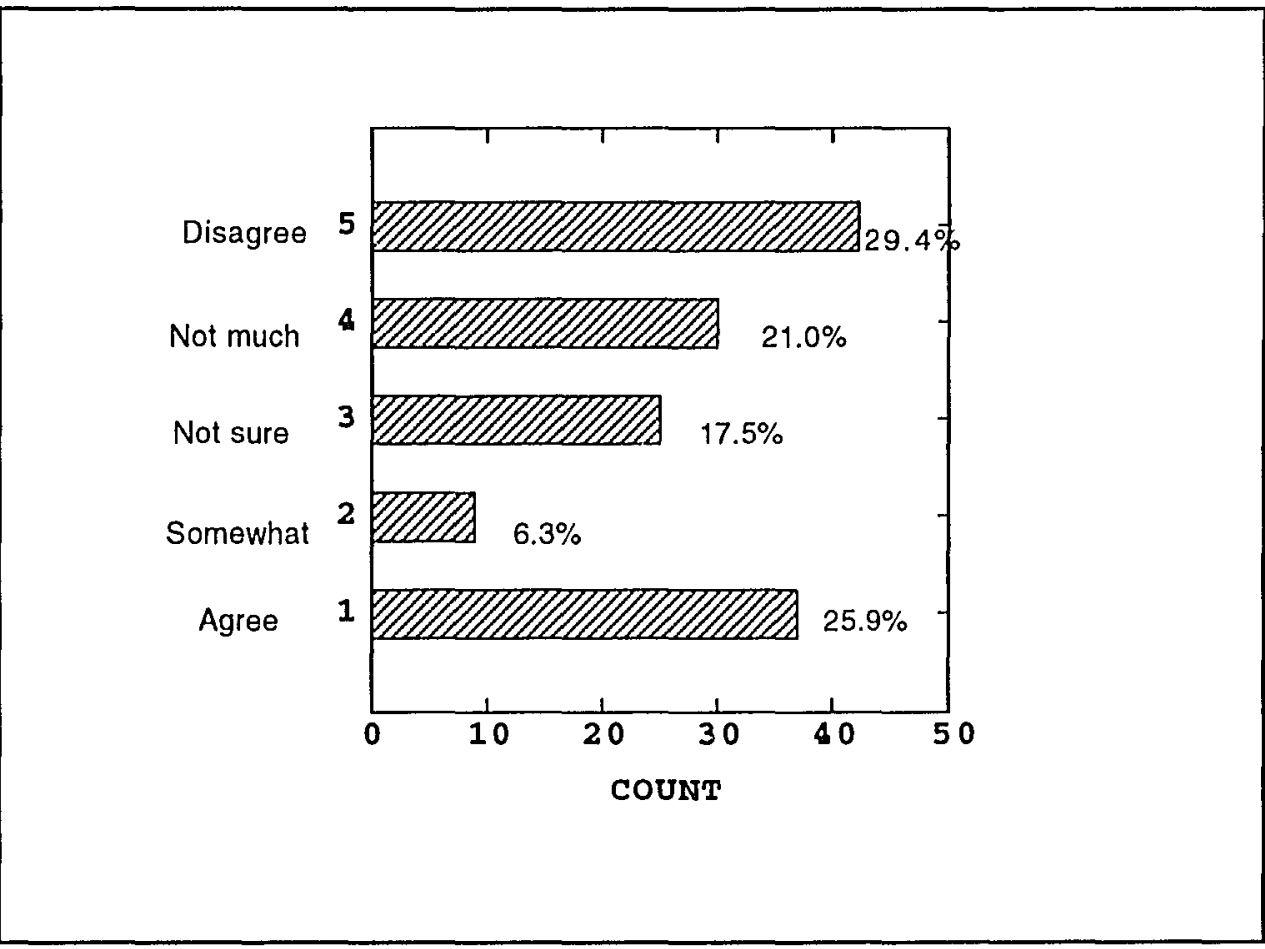

Figure 18. Vietnamese students do not belong to gangs.

- One out of four students did not believe that Vietnamese students belonged to gangs.

- About 3 out of 10 respondents did not agree with the survey question.

- The remaining respondents were "somewhat" or "not sure" about it. This might be due to different definitions on gangs.

- One out of five students were "not much" in agreement with this survey question.

- There was a high level of difference of perceptions on this item. 


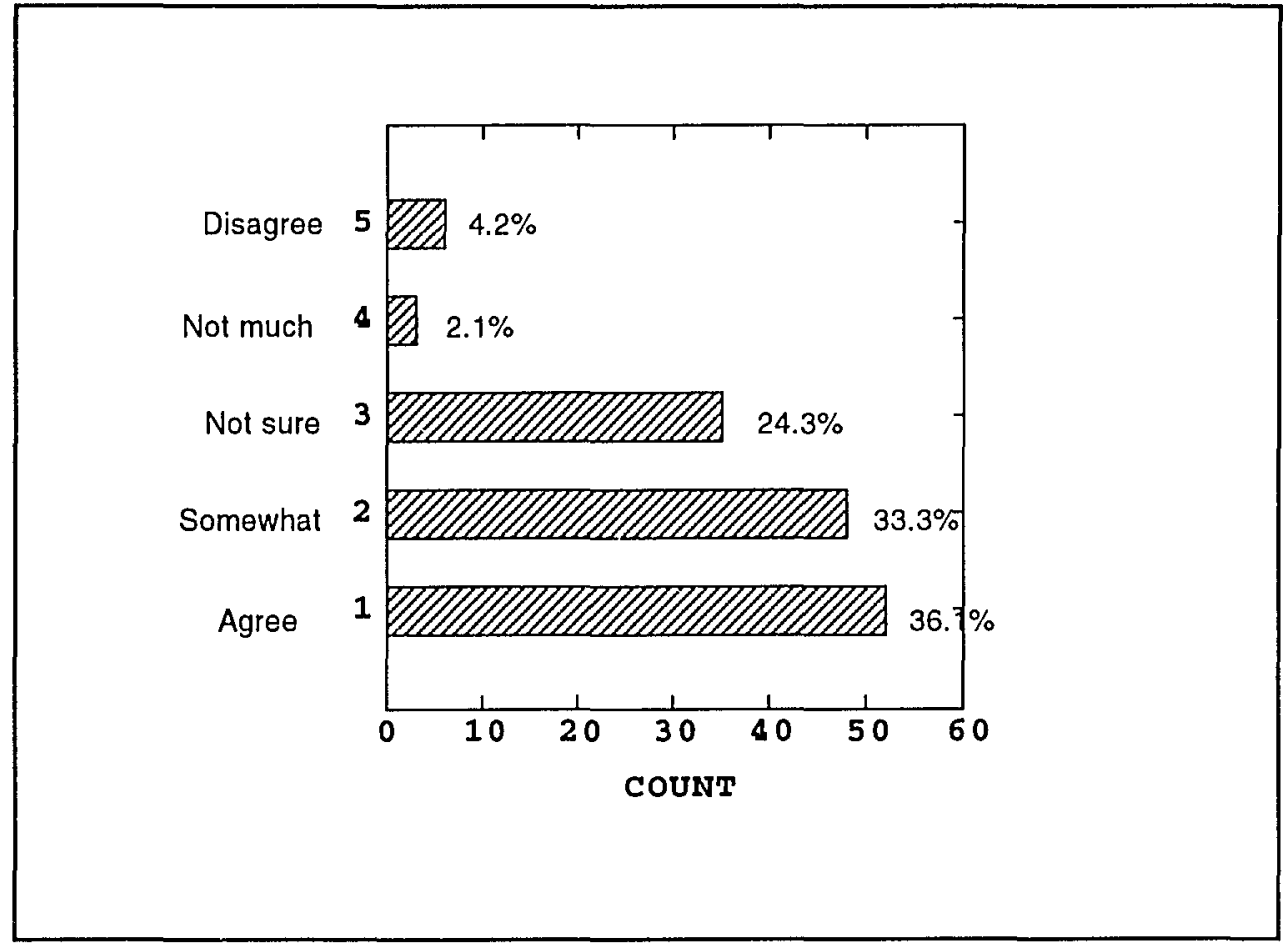

Figure 19. My school makes me feel welcome.

- One third of these respondents perceived that school welcomed them.

- About another third "somewhat" agreed with the question.

- One out of four students reported "not sure" if the "school welcomes" them.

- A very low percentage disagreed with the question. 


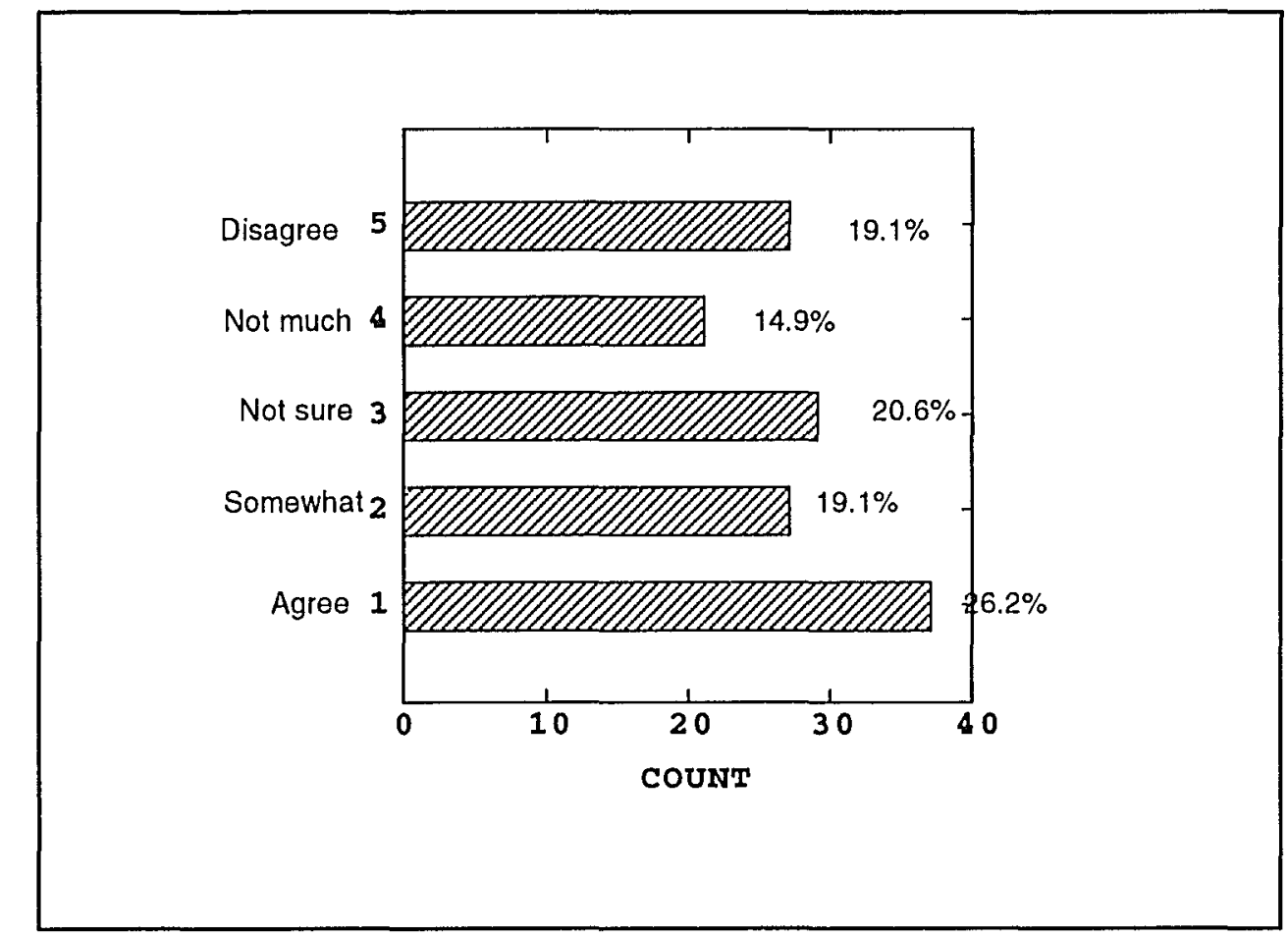

Figure 20. I have close American friends at school.

- Vietnamese students in this sample showed a mixed opinion on the question regarding American friends.

- One out of four students indicated a close relationship with American peers.

- Approximately one out of five respondents had no American friends.

- The group who either "somewhat" (19\%) or "not much" $(14.9 \%)$, were in disagreement with this item. This number could be due to different definitions for "friendship." 


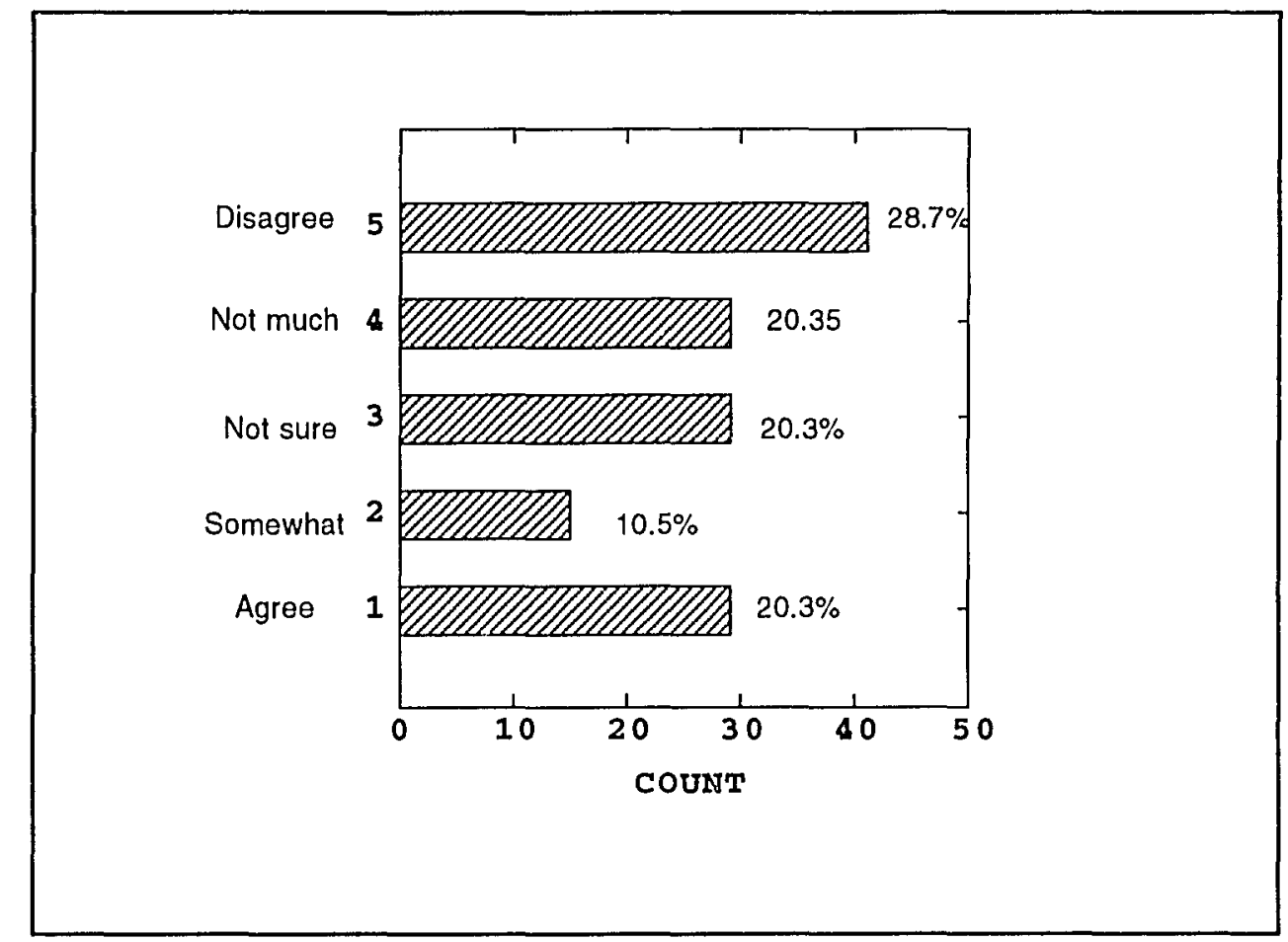

Figure 21. Vietnamese students do not smoke or drink alcohol.

- Almost 3 out of 10 respondents thought that Vietnamese students "smoke or drink."

- One out of five students believed that Vietnamese students did not smoke or drink.

- One out of five students were "not sure" if Vietnamese students drink or smoke. 


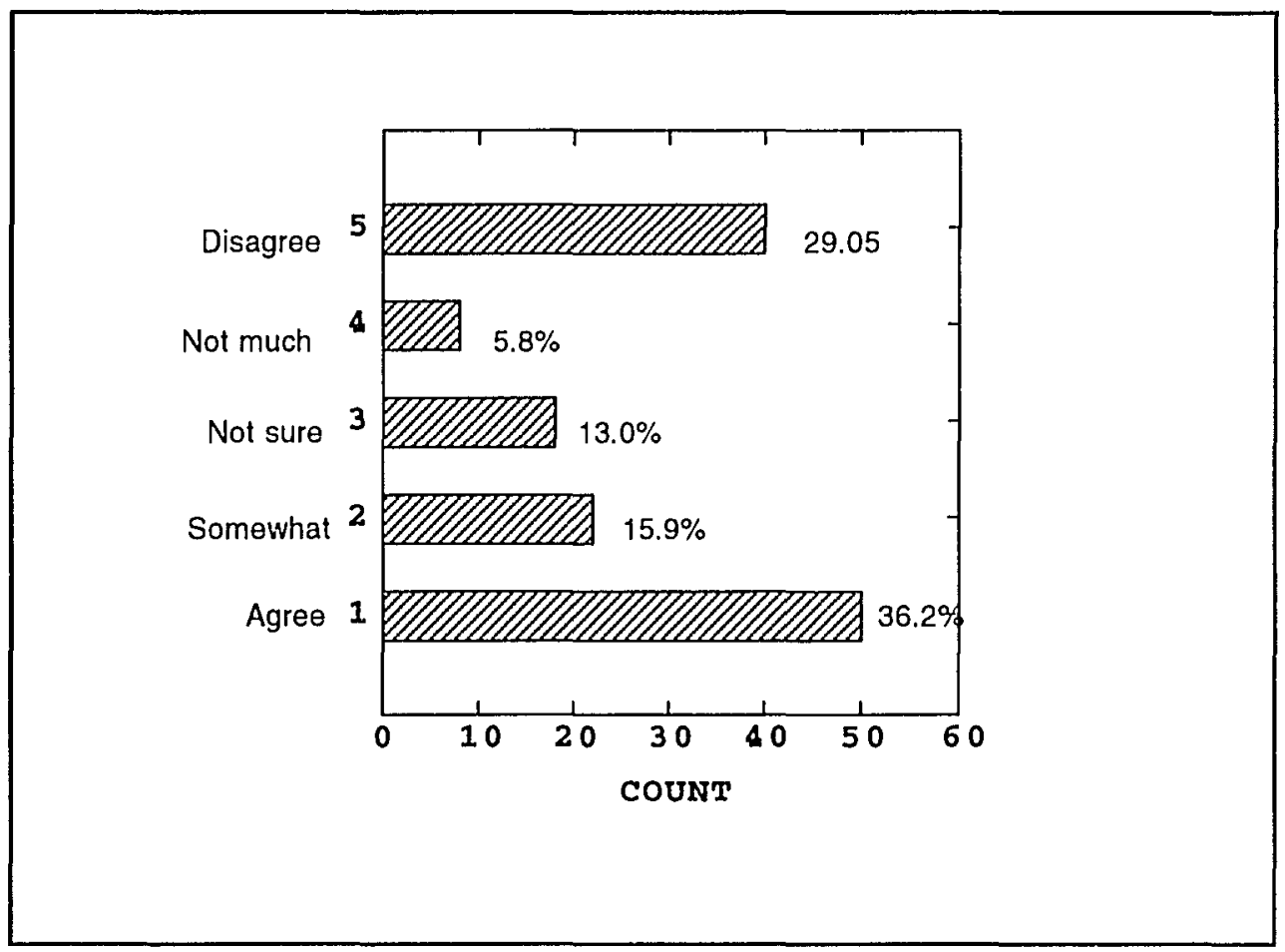

Figure 22. I learn a lot from my ESL teachers.

- One third of students believed that they learned a lot from ESL teachers.

- A slightly smaller percentage disagreed that they learned much from ESL.

- One half of the students reported agreement or "somewhat" agreement with "learn a lot from ESL."

- There was a relatively low level of agreement on this item. 


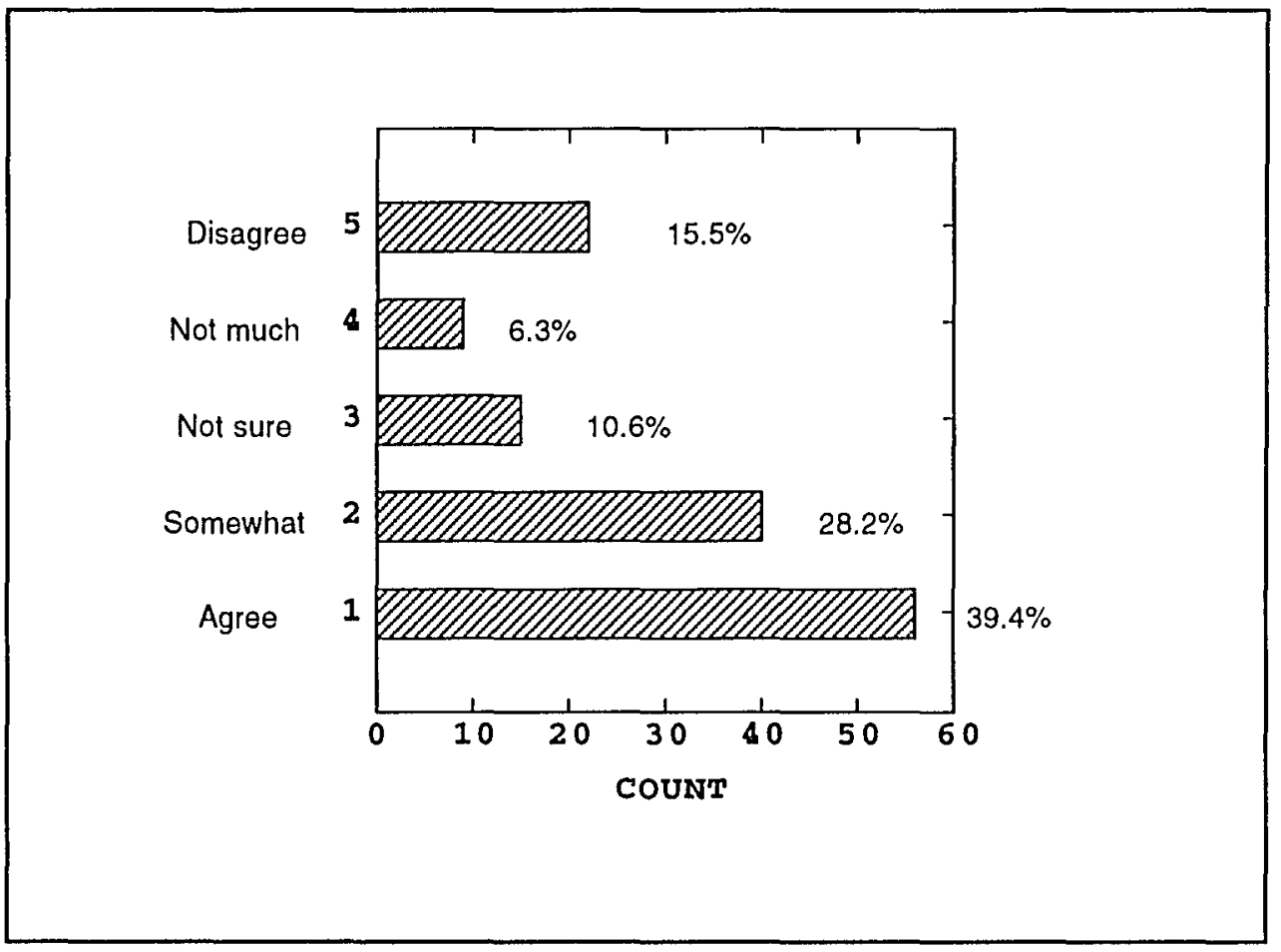

Figure 23. It is OK at my school to use Vietnamese.

- Four out of 10 students reported that it was OK to speak Vietnamese at school.

- Also, one out of four respondents "somewhat" agreed with that statement.

- Only one seventh perceived that it was not OK to use Vietnamese language at school.

- About $10 \%$ of the respondents were "not sure" if it was OK to speak Vietnamese at school. 


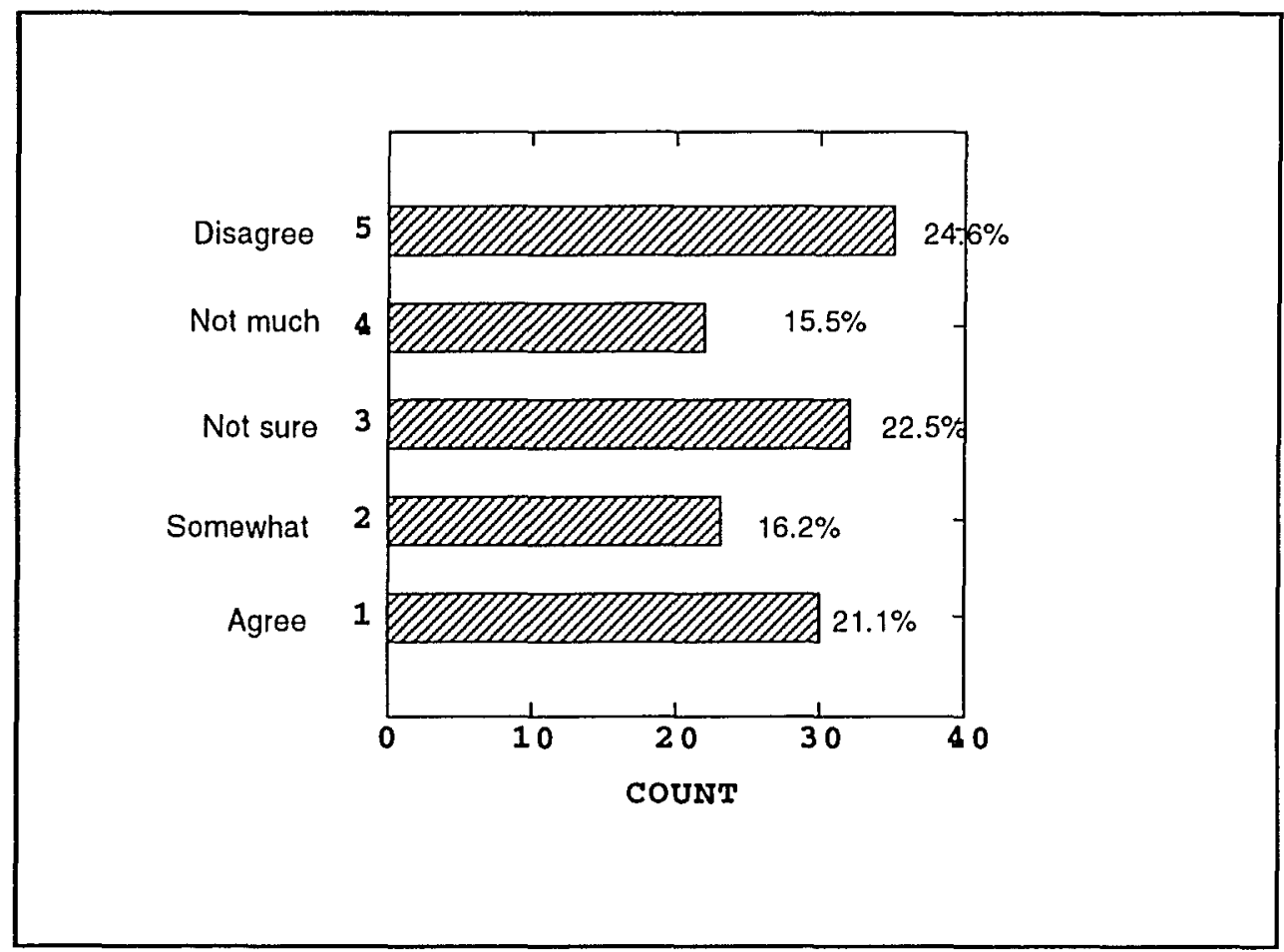

Figure 24. Vietnamese students do not drop out of school.

- One out of four respondents (24.6\%) believed that Vietnamese students dropped out of school.

- About one fifth of respondents were "not sure" about the dropout issue.

- Approximately one fifth of this sample believed that Vietnamese students did not dropout of school.

- The same percentage of students either "somewhat" or "not much" agreed with this survey question.

- There was low agreement with this issue. 


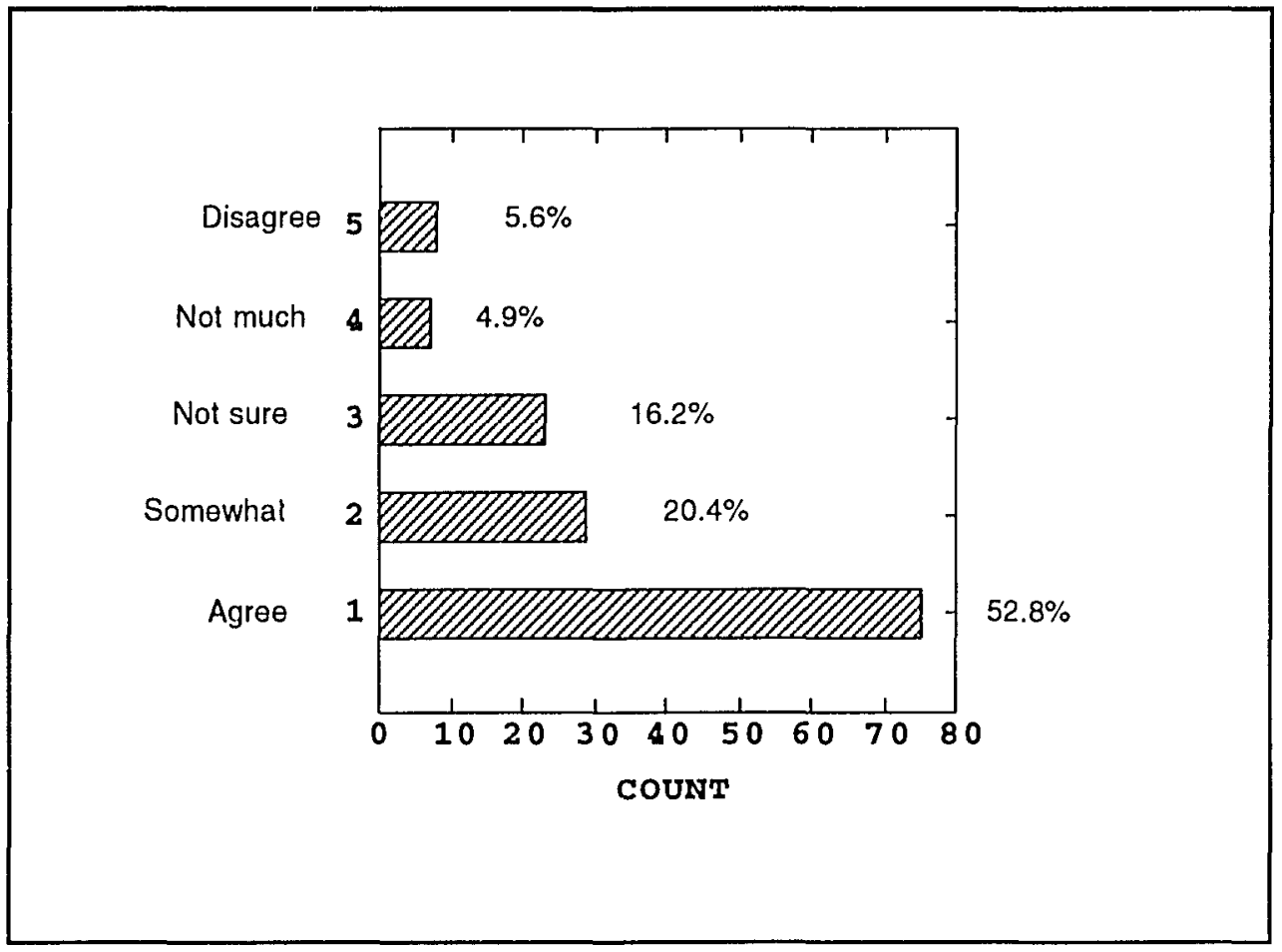

Figure 25. I have plans for my career after high school.

- More than half of the students in this sample believed that they had career plans for their future.

- In addition to that group, about one fifth reported "somewhat" agreement with the question.

- The percentage of respondents who were "not sure" if they had any career plans was $16.2 \%$.

- Only a small percentage reported that they did not have any career plans. 


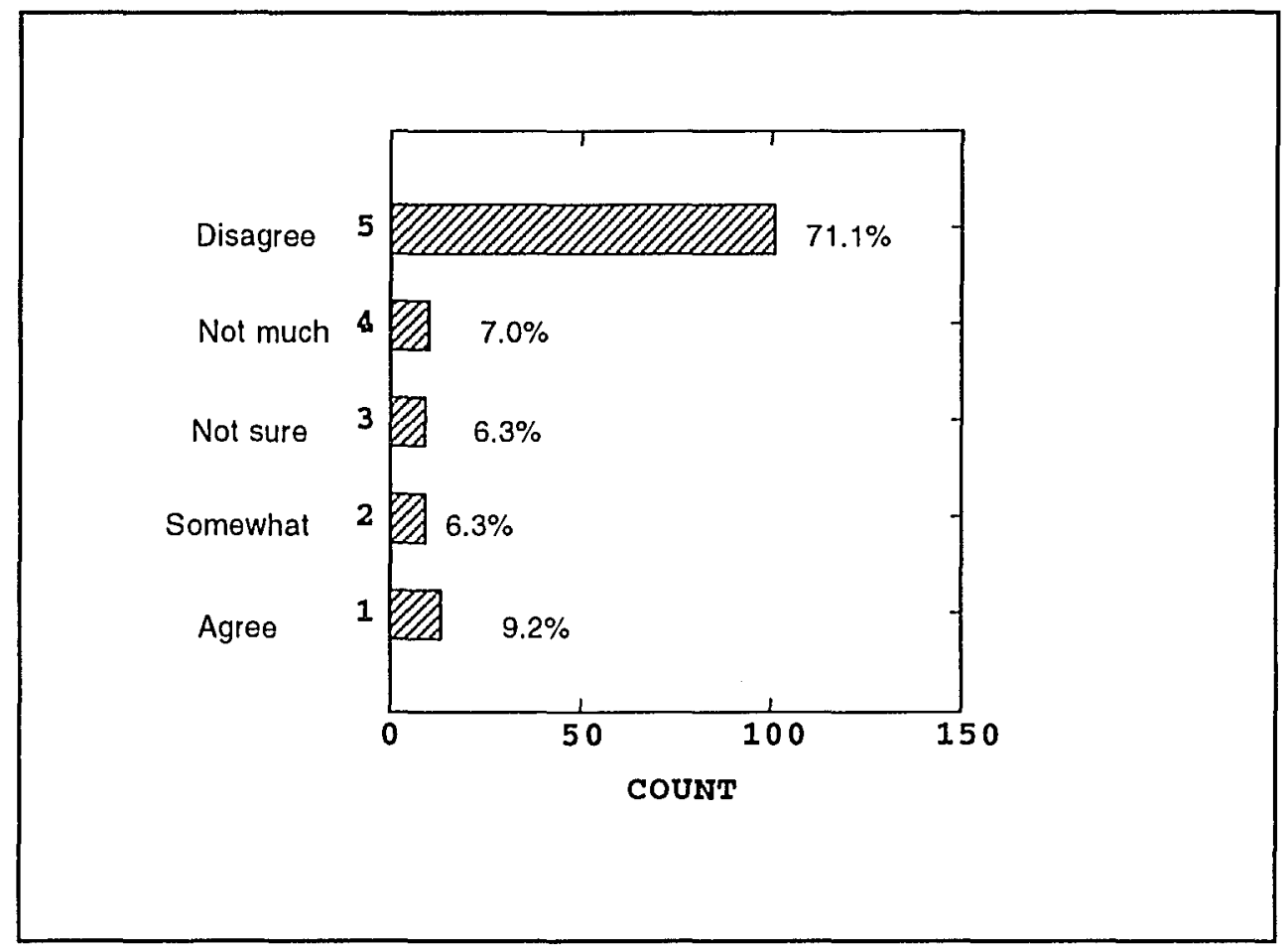

Figure 26. I have been referred to principal for discipline.

- The majority of these students reported that they have never been referred to the principal because of discipline problems.

- Only one seventh of the students reported discipline referrals.

- The same percentage $(6.3 \%$ and $70 \%)$ reported either "not sure" or "not much" in agreement with the survey question. 


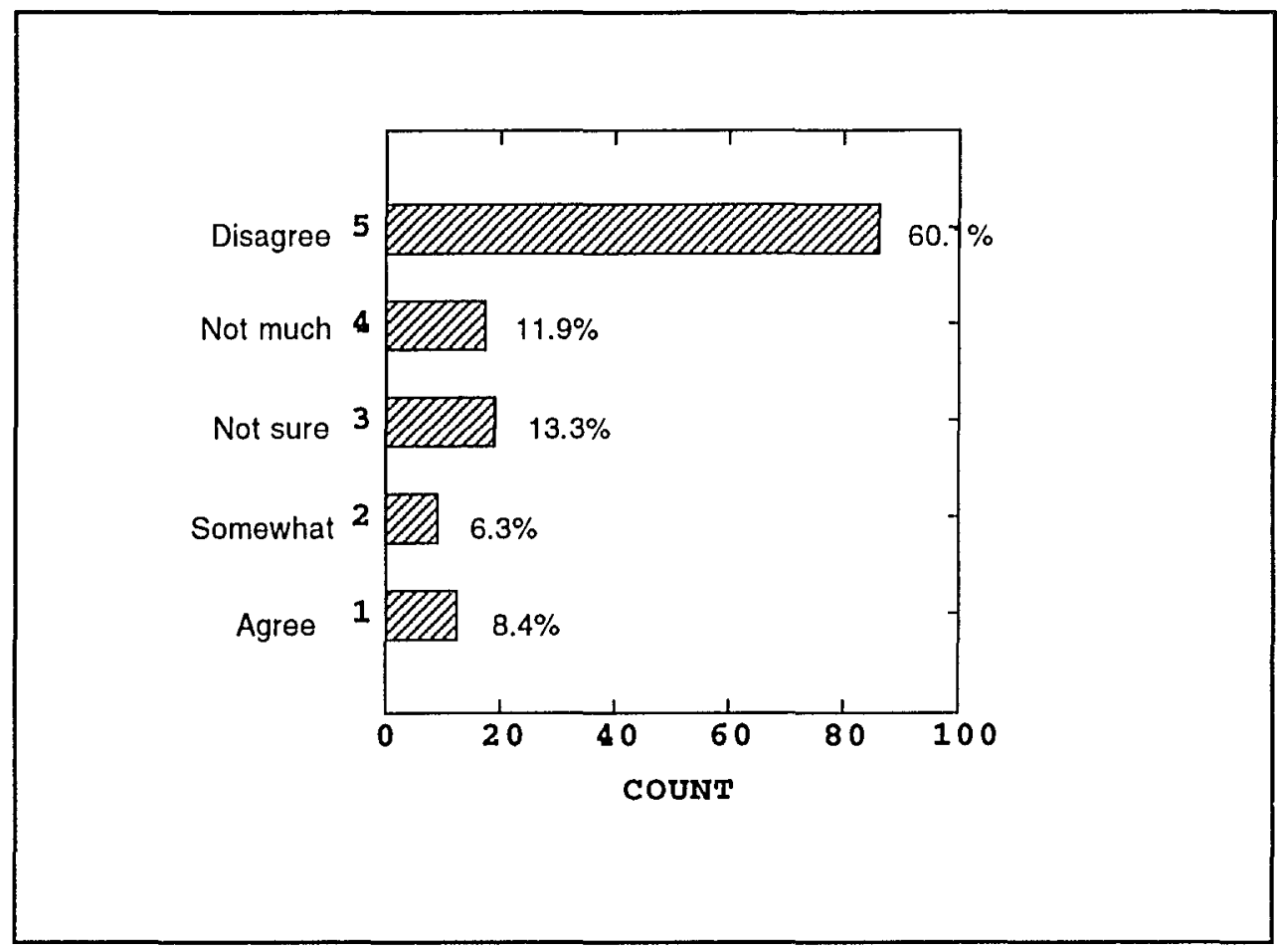

Figure 27. I am not worried about my future.

- Six out of 10 students indicated that they worried about their future.

- The majority of Vietnamese students in this sample showed a future concerns, or future orientation.

- In addition to that, $11.9 \%$ worried "somewhat" about their future.

- Only $8.4 \%$ of the respondents indicated "no worry" about their future. 


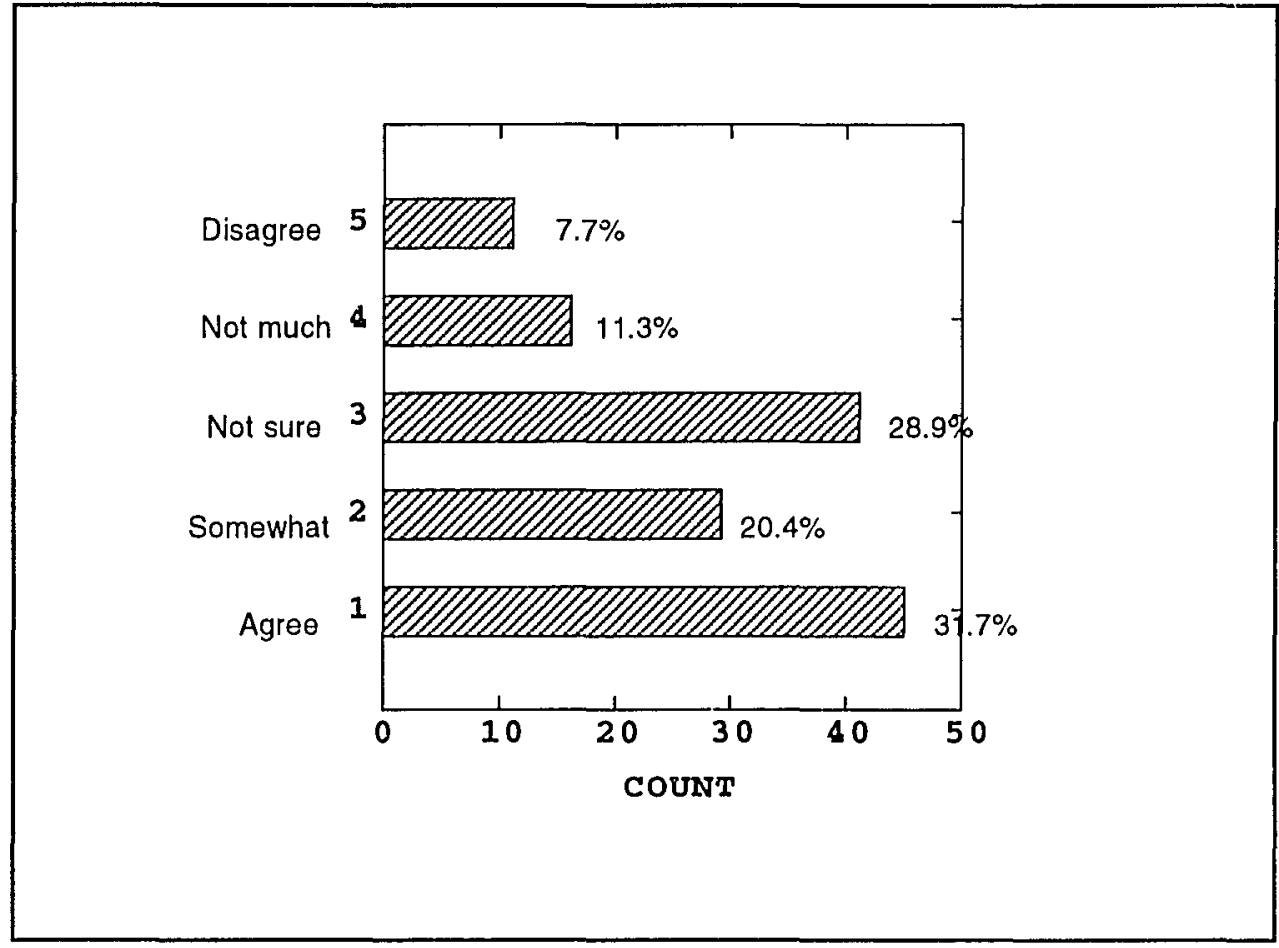

Figure 28. I understand the English spoken in classes.

- Three out of 10 students reported that they understood English in their classes.

- One out of five respondents believed they "somewhat" understood English in their classes.

- One fourth of the students were "not sure" if they understood English in the their classes.

- Almost one fifth of the students reported that they understood "not much" or none of the English spoken in their classes. 


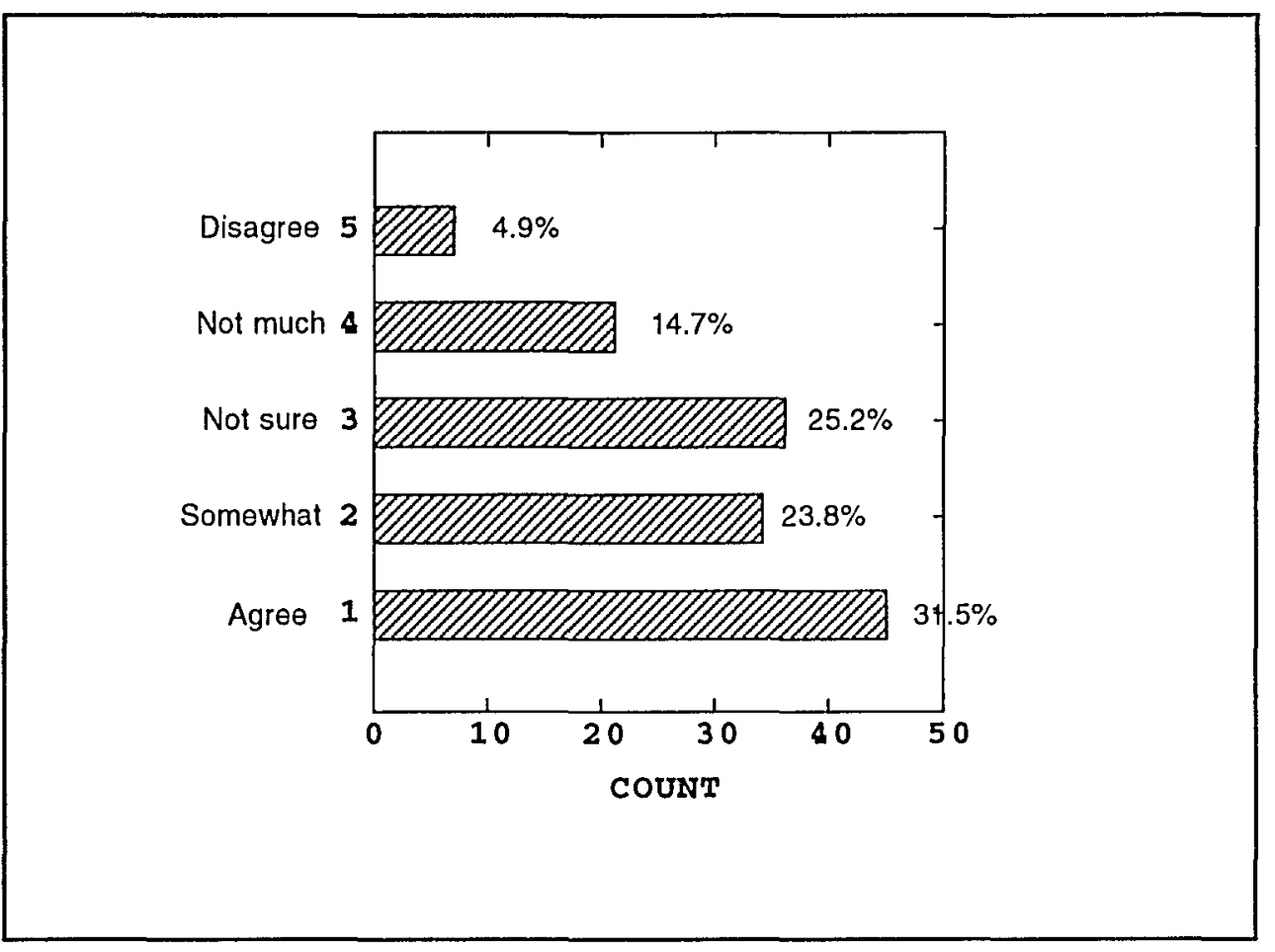

Figure 29. I am accepted and treated well by other students.

- One third of the students in this sample perceived that they were accepted and treated well by others.

- One out of four students were "not sure" about the perception of "acceptance."

- One fifth of the students disagreed or were "not much" in agreement with this item. 


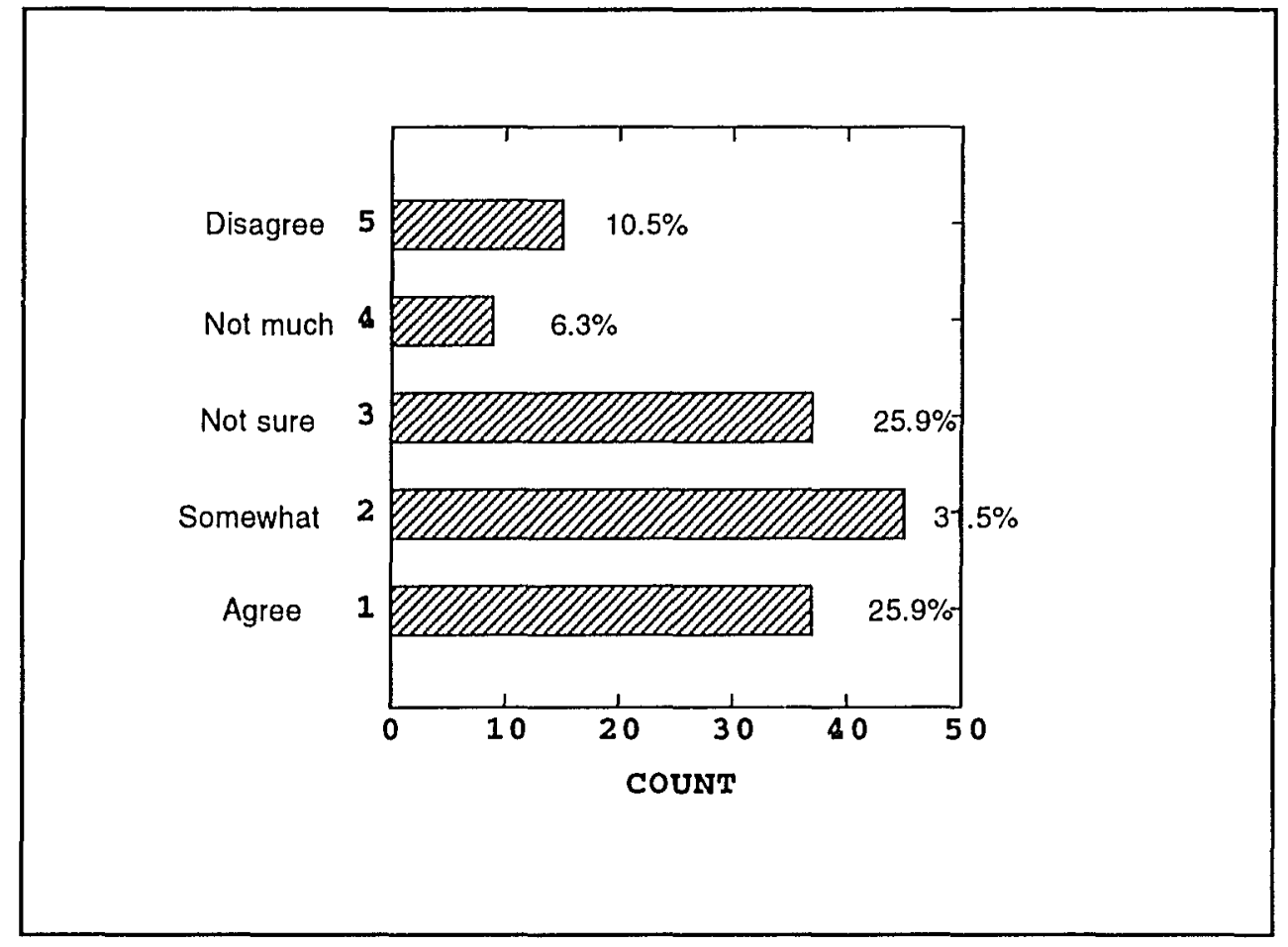

Figure 30. School counselors help me a lot.

- One fourth of these respondents believed that their counselors helped them a lot.

- Another one third "somewhat" agreed to this survey statement.

- About one out of four of the Vietnamese students were "not sure" if counselors helped them or not.

- One tenth of these students did not believe that counselors help them much. 


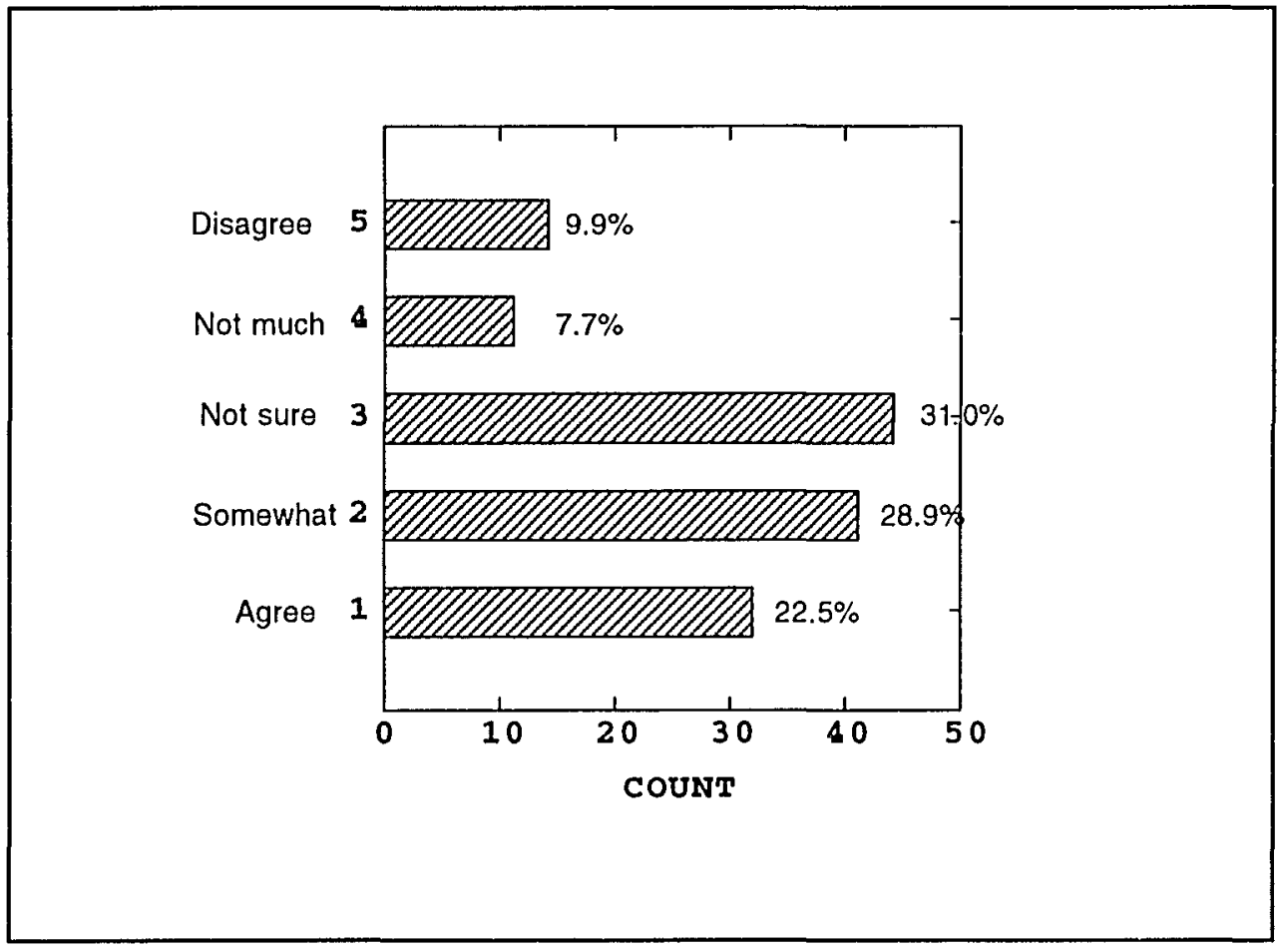

Figure 31. Principal, teacher, counselor understand my culture.

- One fourth of the students reported that the school staff (principal, teachers, and counselors) understood their culture.

- One third of the Vietnamese students in the study perceived that staff understood their culture "somewhat."

- One third of these students were "not sure" if school staff understood their culture.

- Ten percent did not think that staff understood culture. 
Section Two: Survey Findings

Analyzed by Research Questions

Question 1: Community background. The students saw strong support and care from their parents that they do well in school. The two items (\#9, \#11) on this topic were among the most strongly agreed with on the survey. Also, the students felt that they had close Vietnamese-American friends (\#7). Both of these topics suggest that the feeling of community was strong and positive for success.

There was much less agreement on the reputation for VietnameseAmerican students dropping out of school. The responses of agreement and disagreement on this item (\#22) were evenly distributed across the scale. Thus, students saw themselves to be in a community whose young people had a mixed reputation for completing their schooling.

There was a high level of difference of perceptions regarding Vietnamese-American students smoking, drinking, or belonging to gangs (\#16, \#19). This might be due to their different definitions of these two issues or the lack of good understanding of the problems.

Question 2: Educational input. It generally is accepted to use Vietnamese in the schools (\#21). This shows a level of personal support for students. However, otherwise the language issue shows problems for 
students in this sample (\#6, \#26). Only about a third of the students reported not having difficulty understanding or not having a preference for more Vietnamese in their classes. The level of welcome in the school was generally high from teachers (\#8) and school (\#17), but less so from fellow students (\#27); even though one out of three reported having close American friends (\#18). The role of peer acceptance for adolescents makes this an important educational input.

There are some concerns about having educators who understand the culture (\#29). While approximately half of the students saw staff's understanding, it was less clear and specific to the other half.

The great majority of students reported that their educational input did not include involvement in the discipline system (\#24). Thus, however the system operates, it has had little effect on this sample of students.

According to these students, the educational input does not include home visits. This item (\#10) was one of the least agreed with items on the survey.

Question 3: Instructional treatment. ESL teachers (\#20) showed a mixed reaction, including a third who reported not learning a lot. Students in this sample did not see this as a strong treatment for their situations. 
English spoken in classes (\#26) was also another area of difficulty. Only about a third of the students entirely agreed that they understood the English spoken in their classes. This is a relatively low level of response, given the predominance of English spoken in school and the importance of understanding as a part of the instructional treatment. More than half of the Vietnamese students in this sample indicated that they did well in math and sciences, while only a small fraction reported doing well in social studies, a subject that requires more English language skills (\#5).

Question 4: Student input. Student effort (\#13) was self-reported as high by this group. Also, most students reported that they do homework (\#12). This indicates a willingness to contribute toward their own learning. Extracurricular involvement $(\# 14, \# 15)$ was mixed in this sample. Involvement in school in nonacademic settings can enhance the educational experience. Home, family and personal situations complicate the situation. Career plans (\#23) and worry about the future (\#25) are important student components to learning because they provide a framework for attention, motivation and involvement. A strong career orientation was expressed by half of the sample. This may reflect a community factor as their culture emphasizes thinking about the future. The relatively high (approximately two thirds) response for worry about the future indicates that these students provide motivation for learning. 
Section Three: Inferential Statistical

Analysis

Inferential statistics go beyond a description of the survey population (e.g., how many answered, the average response to item \#12), to infer information about the population perceptions from patterns of mathematical relationships among the responses. Care must be taken in applying these findings because they are based upon indirect measures of the population surveyed. Nevertheless, these findings give interesting relationships that can be interpreted to give a better understanding of the issues of this study.

Five major analyses were derived from the study, and completed from the survey data. These include the following ideas:

1. Items that are alike in subject matter, (e.g., language usage) should intercorrelate higher than non-alike topics (items 6-29 inter-item correlation matrix).

2. Attitudes or perceptions should be affected by the length of time students are in U.S. schools (years in school item X survey items 6-29 correlation matrix).

3. Attitudes or perceptions should be affected by whether or not student live with their parents; family stability should affect schooling 
attitudes (analysis of variance [t test] on items 6-29 by parent or other living arrangements).

4. Attitudes or perceptions should be affected by the numbers of people living with the student (number of people living at home item X items 6-29 correlation matrix).

5. Attitudes or perceptions should be affected by whether or not the student works during schooling (analysis of variance [t test] on items 6-29 by yes or no to Working).

Inter-item correlations. Attitudes or perceptions concerning schooling were analyzed by computing product-moment correlations among responses on survey items 6-29. These results appear in Table 5. (Table 6 repeats the item for reference to Table 5.)

Correlations Among Four Areas of Investigation. A selected group (value $\underline{r} \geq .30$ ) is reported in Table 7. These are correlation coefficients among factors explored in the four areas of investigation of this study's theoretical framework. Table 7 shows these correlation coefficients at a significant level of $\mathrm{p}<0.01$. These correlations among four areas of investigation are reported in this section without further analysis due to the limited scope of this paper. Recommendations for future research will be discussed in the last chapter. 
Table 5

\section{Pearson Product-Moment Inter-Item Correlation Matrix}

\begin{tabular}{|c|c|c|c|c|c|c|c|c|c|c|c|c|c|c|c|c|c|c|c|c|c|c|c|c|}
\hline Item & 6 & $:$ & 8 & 9 & 10 & 11 & 12 & 13 & 14 & 15 & 16 & 17 & 18 & 19 & 20 & 21 & 22 & 23 & 24 & 25 & 26 & 27 & 28 & 29 \\
\hline 7 & .02 & 1 & & & & & & & & & & & & & & & & & & & & & & \\
\hline 8 & .01 & .10 & 1 & & & & & & & & & & & & & & & & & & & & & \\
\hline 9 & .05 & -10 & -.21 & 1 & & & & & & & & & & & & & & & & & & & & \\
\hline 10 & -.01 & -.07 & -.06 & .20 & 1 & & & & & & & & & & & & & & & & & & & \\
\hline 11 & .20 & .21 & .27 & -.34 & -.22 & 1 & & & & & & & & & & & & & & & & & & \\
\hline 12 & -.01 & .27 & .26 & -.37 & -.14 & .37 & 1 & & & & & & & & & & & & & & & & & \\
\hline 13 & .13 & .23 & .35 & -.30 & -.23 & .40 & .43 & 1 & & & & & & & & & & & & & & & & \\
\hline 14 & -02 & -.01 & -.01 & .12 & .16 &. .15 & -.14 & -.14 & 1 & & & & & & & & & & & & & & & \\
\hline 15 & -.08 & .04 & .06 & .13 & .05 & -.06 & .07 & -.01 & -.30 & 1 & & & & & & & & & & & & & & \\
\hline 16 & -.01 & .11 & .12 & .01 & .14 & .01 & .03 & .01 & .07 & .04 & 1 & & & & & & & & & & & & & \\
\hline 17 & -.01 & .19 & .45 & -.20 & -.15 & .22 & .22 & .31 & .07 & -.04 & .20 & 1 & & & & & & & & & & & & \\
\hline 18 & -.10 & .07 & .01 & .02 & .04 & -.05 & -.05 & .11 & -.22 & .21 & -.17 & .11 & 1 & & & & & & & & & & & \\
\hline 19 & .07 & .14 & .22 & -.07 & .06 & .07 & -.04 & .10 & .16 & -.07 & .53 & .16 & .05 & 1 & & & & & & & & & & \\
\hline 20 & .06 & .10 & .08 & .10 & .05 & .01 & .10 & .15 & .17 & .06 & .27 & .13 & -.33 & .07 & 1 & & & & & & & & & \\
\hline 21 & .30 & .19 & .10 & -.08 & -.21 & .07 & .06 & .12 & -.07 & .07 & .04 & .02 & -.22 & .16 & .28 & 1 & & & & & & & & \\
\hline 22 & .10 & .01 & .17 & .01 & .03 & -.02 & .03 & .03 & .11 & -.10 & .51 & .17 & -.26 & .50 & .19 & .05 & 1 & & & & & & & \\
\hline 23 & -.06 & .13 & .08 & .02 & -.12 & .20 & .10 & .20 & -.05 & .10 & -.11 & -.01 & .06 & -.04 & -.05 & .18 & -.04 & 1 & & & & & & \\
\hline 24 & .03 & .01 & -.14 & .22 & .25 & -.20 & -.28 & -.13 & -.01 & .03 & -.02 & -.20 & -.02 & -.01 & -.13 &. .11 & .02 & -.05 & 1 & & & & & \\
\hline 25 & .08 & -.20 & -.10 & .27 & .31 & -.30 & -.18 & -.21 & .10 & -.01 & .04 & -.04 & .03 & -.01 & .07 & -.43 & .12 & -.32 & .21 & 1 & & & & \\
\hline 26 & -.21 & .08 & .10 & -10 & .05 & .10 & .02 & .01 & -.13 & .14 & -.15 & -.02 & .30 & .10 & -.37 & -.10 & -.16 & -.01 & -01 & -.10 & 1 & & & \\
\hline 27 & .01 & .02 & .30 & -.07 &.-20 & .17 & .05 & .16 & -.15 & .03 & -.07 & .30 & .32 & .03 & -.15 & .08 & -.15 & .06 & -.10 & -.10 & .35 & 1 & & \\
\hline 28 & .20 & .13 & .20 & .10 & .07 & .17 & .16 & .19 & -.01 & .10 & .16 & .00 & -07 & .12 & .37 & .10 & .24 & .20 & .07 & -.08 & .07 & .16 & 1 & \\
\hline 29 & .20 & .06 & .25 & -.04 & .06 & .20 & .30 & .16 & .02 & .13 & .04 & .29 & .11 & .14 & .15 & .12 & .14 & .02 & -.10 & -.04 & .10 & .11 & .33 & 1 \\
\hline
\end{tabular}


Table 6

Survey Questions: For Correlation Reference

Item \# Survey Questions

1. How long have you been in U.S. schools?

2. How many people live in your house?

3. Who do you live with?

4. Do you have a job where you earn money?

5. Check the school subjects you do well.

6. I prefer to have these above classes taught in Vietnamese.

7. I have close Vietnamese friends.

8. Teachers make me feel welcome.

9. My parents do not care if I do well at school.

10. Teachers, counselors, principal visit me at home.

11. My parents want very much for me to do well at school.

12. I do homework at home.

13. I try very hard to do well in school.

14. I do not belong to any clubs at school.

15. I play sports at school.

16. Vietnamese students do not belong to gangs.

17. My school makes me feel welcome.

18. I have close American friends at school.

19. Vietnamese students do not smoke or drink alcohol.

20. I learn a lot from my ESL teachers.

21. It is $\mathrm{OK}$ at my school to use Vietnamese language

22. Vietnamese students do not dropout of school.

23. I have plans for my career after high school.

24. I have been referred to the principal for discipline.

25. I am not worried about my future.

26. I understand the English spoken in my classes.

27. I am accepted and treated well by other students.

28. School counselors help me a lot.

29. Principal, teachers, counselors understand about my culture. 
Table 7

Correlations Among Four Areas of Investigation

\begin{tabular}{|c|c|c|c|}
\hline \multicolumn{2}{|c|}{ Area of Investigation } & Survey Items & \multirow{2}{*}{$\begin{array}{l}\mathrm{r}^{*} \\
-.44 \\
.73 \\
-.54\end{array}$} \\
\hline I. & \#1 Years in U.S. school: & $\begin{array}{l}\text { \#18 U.S. friends } \\
\# 20 \text { Learn a lot from ESL } \\
\# 26 \text { Understanding English }\end{array}$ & \\
\hline I. & \#11 Parent care about education: & $\begin{array}{l}\# 12 \text { Homework } \\
\# 13 \text { Effort }\end{array}$ & $\begin{array}{l}.37 \\
.40\end{array}$ \\
\hline $\begin{array}{l}\text { II. } \\
\text { II. }\end{array}$ & $\begin{array}{l}\text { \#17 School welcome: } \\
\text { \#8 Teacher welcome: }\end{array}$ & $\begin{array}{ll}\text { \#8 Teacher welcome } \\
\# 13 \text { Effort in learning }\end{array}$ & $\begin{array}{l}.45 \\
.35\end{array}$ \\
\hline II. & \#27 Treatment/acceptance: & $\begin{array}{l}\text { \#17 School welcome } \\
\text { \#26 Understanding English } \\
\text { \#18 American friends }\end{array}$ & $\begin{array}{l}.45 \\
.35 \\
.32\end{array}$ \\
\hline II. & \#21 Vietnamese spoken: & \#25 Worry about future & -.43 \\
\hline II. & \#18 U.S. friends: & $\begin{array}{l}\text { \#20 Learn a lot from ESL } \\
\text { \#26 Understanding English } \\
\text { \#27 Treatment } \\
\text { \#1 Ycars in U.S. schools }\end{array}$ & $\begin{array}{l}-.33 \\
.30 \\
.32 \\
-.44\end{array}$ \\
\hline II. & \#26 Understanding English: & $\begin{array}{l}\text { \#27 Acceptance } \\
\# 1 \text { Years in U.S. schools } \\
\# 18 \text { American friends }\end{array}$ & $\begin{array}{l}.35 \\
-.54 \\
.30\end{array}$ \\
\hline III. & \#20 Learn a lot from ESL: & $\begin{array}{l}\# 28 \text { Counsclor help } \\
\# 1 \text { Years in U.S. schools } \\
\# 18 \text { American friends }\end{array}$ & $\begin{array}{l}.37 \\
.73 \\
-.33\end{array}$ \\
\hline III. & \#28 Counselor help: & $\begin{array}{l}\text { \#29 Understanding culture } \\
\text { \#20 Learn much from ESL }\end{array}$ & $\begin{array}{l}.33 \\
.37\end{array}$ \\
\hline IV. & \#14 Club membership: & \#15 Playing Sports & -.30 \\
\hline IV. & \#12 Homework: & $\begin{array}{l}\text { \#13 Effort in learning } \\
\text { \#29 Understanding culture } \\
\text { \#11 Parents care about education }\end{array}$ & $\begin{array}{l}.43 \\
.30 \\
.36\end{array}$ \\
\hline IV. & \#13 Effort in learning: & $\begin{array}{ll}\# 8 & \text { Teacher Welcome } \\
\# 11 & \text { Parents care } \\
\# 12 & \text { Homework }\end{array}$ & $\begin{array}{l}.35 \\
.40 \\
.43\end{array}$ \\
\hline IV. & \#22 Dropout: & \#16 Gang affiliation & .51 \\
\hline IV. & \#25 Worry about future: & $\begin{array}{l}\text { \#19 } \text { No smoking/drinking } \\
\text { \#21 Vietnamese spoken } \\
\text { \#23 Career plans }\end{array}$ & $\begin{array}{l}.50 \\
-.43 \\
-.32 \\
\end{array}$ \\
\hline
\end{tabular}

Note: * indicates all correlation coefficients significant at level $p<0.01$ 
Length of time in U.S. schools. Attitudes or perceptions concerning schooling were analyzed by correlations between the "years in schools" item and survey items 6-29. These results appear in Table 8.

A correlation selection level of $\underline{r}=0.45$ was selected for item significance. This is because 0.45 represents approximately $20 \%$ of overlap between the two items $\left(\underline{\mathbf{x}}^{2}\right)$. As depicted in Table 8, three items correlated at 0.45 . These were \#20 "I learn a lot from my ESL teachers" (a negative relationship), \#26 "I understand the English spoken in my classes" (a positive relationship), and \#18 "I have close American friends at school" (a positive relationship).

Living with parents or non-parents. Attitudes or perceptions concerning schooling were analyzed by performing 24 separate $\underline{t}$ tests on survey items 6-29, depending on whether students reported living with parents or nonparents (relatives or friends). Table 9 presents these findings. 


\section{Table 8}

\section{Correlations Between "Years in U.S. Schools" and Survey Items 6-29}

\begin{tabular}{llc}
\hline Item \# & \multicolumn{1}{c}{ Survey Questions } \\
\hline 6 & I prefer to have these above classes taught in Vietnamese. & .13 \\
7 & I have close Vietnamese friends. & -.09 \\
8 & Teachers make me feel welcome. & .06 \\
9 & My parents do not care if I do well at school. & -.05 \\
10 & Teachers, counselors, principal visit me at home. & -.03 \\
11 & My parents want very much for me to do well at school. & .00 \\
12 & I do homework at home. & .09 \\
13 & I try very hard to do well in school. & .11 \\
14 & I do not belong to any clubs at school. & .27 \\
15 & I play sports at school. & -.13 \\
16 & Vietnamese students do not belong to gangs. & .14 \\
17 & My school makcs me feel welcome. & .12 \\
18 & I have close American friends at school. & -.44 \\
19 & Victnamese students do not smoke or drink alcohol. & -.02 \\
20 & I learn a lot from my ESL teachers. & .73 \\
21 & It is OK at my school to use Vietnamese language & .26 \\
22 & Victnamese students do not dropout of school. & -.15 \\
23 & I have plans for my career after high school. & .03 \\
24 & I have been referred to the principal for discipline. & -.11 \\
25 & I am not worried about my future. & -.06 \\
26 & I understand the English spoken in my classes. & -.54 \\
27 & I am accepted and treated well by other students. & -.25 \\
28 & School counselors help me a lot. & .16 \\
29 & Principal,teachers,counselors understand about my culture. & .14 \\
\hline
\end{tabular}


A correlation selection level of $\underline{r}=0.45$ was selected for item significance. This is because 0.45 represents approximately $20 \%$ of overlap between the two items $\left(\underline{\mathbf{r}}^{2}\right)$. As depicted in Table 8 , three items correlated at 0.45 . These were \#20 "I learn a lot from my ESL teachers" (a negative relationship), \#26 "I understand the English spoken in my classes" (a positive relationship), and \#18 "I have close American friends at school" (a positive relationship).

Living with parents or non-parents. Attitudes or perceptions concerning schooling were analyzed by performing 24 separate $t$ tests on survey items 6-29, depending on whether students reported living with parents or nonparents (relatives or friends). Table 9 presents these findings.

Four items were found to differ with statistical significance due to living with parents or not. (It should be expected to have 1 in 20 differ merely due to chance with an alpha decision value of 0.05 .)

Item \#6, "I prefer to have classes taught in Vietnamese," had a statistically significant difference in which students living with parents had less need for first language instruction. In other words, students not living with parents preferred more classes be taught in Vietnamese than those living with parents. 


\section{Table 9}

Tests of Significance of Observed Differences Between Variables

"Living With Parents or Non-Parents" and Survey Items 6-29

\begin{tabular}{|c|c|c|c|c|c|c|}
\hline$\#$ & Item & & $\underline{\mathrm{M}}$ & t-value & $\underline{\mathrm{d} f}$ & $\underline{p}$ \\
\hline 6 & $\begin{array}{l}\text { I prefer to have these above } \\
\text { classes taught in Vietnamese. }\end{array}$ & $\begin{array}{l}\text { Other } \\
\text { Parent }\end{array}$ & $\begin{array}{l}2.20 \\
2.96\end{array}$ & 2.28 & 131 & .02 \\
\hline 7 & $\begin{array}{l}\text { I have close Vietnamese } \\
\text { friends. }\end{array}$ & $\begin{array}{l}\text { Other } \\
\text { Parent }\end{array}$ & $\begin{array}{l}1.60 \\
1.37\end{array}$ & -1.12 & 142 & .26 \\
\hline & $\begin{array}{l}\text { Teachers make me feel } \\
\text { welcome. }\end{array}$ & $\begin{array}{l}\text { Other } \\
\text { Parent }\end{array}$ & $\begin{array}{l}2.00 \\
1.80\end{array}$ & -.86 & 141 & .38 \\
\hline & $\begin{array}{l}\text { My parents do not care } \\
\text { if I do well at school. }\end{array}$ & $\begin{array}{l}\text { Other } \\
\text { Parent }\end{array}$ & $\begin{array}{l}4.00 \\
4.23\end{array}$ & .74 & 141 & .45 \\
\hline 10 & $\begin{array}{l}\text { Teachers, counselors, } \\
\text { principal visit me at home. }\end{array}$ & $\begin{array}{l}\text { Other } \\
\text { Parent }\end{array}$ & $\begin{array}{l}4.27 \\
4.61\end{array}$ & 1.61 & 142 & .10 \\
\hline 11 & $\begin{array}{l}\text { My parents want very much } \\
\text { for me to do well at school. }\end{array}$ & $\begin{array}{l}\text { Other } \\
\text { Parent }\end{array}$ & $\begin{array}{l}1.30 \\
1.21\end{array}$ & -.63 & 143 & .52 \\
\hline 12 & I do homework at home. & $\begin{array}{l}\text { Other } \\
\text { Parent }\end{array}$ & $\begin{array}{l}1.82 \\
1.69\end{array}$ & -.54 & 143 & .59 \\
\hline 13 & $\begin{array}{l}\text { I try very hard to do } \\
\text { well in school. }\end{array}$ & $\begin{array}{l}\text { Other } \\
\text { Parent }\end{array}$ & $\begin{array}{l}1.60 \\
1.50\end{array}$ & -.57 & 140 & .56 \\
\hline & $\begin{array}{l}\text { I do not belong to any } \\
\text { clubs at school. }\end{array}$ & $\begin{array}{l}\text { Other } \\
\text { Parent }\end{array}$ & $\begin{array}{l}2.87 \\
3.46\end{array}$ & 2.00 & 141 & .04 \\
\hline 15 & I play sports at school. & $\begin{array}{l}\text { Other } \\
\text { Parent }\end{array}$ & $\begin{array}{l}3.18 \\
3.19\end{array}$ & .03 & 140 & .97 \\
\hline 16 & $\begin{array}{l}\text { Vietnamese students do not } \\
\text { belong to gangs. }\end{array}$ & $\begin{array}{l}\text { Other } \\
\text { Parent }\end{array}$ & $\begin{array}{l}3.57 \\
3.15\end{array}$ & -1.12 & 141 & .26 \\
\hline 17 & $\begin{array}{l}\text { My school makes me } \\
\text { feel welcome. }\end{array}$ & $\begin{array}{l}\text { Other } \\
\text { Parent }\end{array}$ & $\begin{array}{l}2.09 \\
2.04\end{array}$ & -.20 & 142 & .83 \\
\hline & $\begin{array}{l}\text { I have close American } \\
\text { friends at school. }\end{array}$ & $\begin{array}{l}\text { Other } \\
\text { Parent }\end{array}$ & $\begin{array}{l}3.28 \\
2.73\end{array}$ & -1.60 & 139 & .11 \\
\hline
\end{tabular}


Table 9

Tests of Significance of Observed Differences Between Variables

"Living With Parents or Non-Parents"

and Survey Items 6-29

(continued)

\begin{tabular}{|c|c|c|c|c|c|c|}
\hline$\#$ & Item & & $\underline{\mathrm{M}}$ & t-value & $\underline{\mathrm{d} f}$ & $p$ \\
\hline 19 & $\begin{array}{l}\text { Victnamese students do not } \\
\text { smoke or drink alcohol. }\end{array}$ & $\begin{array}{l}\text { Other } \\
\text { Parent }\end{array}$ & $\begin{array}{l}4.10 \\
3.12\end{array}$ & -2.90 & 141 & .004 \\
\hline 20 & $\begin{array}{l}\text { I learn a lot from my } \\
\text { ESL teachers. }\end{array}$ & $\begin{array}{l}\text { Other } \\
\text { Parent }\end{array}$ & $\begin{array}{l}2.00 \\
2.98\end{array}$ & 2.28 & 136 & .02 \\
\hline 21 & $\begin{array}{l}\text { It is OK at my school } \\
\text { to use Victnamese language }\end{array}$ & $\begin{array}{l}\text { Other } \\
\text { Parent }\end{array}$ & $\begin{array}{l}2.22 \\
2.31\end{array}$ & .26 & 140 & .79 \\
\hline 22 & $\begin{array}{l}\text { Vietnamese students do not } \\
\text { dropout of school. }\end{array}$ & $\begin{array}{l}\text { Other } \\
\text { Parent }\end{array}$ & $\begin{array}{l}3.22 \\
3.03\end{array}$ & -.56 & 140 & .57 \\
\hline 23 & $\begin{array}{l}\text { I have plans for my career } \\
\text { after high school. }\end{array}$ & $\begin{array}{l}\text { Other } \\
\text { Parent }\end{array}$ & $\begin{array}{l}2.04 \\
1.87\end{array}$ & -.62 & 140 & .53 \\
\hline 24 & $\begin{array}{l}\text { I have been referred to the } \\
\text { principal or vice-principal }\end{array}$ & $\begin{array}{l}\text { Other } \\
\text { Parent }\end{array}$ & $\begin{array}{l}4.09 \\
4.27\end{array}$ & .55 & 140 & .57 \\
\hline 25 & $\begin{array}{l}\text { I am not worried about } \\
\text { my future. }\end{array}$ & $\begin{array}{l}\text { Other } \\
\text { Parent }\end{array}$ & $\begin{array}{l}3.81 \\
4.13\end{array}$ & 1.05 & 141 & .29 \\
\hline 26 & $\begin{array}{l}\text { I understand the English } \\
\text { spoken in my classes. }\end{array}$ & $\begin{array}{l}\text { Other } \\
\text { Parent }\end{array}$ & $\begin{array}{l}2.72 \\
2.37\end{array}$ & -1.21 & 140 & .22 \\
\hline 27 & $\begin{array}{l}\text { I am accepted and treated } \\
\text { well by other students. }\end{array}$ & $\begin{array}{l}\text { Other } \\
\text { Parent }\end{array}$ & $\begin{array}{l}2.45 \\
2.36\end{array}$ & -.32 & 141 & .74 \\
\hline 28 & $\begin{array}{l}\text { School counselors } \\
\text { help me a lot. }\end{array}$ & $\begin{array}{l}\text { Other } \\
\text { Parent }\end{array}$ & $\begin{array}{l}2.00 \\
2.52\end{array}$ & 1.83 & 141 & .06 \\
\hline 29) & $\begin{array}{l}\text { Principal, teacher,counselor } \\
\text { understand my culture. }\end{array}$ & $\begin{array}{l}\text { Other } \\
\text { Parent }\end{array}$ & $\begin{array}{l}2.54 \\
2.53\end{array}$ & -.04 & 140 & .96 \\
\hline
\end{tabular}


Item \#14, "I do not belong to any clubs at school," had a statistically significant difference in which students living with parents reported less club membership. In other words, students not living with parents reported more club activity.

Item \#19, "Vietnamese students do not smoke or drink alcohol," had a statistically significant difference in which students living with parents saw less use of tobacco and alcohol. In other words, students not living with parents reported more use of tobacco and alcohol.

Item \#20, "I learn a lot from my ESL teachers," had a statistically significant difference in which students living with parents reported learning from ESL teachers at a lower level. In other words, students not living with parents reported greater learning from ESL teachers.

Number of people living at home. Attitudes or perceptions concerning schooling were analyzed by computing product-moment correlations between responses on the "number of people at home" and survey items 6-29. These results appear in Table 10.

A correlation selection level of $\underline{r}=0.45$ was selected for item significance. This is because 0.45 represents approximately $20 \%$ of overlap between the two items $\left(\underline{\underline{r}}^{2}\right)$. As depicted in Table 10, no items correlated above 0.45 . 
Table 10

\section{Correlations Between Variable "Size of Household" and Survey Items 6-29}

\begin{tabular}{clc}
\hline Item \# & \multicolumn{1}{c}{ Survey Items } & Correlation Cocfficient \\
\hline 6 & I prefer to have these above classes taught in Vietnamese. & .12 \\
7 & I have close Vietnamese friends. & .30 \\
8 & Teachers make me feel welcome. & .14 \\
9 & My parents do not care if I do well at school. & -.04 \\
10 & Teachers, counselors, principal visit me at home. & -.10 \\
11 & My parents want very much for me to do well at school. & .28 \\
12 & I do homework at home. & .25 \\
13 & I try very hard to do well in school. & .17 \\
14 & I do not belong to any clubs at school. & .01 \\
15 & I play sports at school. & -.04 \\
16 & Victnamese students do not belong to gangs. & .04 \\
17 & My school makes me feel welcome. & .12 \\
18 & I have close American friends at school. & -.08 \\
19 & Vietnamese students do not smoke or drink alcohol. & -.06 \\
20 & I learn a lot from my ESL teachers. & .07 \\
21 & It is OK at my school to use Vietnamese language & .18 \\
22 & Vietnamese students do not dropout of school. & -.11 \\
23 & I have plans for my career after high school. & .00 \\
24 & I have been referred to the principal for discipline. \\
25 & I am not worried about my future. & -.06 \\
26 & I understand the English spoken in my classes. & -.14 \\
27 & I am accepted and treated well by other students. & .01 \\
28 & School counselors help me a lot. & .24 \\
29 & Principal, teachers, counselors understand about my culture. \\
& & .15 \\
& & .04 \\
\hline
\end{tabular}


Working during schooling. Attitudes or perceptions concerning schooling were analyzed by performing 24 separate $\underline{t}$ tests on survey items 6-29, depending on a YES or NO response to item \#4, "Do you have a job where you earn money?" Table 11 presents these findings.

\section{Table 11}

Tests of Significance of Observed Differences Between Variable "Working During Schooling" and Survey Items 6-29

\begin{tabular}{|c|c|c|c|c|c|c|}
\hline & Item & & $\underline{M}$ & t-value & $\underline{\mathrm{df}}$ & p \\
\hline 6 & $\begin{array}{l}\text { I prefer to have these above } \\
\text { classes taught in Vietnamese. }\end{array}$ & $\begin{array}{l}\mathrm{Y} \\
\mathrm{N}\end{array}$ & $\begin{array}{l}2.73 \\
2.89\end{array}$ & .58 & 131 & .56 \\
\hline 7 & $\begin{array}{l}\text { I have close Vietnamese } \\
\text { friends. }\end{array}$ & $\begin{array}{l}\mathrm{Y} \\
\mathrm{N}\end{array}$ & $\begin{array}{l}1.33 \\
1.43\end{array}$ & .60 & 142 & .58 \\
\hline 8 & $\begin{array}{l}\text { Teachers make me } \\
\text { feel welcome. }\end{array}$ & $\begin{array}{l}\mathrm{Y} \\
\mathrm{N}\end{array}$ & $\begin{array}{l}1.89 \\
1.81\end{array}$ & -.45 & 141 & .65 \\
\hline 9 & $\begin{array}{l}\text { My parents do not care } \\
\text { if I do well at school. }\end{array}$ & $\begin{array}{l}\mathrm{Y} \\
\mathrm{N}\end{array}$ & $\begin{array}{l}4.07 \\
4.24\end{array}$ & .63 & 141 & .52 \\
\hline & $\begin{array}{l}\text { Teachers, counselors, } \\
\text { principal visit me at home. }\end{array}$ & $\begin{array}{l}Y \\
N\end{array}$ & $\begin{array}{l}4.56 \\
4.56\end{array}$ & -.01 & 142 & .99 \\
\hline & $\begin{array}{l}\text { My parents want very much } \\
\text { for me to do well at school. }\end{array}$ & $\begin{array}{l}\mathrm{Y} \\
\mathrm{N}\end{array}$ & $\begin{array}{l}1.23 \\
1.22\end{array}$ & -.03 & 143 & .97 \\
\hline 12 & I do homework at home. & $\begin{array}{l}\mathrm{Y} \\
\mathrm{N}\end{array}$ & $\begin{array}{l}1.97 \\
1.62\end{array}$ & -1.79 & 143 & .07 \\
\hline & $\begin{array}{l}\text { I try very hard to do } \\
\text { well in school. }\end{array}$ & $\begin{array}{l}\mathrm{Y} \\
\mathrm{N}\end{array}$ & $\begin{array}{l}1.55 \\
1.51\end{array}$ & -.28 & 140 & .77 \\
\hline & $\begin{array}{l}\text { I do not belong to any } \\
\text { clubs at school. }\end{array}$ & $\begin{array}{l}Y \\
N\end{array}$ & $\begin{array}{l}3.33 \\
3.38\end{array}$ & .20 & 141 & .83 \\
\hline 15 & I play sports at school. & $\begin{array}{l}Y \\
N\end{array}$ & $\begin{array}{l}3.05 \\
3.24\end{array}$ & .61 & 140 & .54 \\
\hline
\end{tabular}


Table 11

Tests of Significance of Observed Differences Between Variable "Working During Schooling" and Survey Items 6-29 (continued)

\begin{tabular}{|c|c|c|c|c|c|c|}
\hline & Item & & $\underline{\mathrm{M}}$ & t-value & $\underline{\mathrm{df}}$ & D \\
\hline 16 & $\begin{array}{l}\text { Vietnamese students do not } \\
\text { belong to gangs. }\end{array}$ & $\begin{array}{l}\mathrm{Y} \\
\mathrm{N}\end{array}$ & $\begin{array}{l}3.07 \\
3.26\end{array}$ & .65 & 141 & .51 \\
\hline 17 & $\begin{array}{l}\text { My school makes me } \\
\text { feel welcome. }\end{array}$ & $\begin{array}{l}\mathrm{Y} \\
\mathrm{N}\end{array}$ & $\begin{array}{l}2.05 \\
2.04\end{array}$ & -.01 & 142 & .98 \\
\hline 18 & $\begin{array}{l}\text { I have close American } \\
\text { friends at school. }\end{array}$ & $\begin{array}{l}\mathrm{Y} \\
\mathrm{N}\end{array}$ & $\begin{array}{l}2.56 \\
2.91\end{array}$ & 1.26 & 139 & .20 \\
\hline 19 & $\begin{array}{l}\text { Vietnamese students do not } \\
\text { smoke or drink alcohol. }\end{array}$ & $\begin{array}{l}\mathrm{Y} \\
\mathrm{N}\end{array}$ & $\begin{array}{l}3.00 \\
3.36\end{array}$ & 1.31 & 141 & .19 \\
\hline 20) & $\begin{array}{l}\text { I learn a lot from } \\
\text { my ESL teachers. }\end{array}$ & $\begin{array}{l}\mathrm{Y} \\
\mathrm{N}\end{array}$ & $\begin{array}{l}3.00 \\
2.66\end{array}$ & -1.05 & 136 & .29 \\
\hline 21 & $\begin{array}{l}\text { It is } \mathrm{OK} \text { at my school } \\
\text { to use Vietnamese language }\end{array}$ & $\begin{array}{l}\mathrm{Y} \\
\mathrm{N}\end{array}$ & $\begin{array}{l}2.12 \\
2.36\end{array}$ & .88 & 140) & .37 \\
\hline 22 & $\begin{array}{l}\text { Vietnamese students do not } \\
\text { dropout of school. }\end{array}$ & $\begin{array}{l}Y \\
N\end{array}$ & $\begin{array}{l}3.21 \\
3.00\end{array}$ & -.83 & 140) & .40 \\
\hline 23 & $\begin{array}{l}\text { I have plans for my career } \\
\text { after high school. }\end{array}$ & $\begin{array}{l}\mathrm{Y} \\
\mathrm{N}\end{array}$ & $\begin{array}{l}2.05 \\
1.84\end{array}$ & -.92 & 140) & .35 \\
\hline 24 & $\begin{array}{l}\text { I have been referred to the } \\
\text { principal or vice-principal }\end{array}$ & $\begin{array}{l}\mathrm{Y} \\
\mathrm{N}\end{array}$ & $\begin{array}{l}4.28 \\
4.22\end{array}$ & -.19 & 140 & .84 \\
\hline 25 & $\begin{array}{l}\text { I am not worried about } \\
\text { my future. }\end{array}$ & $\begin{array}{l}\mathrm{Y} \\
\mathrm{N}\end{array}$ & $\begin{array}{l}4.46 \\
3.95\end{array}$ & -2.33 & 87 & .02 \\
\hline 26 & $\begin{array}{l}\text { I understand the English } \\
\text { spoken in my classes. }\end{array}$ & $\begin{array}{l}\mathrm{Y} \\
\mathrm{N}\end{array}$ & $\begin{array}{l}2.25 \\
2.49\end{array}$ & 1.01 & 140 & .31 \\
\hline 27 & $\begin{array}{l}\text { I am accepted and treated } \\
\text { well by other students. }\end{array}$ & $\begin{array}{l}\mathrm{Y} \\
\mathrm{N}\end{array}$ & $\begin{array}{l}2.33 \\
2.39\end{array}$ & .267 & 141 & .79 \\
\hline 28 & $\begin{array}{l}\text { School counselors help } \\
\text { me a lot. }\end{array}$ & $\begin{array}{l}\mathrm{Y} \\
\mathrm{N}\end{array}$ & $\begin{array}{l}2.69 \\
2.34\end{array}$ & -1.49 & $14 !$ & .13 \\
\hline 29 & $\begin{array}{l}\text { Principal,teachers,counselors } \\
\text { understand about my culture. }\end{array}$ & $\begin{array}{l}\mathrm{Y} \\
\mathrm{N}\end{array}$ & $\begin{array}{l}2.68 \\
2.48\end{array}$ & -.88 & 140) & .37 \\
\hline
\end{tabular}


Only one item was found to differ with statistical significance due to "student working." It should be expected to have 1 in 20 differ merely due to chance with an alpha decision value of 0.05 . The item of statistically significant difference was \#25, "I am not worried about my future," which found more agreement with those not working than those having jobs for pay. In other words, those with jobs reported more worry about the future than those without.

Survey validity. Validity or dependability of the survey results is important as descriptive data are presented in this chapter and interpretations made in the next chapter. Two empirical checks of response validity were made in this study. The first check was that negatively stated items would be responded to in an appropriate (expected) direction. This suggests that students read each item and thought about their answers, rather than merely agreeing or disagreeing with each item according to an overall attitude of agreement or disagreement. While this mixture of positive and negative statements made answering and analyzing the survey more awkward, it gave reassurance that respondents answered the items thoughtfully and with validity.

The second empirical check on survey validity is the contention that items that are conceptually or topically related to each other should show higher correlations than items that are not associated with each other. 
To this end, an average (mean) absolute correlation and distribution (standard deviation) among all inter-item correlations was computed and compared with groups of topically or conceptually related variables.

Table 12 presents 15 groups of related items with associated intercorrelations. This grouping of 40 relationships showed a mean absolute correlation of $0.41(\underline{\mathrm{SD}}=0.11)$.

Table 12

Correlations of Inter-Item Reliability

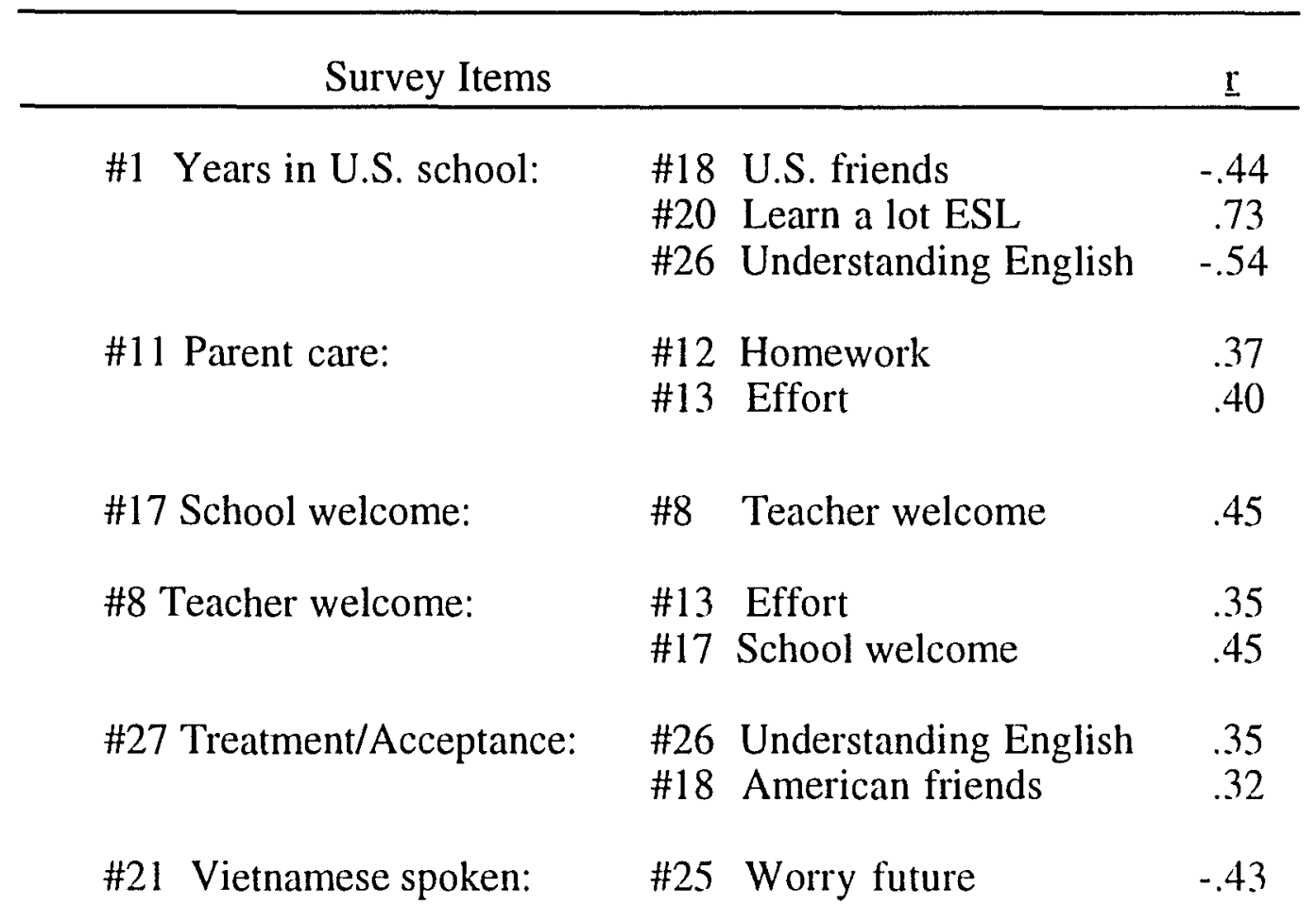


Table 12

Correlations of Inter-Item Reliability (continued)

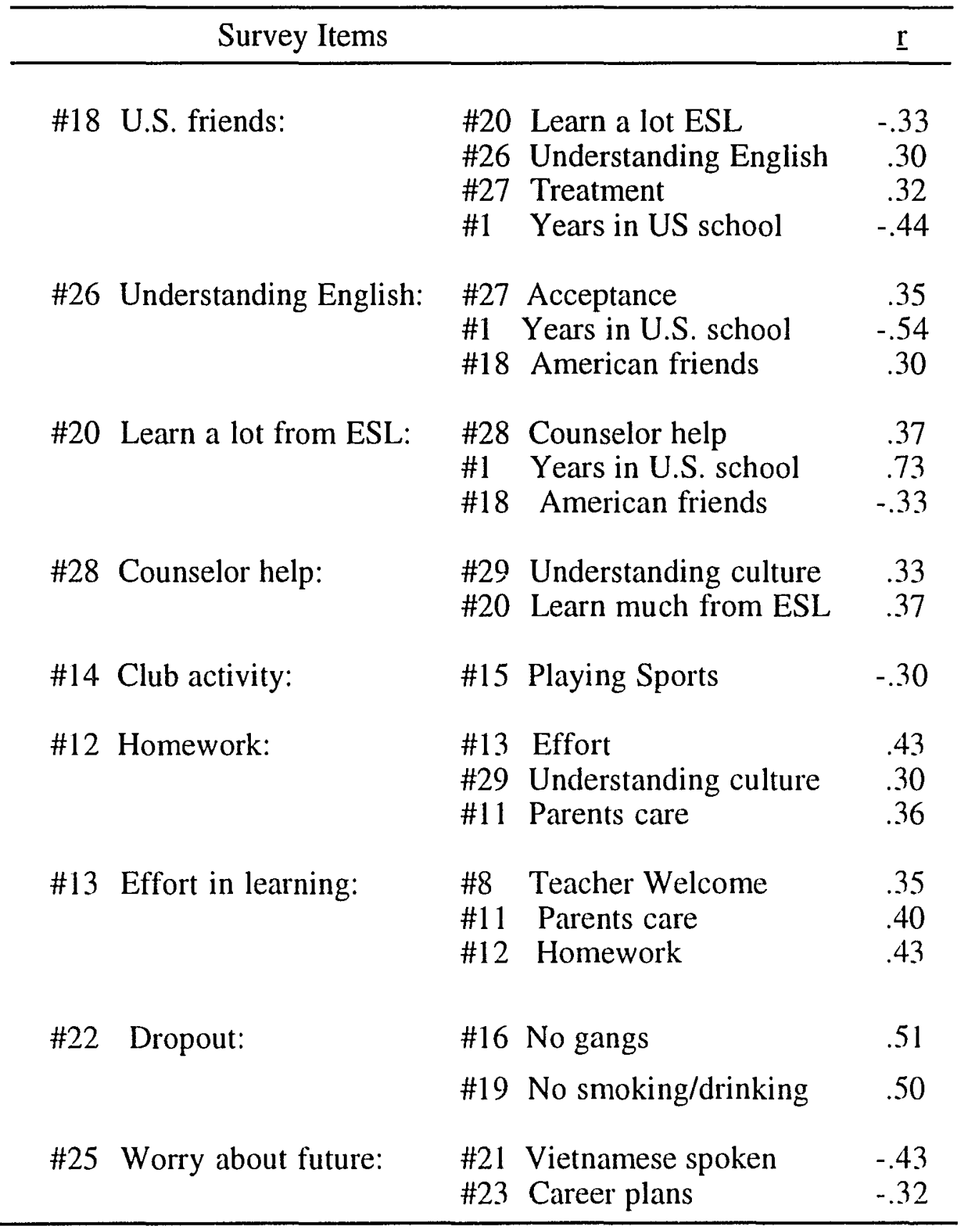




\section{Part Two: Interview Descriptions}

In addition to the survey data analysis, two interviews were conducted to obtain more information about how the attitudes about schooling fit into the life for high school Vietnamese-Americans. The interview portion of this study is for the purpose of explication and illumination of the theoretical issues and survey findings. The task with this analysis was to put a holistic, complex and human format on the survey results, theoretical discussion, and actual setting and people of this study. The objective of these interview descriptions was to tell a comprehensive story of the issues of this study. The interview activity was not intended to be broadly inferential in generating new ideas that generalize to a larger population. For example, the two interviews reported here do not represent the 145 students who responded to the survey. The novel information of this study was obtained through the survey questionnaire. Additional perspectives on this information were sought with the use of the two interview reports.

Two students were selected for interviews. As described in Chapter III, the interviews took a total of four hours. Responses were recorded in audiotapes and notes. The two interviews were then reconstructed holistically into the two profiles described below for a better illumination 
of the factors investigated by this present study. To study the schooling of these students, it is important to consider their life and school experiences. As Peterson (1976) rationalized that "...the learner as an individual subject who interacts with his or her environment to construct knowledge out of experience" (p. 13). The contents are analyzed by summarizing responses to issues and variables addressed in the survey instrument.

This section describes the profiles of the two unique individuals in the interview phase of this study. These two subjects were chosen by design as a successful case and a failing case. Tu was a valedictorian and student body president of a high school. Hung was a drug user, a gang-affiliated member, and a high-risk case. The interviews of these students provide us with moving stories of overcoming linguistic, cultural, and social barriers in being Vietnamese-American students in Oregon. They highlight many struggles facing them and many cultural insights in the way they saw themselves and their world. Their learning and exposure to the new culture, school, and society, helped them establish their self-identity, or made them feel confused about their self-image. Those kinds of revelations help educators understand that we need to consider other social/cultural factors beyond linguistic concerns in order to design sound and effective educational programs for these students. 


\section{Profile One: A High Achiever}

Tu has been in the United States for 13 years. He came here in 1979 with his mother and four brothers and sisters. His mother was the only one that brought them here, because Tu's father died in Vietnam. Tu considered himself a boat person as he had left Vietnam on a boat and went to Malaysia, and stayed at the refugee camps there for three months and then came to the United States. He is the second youngest in the family. Tu grew up in a single parent family home.

Tu lived in Saigon, Vietnam. Before his father died in 1977, his family was pretty well off. His father ran a printing business. When the Communists took over in 1975 , they closed everything down and people started the exodus out of the country. Tu's father was in a motorcycle accident and died. From that point on, it was his mother who gave the family a second chance at life.

Tu started school in Vietnam. After completing kindergarten, his mother took him out of school and the family left Vietnam. Tu went to school in the United States from first grade up to the twelfth. When he came to America, he did not speak English. In 1979, the school placed him in first grade because he did not have any background knowledge of the English language. Tu only went to the first grade for six months. After 
that school year ended, he was old enough to be in third grade. The school promoted him, he skipped second grade and went to third.

In a sense, Tu grew up in America. He had more contacts with American friends than Vietnamese friends. All through grade school and middle school he had close American friends. He went to middle school and high school with them. He did not have many Vietnamese or ChineseVietnamese friends until he was in high school. He was friends with more Americans for a longer period of time than he was with his own ethnic friends. Tu had one very good friend who was Vietnamese. He met him when he was a sophomore. Tu said that he did not have one single Asian friend at school until that year. His American friends knew he was different but did not see him totally in one culture. He was mainstreamed to where he could interact with them normally. Tu went to movies and parties with them, and at the same time he maintained values that he could relate to his Vietnamese friends.

Everyone in Tu's family placed high value on education. When their family came to America, his brothers were in high school and he was in grade school. At home, Tu saw them study a lot. He saw them come home from school and help do the chores and then study. The example that they set provided him with an intangible way of saying he had to do it too. When it reached the point that Tu had to do homework and school work, it 
was his turn to help out and do the things that were expected of everyone at home and to share the responsibilities. His siblings helped him a lot in terms of placing the value on education. Tu emphasized that there was never coercion or any bribery in the process. The value was implicit, but it was very strong so that the children learned and studied for the sake of learning; not for a monetary reward or a threat by their mother of being punished. Tu felt that was very important in setting the tone, especially from his two older brothers because of how hard they studied and worked at home.

The biggest barrier to Tu was language. To be successful in America he had to learn English. He felt he had to master English so that he could communicate in writing, reading, and speaking. In high school, he was placed in English classes that required him to spend time writing and rewriting, and thinking how to express himself clearly. Another barrier encountered was balancing his own heritage and identity versus being accepted in the American school system with American students. The American students had western values and western thinking that Tu did not necessarily agree with, and sometimes conflicted with his own values and traditions. For him to find that fine line between who he was and who he was becoming as a result of living in America was another struggle. Constantly fighting to not lose his identity, yet maintaining a level 
of interaction with the mainstream and being accepted in this society was another barrier. Tu felt fortunate in a sense that he could look back on his high school, middle school and grade school years and see a lot of successes in his own development. In his high school and middle school years, he felt a sense of great accomplishment and achievement in his academic record. Starting in sixth grade, Tu worked very hard and by the time he entered 8 th grade he maintained a 4.0 GPA. As Tu went through 8th grade he gave himself a goal to maintain a 4.0 GPA throughout his middle school years. In high school Tu had to work harder to maintain his level of expectations. He wanted to do well and to learn.

One of Tu's biggest achievements was being valedictorian of his class by maintaining a $4.0 \mathrm{GPA}$ throughout high school. Another achievement that gave him a great sense of joy was being student body president his senior year. Tu had two very supportive teachers in his junior year in high school who helped him develop socially and academically. They had the biggest influence in terms of encouraging him to run for student office, and be active and involved in the school. Not only did he have to study hard, he had to study harder than other students to see that he was succeeding. The teachers encouraged him to become involved in clubs and activities at school that were not related to studying. The first two years of high school, Tu studied a great deal. He went to school in the morning; 
after school he went home and watched TV, and then studied. Tu had no social life those two years. Through these teachers he saw that there was more to education than just studying. There were not any culture clubs in Tu's school. The teachers encouraged him to form them and share with the school some of their cultures. He started culture clubs for Chinese, Vietnamese, Laotian, and African-Americans. In his junior year, one of his teachers suggested that Tu run for student body office. She reminded him of how he helped with the culture clubs, and how qualified he was. Tu thought to make a difference in his own school he would have to step out into the public. Not only could he serve as a role model but he could learn within the process and know more about it. His decision to run was not just because he wanted to be student body president. It was a lot of little steps building up, leading to his decision to run. For two years a lot of students did not know him and so when he decided to run for siudent office, he did not have the name recognition that some of his peers had. Tu knew a lot of times people looked at student government elections as a popularity contest. Yet he was able to run and become student body president in his senior year. One of the biggest factors that contributed to winning the election, was his ability to speak and make a speech in front of the whole student body. He saw that different people would vote just because they were a friend of a friend who was running. When he went 
up to the stage to make his speech, he did not have the votes needed to win the election. The speech was powerful enough to captivate the audience, and took the balance of the election in his favor. His speech reached out to the whole student body and said to them this was the reason he was running, why he wanted to be student body president. Tu still saves this speech at home.

Tu reported that often the students saw him as an American student and that he was one of them, not a minority, a refugee, or an Asian student. Regardless of his race or skin color, as long as he had the ability, the capability to show them and demonstrate to them what he was bringing to the office and what he hoped to do. He made his case to them and they accepted it. Tu advised that if running in a school election you had to demonstrate that you were mainstream, that you could succeed and that you were no different from other students. Tu also suggested whether winning or losing, it was a very good learning process and he would encourage students to try it and learn.

In his junior and senior years, Tu was a member of the chess club that went to the state tournament both years. He was involved in the culture clubs and helped out with assemblies. In his senior year he was very busy in student government. He was also doing a lot of extracurricular activities beyond that level. In being student body president he attended parent 
meetings, PTA, and dealt with administrators and planned activities. He had many opportunities to go to meetings and perceptions that allowed him to see the outside world. Tu had the opportunity to attend once a month meetings with many business leaders within the community. Tu was also selected as Junior Rotarian of the Rotary Club.

Tu felt the biggest reason Asian students did not participate was because they were not adjusted to the culture. He said when students were already having trouble in school with academic work, it made it very hard to be more involved in other things. Especially when students did not even see success in an area that they felt they could control and that was their own school work. Tu saw that in trying to be active and interactive socially, he not only encountered the language barrier, but the social barrier, the difference between values, the difference between groups of people when interacting. Some American students just could not relate to $\mathrm{Tu}$, and he could simply not relate to them. That barrier takes a lot of time to break down. Tu wanted to create culture clubs to allow students to be involved in school.

Tu felt that joining clubs helped students to be more involved in school. If they were not doing well in school work, they could still have something else to look forward to. Tu saw the culture clubs to be a chance 
for students to keep in touch with their own roots, heritage and identity. He felt it was even more important for those students who did not have a family in America.

Tu thought the school had a responsibility in making every student feel a part of it. He felt one way for minority students was through those types of clubs. Students need a sense of belonging and identity, especially in the teenage years. If students do not feel school is right for them, they tend to be more discouraged and distant. This makes it harder to succeed. Tu felt schools must find a way to make students feel they belong, regardless of who they are, because education is the key. If they gave up education they had a lot to lose.

Tu felt it was not the student's failure, but the failure of the principals and the teachers that students did not succeed. Some principals, especially disciplinary principals, had an intimidating attitude. Because these students were minorities or refugees, they did not know what to do for them. Basically they were seen to have an arrogant attitude that contributed to students' rebellion against the system. Tu had friends who were not as successful and yet still wanted to go to school because that was very important for Asians. The value of education is very strong in Vietnamese tradition. The attitude of principals and vice-principals was critical where all they did was punishment and was not supportive in solving the problem. 
Then, the situation might force the students who were on the edge to fall on the wrong side. For example, Tu knew a student who was younger than him by three years, and not a bad student in any way. However, circumstances forced his friend into a tragic situation. An event that Tu will remember for the rest of his life, because it affected him very personally. His friend was only 16 years old when he was killed. Tu met him when he was really young because they were family friends. There was a father and son, just two people who came to the United States with nothing and then having to start a new life here. Tu's friend wanted to learn in school but he did not have as much support at home as Tu did. It was much more difficult for him to learn and to succeed. Added on to that were a lot of barriers. The more the school seemed to reject him, the more he found he did not belong to the school. He became involved in gang activities and that eventually led to his tragic end where he was shot in the head by another gang member in Chinatown. Tu felt it was more the system's failure. Tu's friend did not have the support and encouragement to do the right things. He lost direction and his sense of value, of meaning in life.

As children spend the most time of their first 12 years in school, the system should have mechanisms to create an environment that makes students feel they belong there. Tu felt that the attitude of teachers and 
administrators ought to change. They did not understand minority values, and Asian values and perspectives. They needed to deal with it in a much more sympathetic and understanding way, rather than confrontational. If the person in charge of the school had an understanding of different cultures and different values, Tu thought that could help greatly in minimizing the confrontation between students and school.

Tu had a strong family. The values he was taught brought him up to have self-confidence and gave him his own identity. Tu felt it was essential that people respect him, more than to accept him. Tu's philosophy was that "acceptance" was a form when one was not sure of oneself. He felt it was nice to have non-Asian friends accept him for who he was and not who he had to become to be accepted. Tu saw a difference. Tu was accepted and it allowed him to interact with non-Asian friends much easier. Tu's nonAsian friends gave him an opportunity to learn the western culture and he was able to assimilate much easier and faster into American society.

Tu liked first and foremost the individuality and freedom in school. It gave him a lot of flexibility as an individual within the school system to do what he wanted. He had many opportunities. He thought he had a very good high school environment in which to study and learn. But he had some dislikes, too. One of them was that as a minority student, he had constantly to work twice as hard, to do everything twice as much just to 
prove himself that he was not any different than the mainstream students. He was as much a part of the school as they were. Yet he constantly encountered this subtly hidden barrier in a lot of situations where he had to prove himself. In a sense, he thought he was always on trial. In every situation he encountered, he had to prove that he could overcome that hidden obstacle before being accepted. Tu said that there certainly should be improvement in many of the teachers, some teachers he really did not like. As motivated as he was, their classes were not stimulating and conducive to learning. To him, that was a sign of a very bad teacher. If the teachers could not control the class or did not know how to present the material, they just turned the student off to learning. Tu felt a student could only learn so much and needed the guidance of teachers. The higher the level of expectations, the more students were willing to reach it.

Tu thought there was not a need to teach students in their own language in classes. He felt they needed to learn English if they were to succeed in American society. Tu suggested it might help some students if classes were taught in their native language. He thought the emphasis needed to be placed again on the attitudes of counselors and administrators. Many had the attitude that these new immigrant students or refugees did not speak English, so they put them in remedial classes. When he was student body president, he had a chance to see some ESL classes. It made 
him mad that he knew some students who were really capable of doing a lot more, yet the school forced them into lower level classes that did not motivate students to work harder. Tu had a personal experience in this. When his second oldest brother came to the United States he started high school as a freshman. Because he did not speak English enough, they put him in prealgebra. He was a perfect example of the failure of the system. The principal's attitude was that simply because he did not speak English, he did not know how to do mathematics. His brother proved the school wrong. He took prealgebra as a freshman and then worked hard by himself and succeeded. He demanded that the counselors put him in higher level mathematics classes. By the end of his senior year, Tu's brother had finished calculus. He proved that lack of English language skills did not necessarily mean that he could not learn. Teachers and counselors need to realize this, Tu commented. Counselors should place a student in terms of the level of the student's learning. They should be placed in a much higher level of learning first and if students cannot handle it, then place them down rather than assuming that the student cannot learn and put them into a lower class. Tu felt students would lose motivation for learning because they already probably knew the material. When Tu first came here he did not speak English, but this educational system developed him into a person who could communicate and articulate clearly. From that perspective, he 
saw that the educational system had served its purpose. In learning the first language, he was very young when he came to America, so he did not have much Vietnamese in his vocabulary. All he did was to learn English. However, the sacrifice was his own language. He thought that American schools should focus on teaching minority students English, and the parents should focus their energy on keeping the language alive at home. He had almost forgotten Vietnamese until high school when he met some Vietnamese friends and regained it by speaking Vietnamese with them. Once he regained it, he realized the importance and value of knowing another language. "When you moved from one world to another world," Tu said, "there was a saying 'when in Rome, do as the Romans do."' He still had his own identity. He thought that the school system should focus on helping, using all its resources in helping students adjust to American society. Tu felt the school system had some responsibility to make the school richer multiculturally. He felt that students would lose their identity and not belong to anything, because they were never going to be caucasian.

Tu knew students who came to America in their sophomore or junior year and they had so much to catch up on. They did not have the support, ability, knowledge and level of preparation to finish high school. It is difficult to help these students finish their diploma in two or three years. It may help to give native language instruction in their classes so they could 
pass the classes and fulfill the requirements to graduate. He had teachers who supported and encouraged him, however, he had no older student role model. He did not have another student to look up to. In his senior year, when he was so visible as student body president, he ended up as the role model for many minority students. He feels very lucky that he had many teachers who were very supportive of him. Tu saw a definite need for adult role models. He thought it would make a difference to Asian students who come to America to have role models in their own ethnic group. Mentors and adults, like teachers and counselors who were Asian, could benefit Asian students greatly. Tu felt that schools must try to get more adult role models for Asian students. He remembered from his twelve years in the public school system that only one time he encountered an Asian teacher. All of the other classes he took were taught by Caucasian teachers, and his counselor was also Caucasian.

All through his high school years, none of the counselors called his home. The only time that he expected teachers or principals to call his family was if he were in trouble. Communication was through letters, stating that he was in good academic standing and was fulfilling graduation requirements. That was the only form of communication between school and his family. The letters were in English, and his mother did not know how to speak or read English. So the letters ended up being a waste of 
time and money. He ended up reading the letters and he knew what he was doing. Tu could definitely see the case for another student if they were in trouble and a school administrator or counselor sent a letter home in English, the parents would not understand it. The problem would not be solved and might worsen. Toward the end of his high school years, it was encouraging to see that they finally sent letters home in different languages.

Tu felt that if the school wanted more Asian parent involvement, they had to let Asian parents know what was going on at school. There were only two incidences that $\mathrm{Tu}$ could cite that school encouraged parent participation. Toward the end of April and May, counselors would talk to him with a list of all the classes he could take the next year and encouraged him to take it home and discuss with his parents what classes he should take. Counselors talked to him one on one to make sure that he speak with his parents. School also had open house for parents. Letters written in English were sent out stating the day of open house and encouraged parents to come. The school encouraged mainstream parents, people who knew English. Parents who did not speak or read English, needed another form of communication. When Tu was in high school, the school did not provide that. Tu thought that the school could definitely help Asian parents get more involved by having more Asian support staff at school to 
contact Asian parents. When he was student body president, the principal finally realized there were a lot more Asian students in the school, therefore, he needed to communicate with Asian parents. The principal, along with some teachers and counselors, organized an Asian parent night that was only for Asian parents. Asian parents came and showed an interest in school. It was important to find an appropriate way in conducting those types of meetings between school and Asian parents.

Tu did not have any friends who dropped out of school. He had one friend who was killed when in high school. He was a sophomore and did not see a very good future in education. Tu's friend worked at night at a casino in Chinatown, where he was shot. Tu felt that his environment forced him to a corner where he could not find a way out. Rather than continuing with school, he went to work. Because he did not have the skills or the language to find a good job, he ended up working at a casino in Chinatown.

Some Asian parents, Tu knew, denied that their kids were involved in gangs, or that their kids had alcohol or drug problems. Tu felt the way the school could help was by communicating with the parents in dealing with the problem, rather than being confrontational. Parents are brought in only when a crisis erupted and the student needed to be expelled from school. Counselors and teachers can see some problems in a student early 
on. It does not need to reach a crisis stage where either the student is in a gang carrying a gun or is taking drugs and caught with drugs in the locker. It did not need to reach that stage to bring the parents in. Many times it might be too late. In respect to the gangs and alcohol and drug problems, Tu recognized that every group has them and Asian-Americans are no different. Gang activity must be dealt with in a constructive mutually respectful manner that creates cooperation, rather than confrontation and denial. Tu's friend (who was killed) early on, had school problems. Teachers did not notify the father who did not know how to correct or guide his son. The father worked, and there were so many factors that worked against them. School problems were not dealt with and Tu's friend was not given support. It made him feel that he did not have a future. His friend ended up feeling stupid because he was failing these classes. He needed to find a job and make some money and help his father.

Tu felt that the school could have helped in identifying the problem and not letting it reach a crisis stage. Preventive measures and support need to be built into the educational system for these particular cases of alcohol abuse, drug abuse or gang related problems. The problem could be solved rather than waiting until the vice-principal searched the locker, found the gun and expelled the student. 
Tu knew that there were bad apples within his own ethnic group that created problems. The whole gang issue, Asian gangs, had tarnished his ethnic group's image. For many people, it was more a problem of cultural, economic, and social adjustments. Tu felt the first barriers they encountered were language, economic, and cultural barriers. They had many other things working against them and they had to overcome. It did not make sense to Tu for these students to fall through the crack. He was proof that he went through the system and was successful, given that he had the support at home as well as in the system. There was no reason why other students could not go through it. Tu saw each person learn and operate at a different level. He felt the system should adjust and be more responsive to the majority of the students so that they could have a better chance to succeed. Schools must be proactive and preventive to succeed. That was one thing that $\mathrm{Tu}$ could see the system improve on and preventing the tragedy from happening, preventing the crisis, preventing the situation from reaching a crisis level would alleviate and solve a lot of those problems.

\section{Profile Two: A High Risk Case}

When Hung was young he lived in Saigon, Vietnam. His parents used to work in a restaurant. His mother was a waitress and his father worked 
as a cook. In 1981 Hung's family escaped from Vietnam to come to America for freedom. Hung was nine years old when his family reached America in 1982. Hung's family included his mother and father, and his four brothers and one sister. Hung felt he had more freedom in America. He could dress any way he wanted; in Vietnam he had to wear uniforms. In America teachers did not hit him when he did something wrong. In Asian culture, teachers had a right to spank him. It was more strict in Asian culture.

In American schools, some students were prejudiced. They made fun of him because he was a different color from them. When Hung went to elementary school, he was beaten by a white student, Hung was nine years old. Hung had done nothing, other kids came and picked on him. In middle school, he had many fights with white students. Hung felt they were racist and prejudiced because they made fun of him. Also, in middle school Hung got arrested for smoking marijuana. The first thing the school did was sending him home. Some teachers were disappointed and mad at Hung. His ESL teacher was one of them. Hung said he knew she cared about him and that was why she was mad at him.

In high school, he had some problems with the principal. Whatever he did, it was always wrong. They would try to kick him out of school. He was at that high school almost two years. At first he was doing fine. 
Hung had only one fight at the school, and it was with a skinhead. A skinhead was picking on Hung's Vietnamese friend, so he and his friend fought with him. Then the school said he was selling drugs at school. Hung asked the principal if the school had any evidence. The principal said he did not need proof. The principal told him to go to vocational school and get some credits then he could come back. Hung went to vocational high school and he got some credits. He also went to summer school and received some credits. In that Fall, Hung went back to that school to register. He spoke to the vice-principal, but the vice-principal told Hung that he could not come back. The vice-principal said he was sorry, but he could not let him return. Hung was told to bring his mother to the school. He then brought his mother, but it did not help. Hung requested many times to come back to that high school and was still refused. Hung felt the principal and vice-principal were prejudiced. Even if he did not do anything wrong, they would find a way to kick him out. Hung witnessed a fight between a caucasian student and an Asian student, the principal helped and protected the caucasian student.

Hung felt teachers at that high school did not help him much. If he skipped school, they did not care. If he was absent, an automatic calling machine would call his home and report how many times he had been absent or missed class. They treated Hung like it was his problem. At 
vocational high school, it was real people who called his home, like his ESL teacher. She called his home and would talk to his parents. Hung could tell she cared about him. She was angry with him for skipping.

Hung would like to have had homework and felt it would help him. He wanted to be able to complete his work faster and get credit for it. The problem was at the school. The school did not let him take his book home to do homework because they thought he would cheat by having someone else do it for him. In Hung's opinion, there were some teachers who were prejudiced but they did not show it. They kept it inside, but he could tell.

Hung felt he needed to know English for his education, but he wanted to learn how to read and write in Vietnamese. Math and personal finance were difficult for him. He also took social studies and government. Hung felt it would have been great and help a lot to have his classes taught in his native language, if he could have had Vietnamese teachers who could teach and help him understand the subject. There were many English words Hung did not understand the meaning of. Hung thought it would be a good idea if all the schools could have enough Vietnamese translators to help the Vietnamese students and other ethnic groups have a translator to help them.

Hung did not belong to any clubs at school and had nothing to do after school. He did not have a job. Sometimes, he helped his mother by 
cooking or washing dishes. Hung wanted to be a businessman or to learn about cars to be a mechanic. Hung would like to own a restaurant one day or work in one. Hung would like go to college. Hung's parents cared about his education. If he did not go to school, his parents would yell at him. When he was younger, they spanked him with a stick. Hung and his brothers and sister spoke both English and Vietnamese at home, but his parents did not as they did not know much English. Hung saw himself as Asian. He would like to be an American citizen, but he would keep his own culture so he could pass it on to the next generation. Hung would like to visit Vietnam in the future, if had enough money. He had an uncle and grandmother still in Vietnam.

Hung had many Asian friends and the police thought he was a gang member, because they hung around together in a group. The police made him feel like a bad boy. The gang enforcement police once arrested Hung and his friends. The police pulled them over for no reason. Hung felt they saw Asians in the car so they thought something must be bad in the car. His friends asked why they were pulled over and the policemen then pulled them from the car. One officer held Hung's head and twisted his hand until it snapped. Hung had spoken in his native language and he felt the police officer had been angered by that. He hung around with his group of friends because they supported each other. If there was a fight, they would 
help each other. The school and police labeled these groups as Asian gangs, but Hung saw it as a support group. It was the school and police that called them "Asian gangs." Hung said they did not talk about gang stuff or when they fought they did not try to impress people to remember who they were by their name. Hung said there were so many Asian students that the school did not know which ones belonged to gangs and to what gang they belonged as they did not have names.

Hung got kicked out of school many times. He skipped too much and at times, dropped out of school. He sometimes felt ashamed. He was growing up and had to think about his future and a career. Sometimes, he worried about his future. If he did not have an education or a high school diploma, it would be really hard for him in the future to find a job. Hung did not feel good when he had to ask people for help when he did not understand. Some people acted like they were helping him but they really did not help. Most of Hung's friends dropped out of school. Some went to work, some sat home and did nothing. Hung felt some reasons why his friends dropped out of school were because they wanted a job to make money and some did not learn anything in school so they dropped out. Hung knew it was really hard for some of this friends at school because their English speaking ability was very low. His friends had a hard time asking for help because they did not know what to say or how to say it. 
They had no translators. When Hung almost dropped out, his teacher called him and told him he should come back to school. He thought that his teacher cared about him and his future. Hung felt if more teachers did that, there would not be as many dropouts. Hung felt the school should have a meeting or assembly to talk to kids about skipping school. Hung saw two options for students, one way was to go to school and have a good future; the other was not to finish and mess up your life. He felt teachers could spend more time in explaining to students and in helping them understand.

He hung around with mostly Asian students. American students were not friendly, he thought. When he said "hi" or "what's up," they would walk away. He did not have good communication with them. Hung had one American friend who was not a student and did not go to school. Hung would like to have American friends because it would help him learn English and learn about American culture, and the American friends could learn about his culture. It was difficult for Hung to know which Americans would accept him and be friends with him; some people seemed really nice and others really bad.

Hung had two counselors who helped him and were on his side. They were very nice to Hung and seemed to know what he was going through They cared about Asian students and were sensitive and understood 
their culture. Hung felt most ESL teachers understood his culture but regular classroom teachers did not.

Hung felt there was a serious problem with drugs and alcohol among Asian students. Hung knew that some Asians smoked and drank. He had a friend who was a drug addict and another friend who was an alcoholic. Hung tried to help his friends, but they did not listen. He felt bad when he saw his alcoholic friend's hands shaken when he did not have a drink. He spent hundreds of dollars on buying cocaine for the other friend. Hung did not want to be like those friends, they had no life. He said he had his future and needed to go on.

\section{$\underline{\text { Interview Content Analysis }}$}

This section was also analyzed based on the four major areas of interests of this study: Community Background, Educational Input, Instructional Treatment, and Student Input as presented in Chapter I.

Background information. Tu is a high achiever, graduated from high school last year as Valedictorian with a 4.0 GPA, he also was the student body president at his high school. Tu has been in the United States since 1979. Tu went to elementary, middle and high schools in Portland.

I have been very fortunate that I can look back on my high school, middle school and grade school years, I see a lot of successes in my education. (Tu) 
Hung also came from Saigon. He came to the United States in 1982. Both of his parents lived in Portland and worked in a restaurant. He encountered many problems at schools since his elementary years. In elementary school, when he was nine years old, he was beaten by American children. He said: "I didn't do anything, they just came and picked on me." In middle school, he had fights with American children because "...they made fun of us." In high school, he had problems with the school administrators. "...the principal is prejudice... whatever I do is always wrong, they'll find ways to kick me out."

Family value in education (item \# 9,\#11). Tu stated the importance his mother and family place on education:

The high value that everyone in my family places in education is very great...The example that they set provided me with an intangible way of saying you have to do it...They definitely helped me a lot....

Hung only mentioned the value of education briefly:

When I don't go to school, they [parents] yell at me. Before they even spank me with a stick...I want to be a cook, because my dad is a cook. I'm his son and I want to follow him.

Vietnamese as a language of instruction (item \#6). The two interviews presented somewhat similar opinions on this issue, as in the survey. Even though Tu stressed the importance of learning English, he thought that newer students would benefit from Vietnamese classes. 
You can use the native language to teach them the instruction and materials so they pass the class and they fulfill the requirements to graduate...In learning the first language, I was really young when I came here so I did not have a lot of Vietnamese in my own vocabulary. All I did was learn English. The sacrifice was my own language.

Hung, the at-risk student, seemed more interested in the idea of learning all subjects in Vietnamese.

I need to learn how to read and write in Vietnamese. Math and Personal Finance are difficult. I don't really know much about Math. Social Studies and Government I am taking now. Explain all of that in my language would be great, that would help a lot. If I have Vietnamese teachers, they'll help me understand. There's a lot of words I don't understand the meaning of.

Their opinions were that students who did not have enough English language skills would benefit from classes taught in their first language.

Peer relationships: American/Vietnamese friends (items \#7, \#18).

Peer relationships are a normal social development in any age group.

Immigrant or minority students not only need to establish and maintain the relationship with friends of the same age group but they also encounter another social cultural factor: to have relationships with peers from a different cultural ethnic background. The interviews with Tu and Hung provided additional explanation for friendship variables. Tu mentioned that he was student body president and was a Junior Rotarian. He had 
excellent English. In regard to friendship and American students'

treatment toward him, he said:

Actually I was friends with more Americans for a longer period of time than I was with my own ethnic friends...I grew up in America...My American friends knew I was different but did not see me totally in one culture...I could interact with them normally. I went to movies, parties with them at the same time I maintained values that I could relate to my Vietnamese friends.

Tu was a student whose bilingual and bicultural abilities allowed him to move back and forth between cultures rather easily, even though he had some reservation about western values.

Another barrier I encounter is balancing my own heritage and identity versus being accepted in the American system... The American students have western values and thinking that I don't necessarily agree with and sometimes conflict with my own values and traditions.

Tu always had a self-consciousness about his identity, not wanting to lose it totally, yet wanting to maintain a level of interaction with mainstream America. He saw this as a constant struggle he had to overcome. He said that he was very confident of himself; that gave him his own identity. He felt: "It was essential that people respect me more than it was to be accepted."

Hung was on the opposite side, having fights with American students:

In elementary school, I got beaten up by a white boy when I was nine years old...In middle school, I had a lot of fights with white boys too. They made fun of us...Some students 
are prejudice. In high school, I had a fight with a skinhead... At this high school, I have American friends but we just say "Hi" and "Bye," not close friends... When I say something to American students like "what's up?" they just walk away. So I hang around with Asian students.

Even though Hung had many fights with American friends, he expressed a desire to have them as friends but somehow he could not make the connection. His attempts in saying "hi" seemed insufficient to break the barrier. He also said: "It would be nice to have American friends. We don't know which American will accept you, which will not, because some are nice and some are not."

Hung and Tu were in the opposite end of a friendship bridge. Tu not only crossed it but also participated in many social cultural activities in both cultures. He had "American friends," he "understood English in classes," he was "accepted," he "belonged to clubs," he was "welcome." Hung was the opposite. He had not crossed the bridge, he did not understand English in classes, he was not "accepted," he did not "belong to any clubs," and he did not "feel welcome."

Home school relationship (item \#10). In the personal interviews, Tu and Hung provided insights into the relationship between their schools and their parents. Even though Tu, the high achiever, was active in school and achieving, he did not approve of the way school handled parent communication. He said: 
This is one thing that could be improved on. All through my high school years, none of the counselors called my house. The only time that you expect teachers or principals to call your parents is when you are in trouble.

And the only form of communication was through letters. So it ended up being a waste of time, a waste of their time, a waste of money. I ended up reading those letters. I can definitely see the case for another student who, for the reason that if they're in trouble, and school sends a letter in English, it's just futile because the parents aren't going to get it.

In regard to parental involvement in school, he observed that:

The school encourages parents in the mainstream, people who know English. When you have parents who don't speak English and can't read English, the school has to have another form of communication. The school did not provide that at all when I was in high school. They definitely could help Asian parents get more involved by at least having Asian support staff at school to contact Asian parents.

Hung, the at risk dropout, had this to say about school communication with home:

School calls when a kid is in trouble or absent from class... But a lot of time, they don't call at all. No counselors or principal call home at all... At one high school, a machine calls home and tells me how many times I've been absent...It's a machine talk and I can only listen, I can not talk to it. It seems like they don't really care.

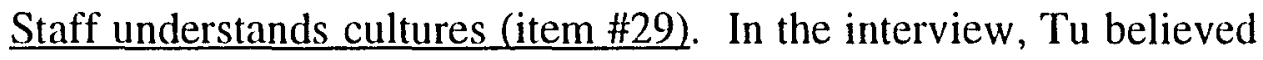

that schools could do more to understand minority cultures.

The attitude of teachers and administrators must change. They don't understand minority values and Asian values. These are minorities or refugees, they do not know what to do for them. They have a superior attitude. 
Tu felt that schools lack of cultural understanding and supportive attitude could force students who were on the edge to fall over on the wrong side.

Hung, the at risk dropout, felt he always had to encounter a lack of cultural understanding.

...some teachers who are prejudice, but they don't show it. They keep it inside, but you can tell...One principal over there is real prejudice...if I do something wrong they will find a way to kick me out.

Hung did not feel that the school welcomed him. He said that most ESL teachers knew about his culture and were sensitive, but regular teachers did not know much. He mentioned two counselors who were "nice," "always helped him" and "were on his side." "They help me a lot. They care about Asian students. They care about American people too. They really understand about Asians." Both Tu, the student body president and Hung, the at risk dropout, saw a need for staff cultural understanding and support.

English language (item \#26). Without English skills, students have a hard time functioning successfully in the regular American schools. Tu, the high achiever, emphasized that:

The biggest barrier was the language one. To be successful in America, you have to learn English. You have to master English so that you can communicate...not only you encounter the language barrier, but you also encounter the social 
barriers...when I first came, I had to repeat first grade because I didn't have any English...these new immigrant studerts or refugees don't speak English so they put them in remedial classes.

Hung felt that English was important for him in life situations.

If I don't know English, how could I go buy something. In America, everybody speaks English...I think English is awfully difficult. My friends, their English is low and sometimes they want to talk to teachers, ask for help and they don't know what to say.

Both students indicated the need and importance of English.

English as a second language (item \#20). The interviews of these two individuals yielded some insights to the ESL issue.

When I was student body president, I had a chance to see some ESL classes. It made me mad that I knew some students who were really capable of doing a lot more, yet the program forced them into lower level classes that didn't motivate students to work harder....that lack of English language skills doesn't necessarily mean that students can't learn.

On the contrary, Hung was more appreciative of ESL teachers.

When some teachers were mad at me, like the ESL teacher, I know she cared. At this vocational high school, when I was absent, my ESL teacher called home.

The opinions of these two individuals about ESL classes and teachers were mixed.

Student effort in learning (items \#12,\#13). Tu mentioned many times about his effort in academic achievements doing homework at home or his wanting to maintain a high GPA. 
When I went into sixth grade, I personally set within myself a goal that I want to achieve...I had to work harder to maintain a certain level of expectations...I wanted to do well...maintaining a 4.0 GPA throughout high school...

Hung did not have much to say about his effort in learning. Even though he understood the importance of education it was not the priority in his life.

I don't have no education or won't have a diploma... I get kicked out alot from school...I skipped too much, dropped out of school at times.

School don't let me take homework home. They think I would cheat. Homework is good. Sometimes I want to take a book home to do it, but they don't let me. So I couldn't do it.

The effort that Tu put in his schooling supported him in achieving his academic goals. Hung not only demonstrated little investment in his effort, but had a tendency to blame someone else to the point where he said that teachers did not allow him to bring books and homework home.

Extracurricular activities (items \#14,\#15). Being a high achiever, the student body president and a valedictorian, Tu was an example of the success that all immigrant students could achieve. In the interview, Tu summarized that into this statement:

Along with all academic achievements, I had many opportunitiesto experience other aspects of the education of schooling in America. By being with student body 
government that gave me opportunities to go to meetings and receptions that allow me to see the outside world.

Tu mentioned two teachers who were very supportive of him, who guided him and helped him by encouraging him to become involved in clubs and other activities at school that were not related to studying at all. He said:

"...that was the biggest influence" he had at the school. He also said:

Asians have a tendency just to study, because that is the way they were brought up.

Asian students don't participate a lot is because they are not adjusted to the culture.

I think that the school system should focus on helping, use all its energy and resources, students to adjust to American society. The school has some responsibility to create "culture clubs" and help students have some type of tie-in, which would make the school richer in a sense, multicultural.

When he was asked of his after school activities, Hung responded: "What do I do after school? Actually nothing...I do not belong to any club at school." Hung sounded like a driver who entered the freeway without seeing the "wrong way" sign. He ended up falling through the crack. He met friends who smoked pot, and used drugs.

When I was in middle school, I had some problem and I got busted for smoking weed...I hang around with some friends and they [school personnel] think those people are gang members. They think I am a gang member too. But actually I'm not...I feel like a bad boy. 
He said that by "hanging around with one group, other people call them Asian gangs...It is just like a support group, they support each other."

Indeed, they supported each other because maybe these were all the friends they had at school. A sense of belonging is important to everybody.

At risk issues: Gang, alcohol, drug, dropout (items \#16, \#19,\#22).

The interviews with both $\mathrm{Tu}$ and Hung yielded interesting insights. Tu, even though he was nearly a perfect student, had a close friend who was killed in a gang-related incident. Tu said that his friend:

..got involved in gang activities and that led to his eventually tragic ending where he was shot in the head by another gang member in downtown Portland. That was a firsthand close-up experience and it was a tragedy that has hit me. I look at it now and analyze it, I think it was more the system's failure... that students don't fail, it's the system that fails students, that makes students fail.

Tu went on to suggest that "the system should have a mechanism in there to create an environment that makes the student feel that he belongs. I think the school has a responsibility in making every student feel a part of it." He also acknowledged that there were some "bad apples" that tarnished "his own ethnic group's image." In regard to drug and alcohol he believed that some Asian parents denied that their kids had some problems. But he said that teachers and counselors could see some of these problems early on and provide some preventive intervention rather than wait until the student was 
caught with a gun or with drugs in the locker. "A lot of time, it might be too late." He also suggested that "...the system can improve on this by preventing the situation from reaching a crisis level."

Hung, the at-risk student, had more personal experiences with drug/alcohol, gangs and dropout situations. He said in middle and high school, he was hanging around with other Asian friends and he was labeled as a gang member. He was arrested by the school police. The city police also arrested him once because he was with a friend who was labeled as a gang member. "I got beaten up by a cop before... They pulled us over and one of them pulled my hand that it snapped. We talked in our language and they thought we talked about them." Hung believed that there were gangs at school, and they did bad things like fighting, stealing and breaking into cars. He admitted one time he even had a fight with a skinhead at one high school. He also mentioned one of his friends was an alcoholic. Another friend of his was a drug addict who spent hundreds of dollars for "crack." He said he got kicked out of school a lot and he felt ashamed. He felt "like a bad boy." Hung mentioned once he almost dropped out and his counselor called him and told him that he should come back, and he did because he knew that she cared about him and his future. 
About the future (item \#23. \#25). Tu's parent and family placed high value on education and he had a well thought-out career plan. He planned to attend Stanford University. The future was open wide for him. Tu believed that "Education is the key and if you forego education, then you lose a lot." Tu seemed self-confident and determined to succeed.

On the other side, Hung seemed confused and unsure about his future.

I want to be a businessman. But I want to learn about car. I want to be a cook. I follow my Dad. In a way, I like to go to college, to finish college.

Sometimes I worry about the future. I don't have no education or don't have a diploma from high school. It will be hard for me to find a job.

\section{Summary}

This chapter provides the analyses and findings of this study responding to the research questions presented in Chapter I. The Survey Data Analysis and Interview Descriptions as well as a summary are included in this chapter.

The Survey Data Analysis contains three sections: a factor-by-factor descriptive report, statistical analyses providing answers for the first four research questions, and the inferential analyses responding to the fifth research question. 
The Interview Descriptions contain the two descriptive profiles of two interviewees: a high-achiever and a high-risk case; and a content analysis of the interviews based on variables investigated by this study.

The combined approaches of the survey of 145 respondents and the interviews of two unique individuals gave this study both the qualification needed for statistical analyses and the holistic views of the variables through the actual learning experiences of these two respondents who represented the two extremes of the sample.

Even though special care was taken to insure quality and high standards for this study, many limitations were unavoidable. The findings of the statistical analyses and the interview content analysis are comprehensive considering the limited scope of this investigation. Many result reports seem simple and redundant to researchers, but they may appear complicated to the average reader. With that premise, many items were included in the analysis report even though they seemed not as significant.

The factor-by-factor report includes the descriptive analysis presented graphically with descriptive highlights. The results were synthesized to respond to research questions $1,2,3$ and 4 , regarding Community Background, Educational Input, Instructional Treatment, and Student Input. Research question 5 was answered by a series of inferential statistical analyses that include inter-item correlation, correlations among 
four areas of investigation, and analyses of variance (t test). The second part of this chapter was devoted to the interview descriptions and the content analysis based on factors investigated by this study.

The findings from this chapter are synthesized and discussed in the next chapter for possible recommendations. 


\section{CHAPTER V}

\section{CONCLUSION}

Many educational institutions around the country are faced with demographic changes in student populations in the 21 st century. In many urban school districts, the number of language-minority students is increasing faster than the preparedness of the system. As First (1989) commented, "...the nation is a decade behind in producing teachers with skills and sensitivities in working with the diverse population" (p. xiii ). The question for policy makers is not how to assimilate these children, but how to provide adequate, sound, and effective educational services to them. Many districts are taking the initiative to make needed changes based on current research on effective educational strategies, and the educational and social cultural factors described in Chapter II.

The purpose of this study was to examine the views of Vietnamese students about their schooling. This study examined factors pertaining to educational topics, socio-cultural aspects, student input factors, and how the students see themselves functioning in high school settings in Oregon. 
This chapter focuses on the discussions of the study's results to find answers to the five research questions as well as recommendations for educators and parents. The research questions are reinstated below:

1. How do Vietnamese-American high school students in Oregon perceive the community background for their schooling, including friendships, parental concern, and trends for completing schooling?

2. How do Vietnamese-American high school students in Oregon perceive the educational input for their schooling, including such factors as language used in the classroom, teacher support, discipline programs, and educator knowledge about their culture?

3. How do Vietnamese-American high school students in Oregon perceive the instructional treatment for their schooling, including ESL teaching, understanding English, and school counselors?

4. How do Vietnamese-American high school students in Oregon perceive their own student input for their schooling including such factors as language preferences, homework, effort, participation in extracurricular activity, school completion, friendship, and future plans?

5. How do the student perceptions of specific expressions of the four contextual factors relate to each other?

This chapter contains three parts: Discussion, Recommendations, and Conclusion. 


\section{Part One: Discussion}

The discussion of each research question centers around the survey findings. The discussion of the first four research topics is based on descriptive statistical analyses, while the inferential statistical results are the bases for research question five.

\section{$\underline{\text { Research Question } 1}$}

How do Vietnamese-American high school students in Oregon perceive the community background for their schooling, including friendships, parental concern, and trends for completing schooling?

On the question regarding "parents care about education," $84.8 \%$ of survey respondents reported positively. Another $10.3 \%$ said they "somewhat" cared. Together, more than $95 \%$ of these students believed that their parents care about their education. The majority of the students also felt that they had close Vietnamese friends $(77.1 \%)$.

This finding supports the observations and statements made by Caplan et al. (1990) and Rumbaut and Ima (1987). These authors found that Vietnamese families value education highly, and this has a strong effect on their children's academic achievement. 
Overall, Vietnamese-American students in this sample saw strong support and care from their parents that they do well in school. They also indicated that they maintained a close relationship with Vietnamese friends. They also had mixed opinions on the issue of completing their schooling as well as issues of smoking/drinking or gang affiliation. There was a high level of difference of perceptions regarding Vietnamese-American students smoking, drinking, or belonging to gangs (\#16,\#19), and dropping out of school (\#22). This might be due to their different definitions of these two issues or the lack of good understanding of the problems.

\section{Research Question 2}

How do Vietnamese-American high school students in Oregon perceive the educational input for their schooling, including such factors as language used in the classroom, teacher support, discipline programs, and educator knowledge about their culture?

Only $24.8 \%$ of respondents agreed positively on the issue of Vietnamese classes. Vietnamese students in the sample had mixed opinions about the question of using the first language for instruction.

Peer relationship is a normal social development in any age group. Immigrant or minority students not only need to establish and maintain the relationship with friends of the same age group, but they also encounter 
another social/cultural factor in establishing relationships with peers from a different cultural/ethnic background. The majority of Vietnamese students in the sample indicated they had Vietnamese friends (77.1\%), while only $26.2 \%$ of them had American friends.

One factor affecting minority students' self-esteem, self-identity is the treatment and acceptance by peers from the majority society. In this study, $31.5 \%$ of Vietnamese-American students reported that they were treated well and accepted by other students at school. Roughly $45 \%$ of these respondents did not feel accepted or treated well. Visiting school cafeterias one can notice the clustering of students of different ethnic groups, somewhat confirming that inter-racial peer relationship is poor. Descriptive data also show that only $36.1 \%$ of Vietnamese students perceived positively that their schools make them feel welcome. This finding has an implication for schools regarding services to minority children and efforts to alleviate perception of differential treatment.

The school is the place where students spend most of their waking time, where they are getting their education and where they interact with peers and staff in that environment. The climate, culture and treatment of the school have to be designed to provide maximum comfort for the best learning environment. School staff can set a philosophy that accepts and values students of all ethnic groups. Students in this sample perceived that 
the understanding of their culture from staff was low $(22.5 \%)$. These students also reported that school staff rarely made home visits $(2.1 \%)$. The majority of the students reported that they were not referred to the principal for discipline. This could be due to their respect for authority and low level of delinquency or violation of the law (Rumbaut \& Ima, 1987).

Generally speaking, Vietnamese-American students in this sample saw the educational inputs for their schooling such as school and teacher welcome, staff understanding their culture, peer relationship, language use in the classroom, and home school relations were low. Very few of them were referred for discipline. The staff's level of cultural understanding was modest. Relationships with non-Vietnamese peers were in need of improvement. These students had mixed opinions on the issue of the Vietnamese language as a means of instruction.

\section{$\underline{\text { Research Question } 3}$}

How do Vietnamese-American high school students in Oregon perceive the instructional treatment for their schooling, including ESL teaching, understanding English, and school counselors?

Descriptive results show that among the respondents of the survey, $31.7 \%$ indicated positively that they understood English in classes. Seven 
out of 10 respondents reported not understanding English in their classes. Can they function successfully and meaningfully in the school if they do not understand the instruction in English? Schools can either design programs where "all" of these students understand fully the subjects in English or set up educational programs where these students can fully participate in the learning process in the language they already master. Because of the need of English language skills, English as a second language instruction is the bridge that helps them acquire the language skills in order to function in regular mainstream classes. Descriptive data show that $36.2 \%$ of students in this sample indicated that they learned a lot from ESL. The percentage above can be understood that ESL programs, teachers and services can do more in order to improve the rate of "students learn much from ESL." One fourth of these students believed that counselors were helpful to them. Even though counseling is a new concept to many Vietnamese-American students, it can be that they do not have enough language skills to access counseling services.

In brief, these students saw difficulties in the understanding of English language use in the classroom. Only 3 out of 10 indicated that they understood English in classes. Approximately the same percentage of students believed that they learned a lot from English as a Second Language (ESL). These findings can be disturbing to many educators and policy 
makers, considering the fact that the main educational treatment for these students is English based. However, more than 55\% of these students reported that they were doing well in mathematics and sciences, subjects which require less English language skills.

Many studies have shown that language-minority students can learn and can succeed if they "understand" the subjects, whether they are taught in English or their first language (Cummins, 1989; Krashen, 1981a). Sound and effective education can only happen when students fully participate in the learning process.

\section{$\underline{\text { Research Question } 4}$}

How do Vietnamese-American high school students in Oregon perceive their own student input for their schooling including such factors as language preferences, homework, effort, participation in extracurricular activity, gang membership, friendship, and future plans?

One area that has a positive effect on student academic achievement is student effort in their own learning. In this study, $61.3 \%$ of respondents indicated positively that "I try very hard to do well in school." In addition to that, $29.3 \%$ reported they "somewhat" agreed to that question. Overall, $90.6 \%$ indicated much effort in their schooling, or 9 out of 10 students were positive about it. This group of Vietnamese students is highly 
motivated and interested in learning. This can be due to their cultural influence, where education is highly valued, desirable and respected.

In regard to students doing homework, $57.2 \%$ of respondents reported that they did their homework and $26.2 \%$ "somewhat" agreed to that. Together, 83.4\% were committed to homework. Caplan et al. (1990) mentioned that Vietnamese likely gather around a table after dinner and the children do a few hours of homework every night with the presence of a parent. The U.S. Department of Education (1986) mentioned that when teachers assigned homeworks on a regular basis, students' achievement increased.

Descriptive data show that only $26.2 \%$ of Vietnamese students in the sample indicated that they have American friends. Peer relationship is an important attribute to normal adolescent development and adjustment. Extracurricular involvement (\#14,\#15) was mixed in this sample. Involvement in school in non-academic settings can enhance the educational experience. Three out of 10 respondents believed that Vietnamese students belonged to gangs. On the question pertaining to "smoking and drinking," 28.7\% perceived a smoking and drinking problem among Vietnamese students. One out of four Vietnamese students believed that there are dropouts among Vietnamese.

Career plans (\#23) and worry about the future (\#25) are important student components to learning because they provide a framework for 
attention, motivation and involvement. A strong career orientation was expressed by half of the sample. This may reflect a community factor, as their culture emphasizes thinking about the future. The relatively high (approximately two thirds) response for worry about the future indicates that these students, in general, provide motivation for learning.

To help facilitate their participation in the extracurricular activities, teachers can establish activities that promote friendships among Vietnamese and American students. One activity could be set up where an American student pairs with a Vietnamese student in a club or a sport. This kind of activity can help increase the minority participation in school activities. It can create an atmosphere of acceptance and equality.

Three out of four Vietnamese students do not join any clubs or play any sports. These activities are an integral part of their schooling. These clubs and sports balance the academic learning (mind) and the physical/ social development (physical and social growth). The lack of full participation can be detrimental to their overall schooling.

Descriptive data from the survey show that $24.8 \%$ of students in the sample preferred to have content classes taught in Vietnamese. Another $14.3 \%$ of students "somewhat" preferred to have teaching in Vietnamese. Therefore $39.1 \%$ of the respondents either liked to have Vietnamese as the language of instruction or "somewhat" liked the idea. In other words, 
4 out of 10 would prefer using Vietnamese as the language for teaching. A well-known axiom from UNESCO (1953) stated that "the best language of instruction is the mother tongue." Many researchers articulated that the success of bilingual programs depends on the "perceived status of the second language" by the majority culture (California DOE, 1982; Cummins, 1986; Krashen, 1981). This explains why the Spanish Immersion Program at Ainsworth Elementary and Japanese Immersion program at Richmond Elementary in Portland are successful and desirable by many Anglo parents since these parents perceive Spanish and Japanese as high status languages. This finding is significant in planning bilingual education programs for language minority. In order to assure success and acceptance of these bilingual programs, administrators need to make sure that school staff, parents and students at that school site prepare themselves mentally, psychologically to accept and value these languages. Once they have negative opinions about minority languages, chances of programs being successful and supported by staff could be minimal.

The survey results indicated that $60.1 \%$ of these students worry about their future. In this sample, $52.8 \%$ of them indicated that they had a career plan. These factors are important in their schooling as stated by Rumbaut and Ima (1987) that their future depends heavily upon their academic achievement. 
In terms of their own contributions to their schooling, the VietnameseAmerican students in this sample showed a high level of interest and commitment to their education. Nine out of 10 students indicated strong effort in learning. Eight out of 10 reported doing homework at home. Areas that they showed lacking or weak are extracurricular activities, such as club memberships or playing sports, which are detrimental for their overall education. Because of lack of adequate language skills, compounding with low peer relationships, these students may be inhibited in full social and cognitive development at a normal rate. The lack of club memberships and not participating in extracurricular activities could expose them to vulnerability of delinquencies. Because of their future prospects for self-sufficiency and for becoming contributing members of the society depend heavily upon their academic achievement, school administrators, teachers, parents, and policy makers need to design effective programs that meet their needs (Rumbaut \& Ima, 1987).

\section{Research Question 5}

How do the student perceptions of specific expressions of the four contextual factors relate to each other?

The five inferential statistical analyses derived from the study provide possible answers for Research Question Five. These analyses include: 
(a) Inter-item correlationships among all variables of this study;

(b) Correlationships between variable "Years in U.S. Schools" and other variables; (c) Analysis of variance between variable "Living Arrangement" and other factors; (d) Correlationships between "Size of Household" and other factors; and (e) Analysis of variance between variable "Working While Schooling" and other factors pertaining to their schooling.

(1.) Correlationships among all variables were reported in Table 5. Selected groups of variables with correlation values of $\underline{r}=.30$ or above were reported separately in Table 7 for readers' interest. More research needs to be done for further interpretation.

(2.) "Years in U.S. Schools" (\#1) and other factors: There is a negative relationship between variable "Number of Years in U.S. Schools" and "Learn a Lot From ESL" (\#20); a positive relationship with "Understanding English in Classes" (\#26); and a positive relationship with "Having American Friends" (\#18). This analysis shows that the longer these students attend U.S. schools, the less likely they see much ESL learning; and the more American friends they have, the more likely they perceive positively their English comprehension.

(3.) "Living With Parents \& Non-Parents" (\#3) and other factors: There are significant differences between variable "Living With Parents \& 
Non-Parents" and "Having Classes in Vietnamese" (\#6) at $\mathrm{p}<.02$; and "Belonging to Clubs" (\#14) at $\mathrm{p}<.04$; and "Smoking and Drinking" (\#19) at $\mathrm{p}<.004$; and "Learn a Lot From ESL Teachers" (\#20) at $\mathrm{p}<.02$. Results of this analysis show that students who lived with a non-parent preferred more classes taught in Vietnamese than those with parents. Students living with parents reported less club membership. In other words, students living with non-parents reported more club activities. Students living with parents saw less use of tobacco and alcohol. Students without parents reported more use of tobacco and alcohol among Vietnamese students. Students living with parents reported learning from ESL teachers at a lesser degree than students who were not living with parents.

(4.) There appears no significant correlation between variable "Size of Household" (\#2) and any other variable investigated in this study.

(5.) There is one item that has a significant difference statistically between "Working While Schooling" (\#4) and "Worry About the Future" $(\# 25)$ at $\mathrm{p}<.02$. Regarding the issue "Working while Schooling," only one item was found to correlate significantly. Those students who had jobs for pay found more worry about the future than those not working. 


\section{Part Two: Recommendations}

Based on the survey findings, the interviews and the discussions, recommendations for parents, communities, schools and educators, institutions of higher education, and for future research are included.

\section{$\underline{\text { Recommendations for Parents }}$}

Vietnamese parents value education highly (items \#9, \#11), and this affects the schooling of their children. Thus, parents can continue to provide support and guidance for their children, including homework (item \#12) supervision. The findings also show a lack of communication between school and home (item \#10), which may prevent parents from obtaining adequate knowledge regarding their students' academic and behavioral problems. Parents need to take an initiative to communicate with school on a regular basis and that schools communicate with the home in a language parents can understand.

Cummins (1989) found that it takes up to seven years to acquire enough academic language to function successfully in the school setting. It is meaningful and effective for schools to use native language as a medium of instruction in subject areas (items \#6, \#26) where adequate English language skills are a prerequisite to students' acquisition of necessary 
cognitive academic knowledge. Parents can participate in school planning regarding what is needed to help children succeed. Parents can act as resource persons to help school staff update the cultural understanding (item \#29). "Parental involvement is fundamental to the education of Asian LEP students. These parents must know and exercise their rights in order to effectively address their children's problems" (Chiang, 1994, p. 162). Parents can assist their children to maintain and enrich the home language and culture and to see that bilingual skills are an asset, and not a deficit (National Coalition of Advocates for Students, 1988).

Rumbaut and Ima (1987) reported that the majority of Vietnamese students majored in "mathematics and engineering" fields. This present study shows that $55.1 \%$ of Vietnamese students in this sample reported doing well in mathematics and sciences. If this is a trend, there will be a shortage of Vietnamese-Americans trained in other areas of needed occupations such as education, social services, business management, medical services, etc. Vietnamese-Americans need to explore non-technical areas of occupations and to expand areas of training and interests. One area parents need to be aware of which can prevent their students from completing schooling (item \#22) are the issues of gang affiliation (item \#16) and tobacco and alcohol use (item \#19). These three factors show strong correlations (see table 7). 


\section{Recommendations for Schools and}

Teachers

Since Vietnamese parents place high value in education, schools and staff can encourage parents to continue providing assistance and support to their children's education by making sure that they fulfill school educational expectations. Teachers and counselors can contact the home in regard to homework (item \#12), career planning (item \#23), which are positive indicators from the study's results, cultural presentation and preventive programs on drug/alcohol (item \#19), gang affiliation (item \#16) and dropout prevention (item \#22), which are negative indicators from the study's findings. Schools can communicate with families on a regular basis (and in a language that parents can understand). Based on students' learning styles regarding homework and learning effort, teachers can provide homework to Vietnamese students on a regular basis and design the homework as group work, utilizing cooperative learning strategies.

Schools can help set up inter-racial, inter-linguistic clubs or cultural clubs (item \#14) to provide a place for American and Vietnamese students to interact so they can learn from one another. As Bernard (1990) mentioned that peer interaction would have positive effects on social development as well as academic performance. This kind of inter-racial 
peer interaction will help promote students' self-esteem, self-identity and a sense of belonging. This may help improve the perception of students regarding school/teacher welcome and peer acceptance (items \#8, \#17, and \#27). Multicultural diversity training to all staff to promote awareness, knowledge and skills in working with minority students can be offered as inservice.

Schools could exploit the language skills, the first language, that these children bring to school in order to speed up the learning process especially in subject areas where the demand of language skills is so high. The best means of instruction is the mother tongue, read an axiom from UNESCO (1953).

Staff need to make school a welcome place for all students, as advocated by Caplan et al. (1990). Multicultural learning activities can be an important component of the curriculum. Schools can exploit the multicultural resources in the community as Peterson et al. (1988) suggested that teachers should maximize outside resources by bringing the community to the school.

Recommendations for Higher Education Institutions

The findings of this study show that the Vietnamese-American students possess the potential for academic success. These students are highly 
motivated and committed to learning. Other studies also reported that a great percentage of these students planned to pursue higher education (Rumbaut \& Ima, 1987). However, the majority of these students had a tendency to focus on math and science based majors (Rumbaut \& Ima, 1987). This study shows that $55.1 \%$ of these respondents reported that they also did well in mathematics and science. Institutions of higher education need to be aware of this tendency. They need to increase efforts in the recruitment and retainment of Vietnamese-American college students into other fields such as humanities, education, social and health services. College professors also need to be prepared to meet the educational and intellectual needs of this new group of Asian Americans. There is a need to expand the college course offerings beyond the traditional European-focused studies. Many colleges and universities in major cities in the United States already have experienced an increasing number of Asian-Americans in which Vietnamese-Americans make up a substantive percentage. Courses pertaining to multicultural education would be beneficial to all educators.

Institutions of higher education need also to assume a leadership role in establishing ethnic studies centers where research and courses focusing on ethnic Americans can be explored. Urban universities such as Portland State University can greatly benefit from an Asian Studies Center. 


\section{$\underline{\text { Recommendations for Communities }}$}

The benefits of the American educational system can be tremendous in the eyes of many immigrant students and parents. This is due to the educational opportunities as well as the expertise from well-trained educators in the United States. However, the impact of the Americanization process can be an unavoidable surprise to many immigrant parents. Rumbaut and Ima (1987) have noted that the children of parents with "more ethnic resilience" performed better than children whose parents were more Americanized. Parents and communities must be aware of the side effects of the Americanization process. The acculturation process would allow communities and parents to maintain traditional cultural values while adopting new social and cultural values of the adopted society. On the contrary, the assimilation process may hinder the maintenance of traditional values such as strong family support of education. Communities need to devise some practical coping strategies to maximize the benefits of the educational opportunities at the same time to minimize the side effects of the Americanization process, such as the loss of desirable traditional cultural values. Parents and communities need to carefully examine the United States' political and educational process in order to make the best decision for their children's education. 


\section{Recommendations for Future Research}

This study's findings provide adequate answers for the five research questions, but at the same time pose many potential unanswered queries which deserve further research. Issues such as parental support for education need to be explored in conjunction with social economic status of the student community backgrounds. The role of first language from these students' perspectives was perceived with mixed opinion. The level of English language comprehension could be different in different levels of grades and ages, as well as different settings (self-contained vs. traditional high school schedule). The level of ESL perception could be affected by many other variables not investigated by this study.

Many of the issues responded to by research question number five could be explored further. Also, the inter-correlationships among many factors reported in Table 7 deserve indepth investigation.

\section{Part Three: Conclusion}

The purpose of this study was to examine the issues affecting the schooling of Vietnamese high school students in Oregon, from their perspectives. Adopting Cummins' (1979) Contextual Interaction Theory, four areas of research interest were explored through the survey 
questionnaires of 145 Vietnamese students in seven high schools and a Sunday school; and the interviews of two unique individuals.

The survey and interviews were constructed to focus on the four areas of investigation from the study's theoretical framework: (a) Community Background, (b) Educational Input, (c) Instructional Treatment, and (d) Student Input. Cummins (1979) theorized that the student outcomes are the result of the interaction among these various inputs in their schooling. In other words, these students acquire the educational experience through their interface with their community background factors, school factors, instructional programs, and their own contributions. Peterson (1976) defined the learner as "an individual subject who interacts with his or her environment to construct knowledge..." (p. 13).

The four areas of investigation were incorporated in the study's five research questions exploring the views of Vietnamese high school students on issues such as parental concerns, friendships, first and second languages, teacher support and knowledge about their culture, discipline issues, counseling concerns, ESL teaching, English language comprehension, core subject matters, extracurricular activities, drug/alcohol use, dropout issues, gang affiliation, working during schooling, and future planning. Even though there are many other factors to be explored, but due to the scope of this study, there are limitations. 
The survey data provide the quantification for descriptive and statistical inferential analyses to respond to the five research questions. The interview descriptions include the description of the two individuals: a high-achiever and a high-risk student, and a content analysis illustrating the educational experiences of the successes and failures in their schooling in Oregon.

To capture a global view of their schooling and factors affecting their educational outcomes, a summary and conclusion of the study is included.

\section{Community Background}

The students in this sample came from a large family with a mean of 5.6 people. They were relatively new to the country with their American school residency of 2.82 years. The majority of these students lived with their parents (84.8\%). These students still maintained friendships with their Vietnamese peers $(77.1 \%)$. They had mixed opinions about the many at-risk issues such as smoking, drinking, gang affiliation, and dropping out of school. The agreement and disagreement on the at-risk issues were distributed evenly across the scale. The inter-item correlations among these three variables are consistently above .50 , and need further exploration. 


\section{Educational input}

The schools they were attending showed support and acceptance of them speaking Vietnamese. These students saw difficulties in understanding the English language used in the classroom, only one third of them indicated positively their comprehension of English. However, these students showed mixed opinions about having classes taught in Vietnamese. They had neither adequate English language skills to fully understand instruction in classes nor did they have strong preference in having classes taught in Vietnamese. This could pose a dilemma for them in acquiring the needed cognitive knowledge for their schooling. It can be speculated that once these students understand the benefits of learning subject areas through their stronger language, they may have a different opinion on this issue.

These students perceived that the level of school and teacher welcome was high, showing that their schools and teachers were doing a good job in welcoming these Vietnamese-American students to their schools. However, these students did not perceive a good level of acceptance from their American peers. This could be due to the low peer relationships with fellow students. Only one out of three students reported having American friends. Thus, Vietnamese students at these schools seemed not to be acculturated. In other words, they tended to cluster together with their 
Vietnamese peers. This factor is often overlooked by educational researchers, considering the importance of peer acceptance for adolescents in their social, psychological development. Even though students perceived a high level of school welcome, only half of these students saw a good level of cultural understanding from teachers.

Schools and educators tend to overemphasize the teaching of the English language and overlook the socio-cultural dimensions influencing the schooling of children and the way how they perceive themselves and the world.

It appears that the great majority of Vietnamese students did not have any problems with discipline. They also reported that schools rarely made home visits. The interviews showed that school and home communication or relationship was poor, both from the viewpoints of a high achiever and a high-risk student.

In general, in terms of the educational inputs, there are areas of positive perceptions such as school welcome, school discipline, but many aspects of educational input factors prove worrisome. Issues affecting student learning such as language comprehension in regular classrooms and the dilemma of first language and second language preference are so crucial in providing any sound educational services to these students. 
No less important are the issues pertaining to a student's affective domain such as peer acceptance, friendships which promote student's positive self-identity and self-esteem as well as a sense of belonging. The home school communication is also an important aspect of their schooling, even though these students showed little discipline problems.

\section{Instructional Treatment}

The most studied aspect of education has been the curriculum and instructional programs (instructional treatment) provided to students. The students in this study showed positive opinions regarding subject areas such as mathematics and science, where the English language ability is not as demanding. However, they had difficulties in the English language instruction. Only 3 out of 10 students indicated positively that they understood English in their classes. They also showed mixed opinions about ESL learning. The analysis shows a negative relationship between learning ESL and the years in U.S. schools. Approximately one out of three students perceived ESL positively. They did not see ESL as a strong treatment for their situations. These instructional aspects of their schooling can impact heavily on their educational outcomes, considering all subject matters are English-based.

In general, regular curriculum has not been designed with non-English speakers in mind, which may cause hardship for many language-minority 
students to function successfully academically. From these students' perspectives, ESL is not a strong solution for their educational needs either. The high achiever in the interviews had a negative opinion regarding ESL instruction also. Suggestions and recommendations in this chapter can be explored for possible remedy.

\section{$\underline{\text { Student Input }}$}

The ultimate responsibility of student outcomes rests heavily on the students themselves. Their contributions to their education are major factors in successful schooling. This group of Vietnamese-American students showed strong efforts in their educational endeavor and commitment to homework. Doing homework is a good remedy to make up for their limited English comprehension during class. In terms of extracurricular activities, there were indications that their involvement was minimal. These students showed a lack of participation in club activities or playing sports. These non-academic activities can enhance their schooling experience and promote their integration to school life. Experiences in these areas can make their schooling more meaningful. Many higher education institutions place strong values on non-classroom involvement for their admission criteria. The U.S. Department of Education (1986) report [What Works] mentioned that students who gained experience 
through extracurricular activities in high school, would experience later success in higher education. Besides, the benefits of the interaction with English speakers can be tremendous in terms of language acquisition (Krashen, 1981).

The majority of these students reported having career plans. The inferential statistical analysis shows that those with a paying job worry more about the future than those who do not at $\mathrm{p}<.05$. The positive showings of career planning and future worry are good indicators of motivation, drive, and purpose in their future.

Generally, the Vietnamese-American students in this study were motivated in their schooling. They were committed to school work, and putting much effort in learning. They were planning for their future career. Basically, they possessed the fundamental drive and commitment to their schooling. However, they were not fully participating in the school experiences, neither in their cognitive development (due to language ability) nor in non-academic extracurricular activities. They brought to the school a strong family value for education. They also possessed a strong language, their mother tongue. They had a respect for authority by not violating school rules. Yet, they saw the vulnerability of exposure to gangs, drugs and dropping out. They saw a good level of teacher and staff welcome. Their perception of peer acceptance was low. 
The Vietnamese-American high school students in this sample saw themselves functioning well in mathematics and science subject areas, but they also acknowledged the difficulties in the English language. However, they did not perceive ESL as a strong instructional treatment for their situation.

Overall, these students showed tremendous potential for success academically. They possessed all the qualities promising in becoming contributing and productive members of the society. These students found that the school's educational input aspects were not geared toward them. They perceived tremendous difficulties in the instructional treatment programs. Many factors pertaining to educational inputs and instructional programs are in fact, under the control of schools and staff.

Students must assume the responsibility for their learning, but schools must assume the responsibility for their schooling. Schools should not be blamed for all the failures of students, but schools and teachers must carry the accountability in students' failures.

"If a physician makes a mistake, he'll kill only one patient; but if a teacher makes a mistake, he will kill a whole generation," goes a Vietnamese proverb. 


\section{REFERENCES}

Ambert, A. (1991). Bilingual education and English as a second language: A research handbook. New York: Garland Publishing, Inc.

Ary, D., \& Jacobs, L. (1985). Introduction to research in education. Holt \& Rinehart, New York, NY.

Bain, B., \& Yu, A. (1980, December). Cognitive consequences of raising children bilingually: One parent, one language. Canadian Journal of Psychology, 34, (4), 304-313.

Bernard, B. (1990). The case of peers. Portland, OR: Northwest Regional Educational Laboratory.

Borg, W., \& Gall, M. (1983). Educational research. New York: Longman, Inc.

California Department of Education. (1981). Schooling and language minority students: A theoretical framework. Los Angeles: California State University, Evaluation, Dissemination and Assessment Center.

California Department of Education. (1982). Basic principles for the education of language-minority students: An overview. Sacramento, CA: Author.

California Department of Education. (1986). Beyond language: Social and cultural factors in schooling language minority students. Los Angeles: California State University, Evaluation, Dissemination and Assessment Center.

Caplan, N., Whitmore, J., Bui, Q., \& Choy, M. (1990). Children of the boat people: A study of educational success. Ann Harbor, MI: University of Michigan Press. 
Caplan, N., Whitmore, J. K., Bui, Q., \& Choy, M. (1992). The boat people and achievement in America (4th ed.). Ann Harbor, MI: University of Michigan Press.

Castro, N. (1983). Cultural change and the process of adjustment: A study of the adjustment of Vietnamese refugee children who attend the public schools. Unpublished doctoral dissertation, Arizona State University, Tempe, AZ.

Chiang, R. (1994, Summer). Home school communication for Asian students with limited english proficiency. Kappa Delta Pi Record, 30 , (4), 159-163

Clinton, W. (1992, July). Presidential campaign position paper: Asian Pacific American, Making the difference in 1992. Presented at the Democratic National Convention, New York City.

Converse, J., \& Presser, S. (1986). Survey questions. Newbury Park, CA: Sage.

Cortes, C. (1986). The education of language minority students: A contextual model. In Beyond language: Social and cultural factors in schooling language minority students (pp. 3-35). Los Angeles: California State University.

Crawford, J. (1989). Bilingual education: History, politics, theory and practice. Trenton, NJ: Crane Publishing Co.

Cummins, J. (1978). Bilingualism and the development of metalinguistic awareness. Journal of Cross-Cultural Pedagogy, 2, 131-149.

Cummins, J. (1979, September). Linguistic interdependence and the educational development of bilingual children. Department of Health, Education and Welfare.

Cummins, J. (1981). The role of primary language development in promoting educational success for language minority students. In Schooling and language minority students: A theoretical framework (pp. 3-49), Los Angeles: California State University, Evaluation, Dissemination and Assessment Center. 
Cummins, J. (1989). Empowering minority students. Sacramento, California: Association For Bilingual Education.

Daniels, H. (1990). Not only English: Affirming America's multilingual heritage. Urban, IL: National Council of Teachers of English.

Davis, D., \& McDaid, J. (1992, April). Identifying second language student's needs: A survey of Vietnamese high school students, Urban Education, 27, (1), 32-40.

Denzin, N. (1970). The research act: A theoretical introduction to sociological methods. Chicago: Aldine.

Development Associates. (1980). Evaluation of California's educational services to limited and non-English speaking students: Final report. San Francisco, CA: Author.

Development Associates. (1990). The final report of the national longitudinal evaluation of the effectiveness of services for language minority LEP students. Arlington, VA: Author.

Fink, A., \& Kosecoff, J. (1985). How to conduct surveys. Newbury Park, CA: Sage.

First, J. (1989). New voices: Immigrant students in U.S. public schools. Boston: The National Coalition of Advocates for Students.

Garcia, E. (1994). OBEMLA Director: Opening Address, NAFEA (National Association For The Education and Advancement of Vietnamese, Cambodian and Laotian American) Conference, March 1994, Chicago, IL.

Gardner, R., \& Lambert, W. (1972). Attitude and motivation in second language learning. Rowley, MA: Newbury House Publishers.

Gee, J. (1986). In New voices: Immigrant students in U.S. public schools. Boston, MA.

Guba, E., \& Lincoln, Y. (1981). Effective evaluation. San Francisco: Jossey-Bass. 
Hakuta, K. (1986). Mirror of language: The debate on bilingualism. New York: Basic Books, Inc.

Haney, W. (1987). An estimation of immigrant and immigrant student populations in the U.S. as of October 1986. Boston: Boston College N.C.A.S. Immigrant Student Project

Hodgkinson, H. (1985). All one system: Demographics of education, kindergarten through graduate school. Washington, DC: Institute for Educational Leadership, Inc.

Holt, D. (1986). In California Department of Education (Ed.), Beyond language: Social and cultural factors in schooling language minority students (pp. iii-viii), Los Angeles: California State University.

Jacobs, L. (1987). Differential participation and skill levels in four Hmong third grade students: The social and cultural context of teaching and learning. Unpublished doctoral dissertation, University of California at Santa Barbara.

Kerman, S., Kimball, T., \& Martin, M. (1980). Teacher expectations and student achievement. Downey, CA: Office of the Los Angeles County Superintendent of Schools.

Kim, Y. (1979). Towards an interactive theory of communication acculturation. In D. Nimmo (Ed.), Communication yearbook 3: International Communication Association, New Brunswick, NJ: Transaction Books.

Krashen, S. (198la). Bilingual education and second language acquisition theory. In California Department of Education (Ed.), Schooling and language minority students: A theoretical framework (pp. 51-79). Los Angeles: California State University Evaluation Dissemination and Assessment Center.

Krashen, S. (1981 b). Principles and practice in second language acquisition. New York: Pergamon Press.

Lambert, W. (1975). Culture and language as factors in learning and education. In A. Wolfgang (Ed.), Education of immigrant students (pp. 55-83. Toronto: The Ontario Institute for Studies in Education. 
Mathison, S. (1988). Why Triangulate? Educational Researcher, 17, 13-17.

McGroarty, M. (1986). In Beyond language: Educator's response to sociocultural diversity: Implications for practices (pp. 299-343), California Department of Education.

Merriam, S. (1988). Case study research in education: A qualitative approach. San Francisco, CA: Jossey-Bass Publishers.

Minaya-Rowe, L. (1992). Teacher training in bilingual education and ESL: Recent research developments in Bilingual Education and ESL Research Handbook, Garland Publishers, Inc.

National Coalition of Advocates for Students. (1988). New voices: Immigrant students in U.S. public schools. Boston: Author.

National Clearinghouse on Bilingual Education Forum. (1993). Oyster bilingual school stands the test of time. Washington, DC: Author.

New tack: Bilingual program. (1993, January 16). The Oregonian: Metro/ Northwest.

Oregon Department of Education. (1989, September). Language diversity and English instruction concept paper. Salem, OR: Author.

Oregon Department of Education. (1993). School funding Senate Bill 814, Salem, OR: Author.

Padilla, S. (1986). In Beyond Language. Ethnic minority issues in the U.S.: Challenges for the educational system. California Department of Education.

Patton, M. (1980). Qualitative evaluation methods. Beverly HIlls, CA: Sage.

Paulston, C. (1976). Ethnic relations and bilingual education: Accounting for contradictory data, English as a second language in bilingual education, J. Alatis and K. Twaddell (Eds.), Washington, DC: TESOL. 
Peterson, K. (1976). An experimental evaluation of a science inquiry training program for high school students. Unpublished doctoral dissertation, University of California, Berkeley.

Peterson, K., Deyle, D. \& Watkins, W. (1988). Evaluation that accommodates minority teacher contributions. Urban Education, 23, (2), 133-149.

Portland Public Schools. (1992). English as a second language/bilingual program. (1991-1992 Program Evaluation). Portland, OR: Author.

Refugee issues. (1985 December 19). Los Angeles Time.

Refugee Resettlement Program. (1990). Report to congress. Office of Refugee Resettlement, Washington, DC.

Robinson, C. (1990, Summer/Fall). Indochinese resettlement into the 90's (U.S. Committee for Refugees). The Channel (pp.12-14).

Rumbaut, R., \& Ima, K. (1987). Southeast Asian refugee youth study. San Diego: San Diego State University.

Sherman, D. (1983). Views of school and work interviews with high school juniors. Unpublished doctoral dissertation, University of Oregon, Eugene.

Smith, M. (1987). Equality of educational opportunity for language minority students in Oregon: A survey of E.S.L./bilingual education policy in local school districts. Unpublished doctoral dissertation, Portland State University, Portland, Oregon.

Spandel, R. (1988, November). Refugee report. Salem: Oregon Department of Human Resources.

Spindler, G. (1982). The transmission of culture. In Education and cultural process: Toward an anthroplogy of education. New York: Holt, Rinehart and Winston, 1974.

Stevick, E. (1980). Teaching languages: A way and ways. Rowley, MA: Newbury House Publishers. 
Strouse, J. (1985). Continuing themes in U.S. educational policy for immigrants and refugees: The Hmong experience. Unpublished doctoral dissertation, University of Wisconsin, Madison.

Sue, S., \& Padilla, A. (1986). Ethnic minority issues in the United States: Challenges for the educational system. In California State University (Ed.), Beyond language: Social and cultural facators in schooling and language minority students (pp. 35-72). Los Angeles: California State University.

Swain, M. (1979). Bilingual education: Research and its implications. Washington, DC: TESOL.

Swain, M., \& Cummins, J. (1986). Bilingualism in education: Aspect of theory, research and practice. New York: Longman Publishing Co.

Swain, M., \& Lapkin, S. (1981). Bilingual education in Ontario: A decade of research. Toronto: Ontario. Minister of Education.

Terrell, T. (1981). The natural approach in bilingual education. Schooling and language minority students: A theoretical framework. Los Angeles: California State University.

Tucker, R. (1975). Bilingual education of children: The St. Lambert experiment. Rowley, MA: Newbury House Publishers.

U.S. Commission on Civil Rights. (1973). Teachers and students: Differences in teacher interaction with Mexican-American and Anglo students. Washington, DC: Author.

U.S. Commission on Civil Rights. (1975). A better chance to learn: Bilingual bicultural education. Washington, DC: Author.

U.S. Department of Commerce, Bureau of the Census. (1983). Asian and Pacific Islander population by state: 1980. (Supplementary Report, PC80-S1-12). Washington, DC: U.S. Government Printing Office.

U.S. Department of Commerce, Bureau of the Census. 1990 report. Washington, DC: U.S. Government Printing Office. 
U.S. Department of Education. (1994, March). (Office of Bilingual Education and Minority Language Affairs), Opening Address to the National Conference of National Association For Education and Advancement for Vietnamese, Laotian, and Cambodian American in Chicago.

U.S. Department of Education. (1986). What works. A department report, Washington, DC: Author.

U.S. Department of Health and Human Services. (1990). Refugee Resettlement Program. Report to Congress, Office of Refugee Resettlement, Washington, DC.

U.S. Department of Health, Education \& Welfare, Office of Civil Rights. (1975). Task-force findings specifying remedies available for eliminating past educational practices rules unlawful under Lau v. Nichols. Washington, DC: Office of Civil Rights.

U.S. Department of State. (1990). Office of Refugee Resettlement Report, 12-31-90, Washington, DC: Author.

UNESCO. (1953). The use of vernacular languages in education. Monographs on Fundamentals in Education. UNESCO.

Waggoner, D. (1991). The increasing multi-ethnic and multilingual diversity of the US: Findings from the 1990 Census, Numbers and Needs, Washington, DC.

Yin, R. (1984). Case study research: Design and methods. Newbury Park, CA: Sage.

Zanger, V. (1991). The social context of second language learning: An examination of barriers to integration in five case studies. Unpublished doctoral dissertation, Boston University. 
APPENDIX A

SURVEY QUESTIONNAIRE 


\section{SURVEY QUESTIONNAIRE}

1. How long have you been in U.S. schools? years months

2. How many people live in your house? people

3. Who do you live with? parents relatives_friends

4. Do you have a job where you earn money? __yes __ no 5. Subjects you do well in:__ math_ science_English_social studies

6. I prefer to have these above classes taught in Vietnamese. agree(1) some(2) not sure(3) much(4) disagree(5)

7. I have close Vietnamese friends. agree(1) some(2) not sure(3) much(4) disagree(5)

8. Teachers make me feel welcome. agree(1) some(2) not sure(3) much(4) disagree(5)

9. My parents don't care if I du well at school. agree(1) some(2) not sure(3) much(4) disagree(5)

10. Teachers, counselors, principal visit me at home. agree(1) some(2) not sure(3) much(4) disagree(5)

11. My parents want very much for me to do well at school. agree(1) some(2) not sure(3) much(4) disagree(5)

12. I do homework at home. agree(1) some(2) not sure(3) much(4) disagree(5)

13. I try very hard to do well in school. agree(1) some(2) not sure(3) much(4) disagree(5) 
14. I do not belong to any clubs at school.

$$
\text { agree(1) some(2) not sure(3) much(4) disagree(5) }
$$

15. I play sports at school.

$$
\text { agree(1) some(2) not sure(3) much(4) disagree(5) }
$$

16. Vietnamese students don't belong to gangs.

$$
\text { agree(1) some(2) not sure(3) much(4) disagree(5) }
$$

17. My school makes me feel welcome.

$$
\text { agree(1) some(2) not sure(3) much(4) disagree(5) }
$$

18. I have close American friends at school.

$$
\text { agree(1) some(2) not sure(3) much(4) disagree(5) }
$$

19. Vietnamese students don't smoke or drink alcohol.

$$
\text { agree(1) some(2) not sure(3) much(4) disagree(5) }
$$

20. I learn a lot from my ESL teachers.

$$
\text { agree(1) some(2) not sure(3) much(4) disagree(5) }
$$

21. It is O.K. at my school to use Vietnamese language.

$$
\text { agree(1) some(2) not sure(3) much(4) disagree(5) }
$$

22. Vietnamese students don't drop-out of school.

$$
\text { agree(1) some(2) not sure(3) much(4) disagree(5) }
$$

23. I have plans for my career after high school.

$$
\text { agree(1) some(2) not sure(3) much(4) disagree(5) }
$$

24. I have been referred to the principal because of discipline problems. agree(1) some(2) not sure(3) much(4) disagree(5)

25. I am not worried about my future.

$$
\text { agree(1) some(2) not sure(3) much(4) disagree(5) }
$$

26. I understand the English spoken in my classes.

$$
\text { agree(1) some(2) not sure(3) much(4) disagree(5) }
$$


27. I am accepted and treated well by other students.

$$
\text { agree(1) some(2) not sure(3) much(4) disagree(5) }
$$

28. School counselors help me a lot.

$$
\text { agree(1) some(2) not sure(3) much(4) disagree(5) }
$$

29. Principal,teachers, counselors understand about my culture.

agree(1) some(2) not sure(3) much(4) disagree(5) 


\section{APPENDIX B}

\section{BAN THAM-DO Y-KIEN : VIETNAMESE VERSION}




\section{BAN THAM-DO Y-KIEN : VIETNAMESE VERSION}

1. Em hoc o truong hoc My duoc bao lau? nam thang

2. Nha em dang o gom co bao nhieu nguoi? nguoi

3. Em dang song voi ai? _ cha me_ba con_ban be

4. Em co lam cong-viec gi ra tien khong?__ Co ___ Khong

5. Mon hoc ma em hoc kha:_Toan_Khoa-hoc_Anh-van_Xa-hoi\&Su

6. Toi muon hoc nhung mon tren(cau hoi so 5)bang tieng Viet. rat dung(1) gan dung(2) khonghan(3) hoi sai(4) rat sai(5)

7. Toi co ban than nguoi Viet. rat dung(1) gan dung(2) khonghan(3) hoi sai(4) rat sai(5)

8. O truong, giao-su don tiep toi mot cach nong-nhiet. rat dung(1) gan dung(2) khonghan(3) hoi sai(4) rat sai(5)

9. Cha me toi khong can biet la toi co hoc gioi hay khong. rat dung(1) gan dung(2) khonghan(3) hoi sai(4) rat sai(5)

10. Giao-su, co-van nha truong, hieu-truong co tham toi tai nha. rat dung(1) gan dung(2) khonghan(3) hoi sai(4) rat sai(5)

11. Cha me toi rat muon toi phai hoc gioi o truong. rat dung(1) gan dung(2) khonghan(3) hoi sai(4) rat sai(5)

12. Toi co lam bai va soan bai o nha. rat dung(1) gan dung(2) khonghan(3) hoi sai(4) rat sai(5)

13. Toi co gang rat nhieu de hoc gioi o truong. rat dung(1) gan dung(2) khonghan(3) hoi sai(4) rat sai(5) 
14. Toi khong tham-gia sinh-hoat hoc sinh nao ca.

rat dung(1) gan dung(2) khonghan(3) hoi sai(4) rat sai(5)

15. Toi co tham-du cac doi the-thao cua truong.

rat dung(1) gan dung(2) khonghan(3) hoi sai(4) rat sai(5)

16. Hoc-sinh Viet-Nam khong dinh liu toi van-de du-dang.

rat dung(1) gan dung(2) khonghan(3) hoi sai(4) rat sai(5)

17. Toi cam thay duoc nha truong don-nhan rat tu-te

rat dung(1) gan dung(2) khonghan(3) hoi sai(4) rat sai(5)

18. O truong toi co ban than nguoi My .

rat dung(1) gan dung(2) khonghan(3) hoi sai(4) rat sai(5)

19. Hoc sinh Viet Nam khong uong ruou va khong hut thuoc.

rat dung(1) gan dung(2) khonghan(3) hoi sai(4) rat sai(5)

20. Toi hoc hoi duoc nhieu noi cac giao-su day ESL.

rat dung(1) gan dung(2) khonghan(3) hoi sai(4) rat sai(5)

21. O truong, toi co the dung tieng Viet.

rat dung(1) gan dung(2) khonghan(3) hoi sai(4) rat sai(5)

22. Hoc-sinh Viet-Nam khong bo hoc ngang.

rat dung(1) gan dung(2) khonghan(3) hoi sai(4) rat sai(5)

23. Toi da co y-dinh hoc nghe gi sau khi tot-nghiep trung hoc.

rat dung(1) gan dung(2) khonghan(3) hoi sai(4) rat sai(5)

24. Toi da tung bi keu len phong Hieu-truong vi ly-do ky-luat.

rat dung(1) gan dung(2) khonghan(3) hoi sai(4) rat sai(5)

25. Toi khong co lo-lang gi ve tuong-lai cua toi ca.

rat dung(1) gan dung(2) khonghan(3) hoi sai(4) rat sai(5) 
26. Toi rat thong hieu tieng Anh trong cac lop hoc cua toi.

rat dung(1) gan dung(2) khonghan(3) hoi sai(4) rat sai(5)

27. Toi duoc cac hoc sinh My chap nhan va doi dai tu-te.

rat dung(1) gan dung(2) khonghan(3) hoi sai(4) rat sai(5)

28. Cac co-van hoc duong(counselors) giup do toi duoc nhieu.

rat dung(1) gan dung(2) khonghan(3) hoi sai(4) rat sai(5)

29. Hieu-truong,giao-su, co-van hoc duong hieu biet ve van-hoa cua toi.

rat dung(1) gan dung(2) khonghan(3) hoi sai(4) rat sai(5) 
APPENDIX $\mathrm{C}$

INTERVIEW QUESTIONS 


\section{INTERVIEW QUESTIONS}

1. How long have you been in the country?

2. Were there any special experiences you had in American schools.

3. Name some of your educational achievements so far.

4. What problems have you had in school since coming to America?

5. Are you a member of a club or participating in any after-school activities? What do you do in your spare time?

6. Can you share with me some of the things that you like about American schools and some of the things you dislike about them.

7. What are your educational/career goals?Do you have a plan to achieve these goals?Do you feel you are prepared for your future, or the world of work?

8. Do you have somebody that you see as a role model or who has influenced or helped you in your education?

9. What do you see as your strong characteristics in helping you in your education? And what do you consider as your weaknesses?

10. Is learning English important to you? Are you satisfied with what you have learned? If you had the opportunity to give feedback to your teachers what would you say?

11. Do you think you need to learn your native language? Why/Why not?

Do you have an opportunity to learn your native language now? 
12. Besides English, how are you doing with other subjects such as Math, Science, Health, History, Social Studies, Government,etc.? Are you satisfied with your progress in these areas? Why/Why not?

13. Do school staff communicate with you or your family? In what way and what is the purpose of their communication?

14. Have there been any changes or problems in your family in adjusting to the new society? What is your role in your family? Is there any change in your role comparing with the time you were in Vietnam?

15. Do you have American friends at school? Do you have Vietnamese friends at school? How is your relationship with them?

16. Have your values and attitudes changed since coming to America?

17. Do you know of any friends who dropped out of school? If yes, why?

18. Do you see yourself as a Vietnamese or as an American? Why?

19. There are many publicized stories of Asian gangs and drug/alcohol use among Asian students, what is your opinion on these issues?

20. If you had a wish about your education, what would it be and why? 


\section{APPENDIX D}

CAU HOI PHONG-VAN : VIETNAMESE VERSION 


\section{CAU HOI PHONG-VAN : VIETNAMESE VERSION}

1. Em o ben My duoc bao lau? Em dang hoc lop may?

2. Hay cho toi biet vai thanh cong va dac biet trong viec hoc cua em .

3. Tu ngay den My den gio, em co tro ngai gi o hoc duong hay khong?

4. Em co tham gia cac nhom hoi hay tham du sinh hoat nao sau gio hoc khong? Thi gio ranh roi em lam gi?

5. Em co the cho toi biet mot vai ma em thich ve truong My va vai dieu ma em khong thich.

6. Em co nhung muc tieu ve giao-duc va nghe nghiep khong? Em co chuong-trinh ke hoach gi khong? Em co nghi la em co chuan bi cho tuong lai khong?

7. Em co ai ma co anh huong hoac giup do em ve van de hoc hanh khong?

8. Em co biet nhung kha nang cua em ve van de giao duc khong? Va em co nhung yeu diem gi?

9. Viec hoc tieng My co quan trong doi voi em khong? Em co nghi rang viec hoc tieng Anh cua em thanh cong/thoa man khong? Neu em co dip cho y kien lai voi thay co day tieng My, em co loi khuyen gi?

10. Em co nghi la em can hoc tieng me de khong? Tai sao?

11. Ngoai mon tieng My ra, nhung mon hoc khac nhu Toan, Khoa hoc, Ve sinh Cach tri, su ky, Chinh Quyen v.v, em hoc nhu the nao? 
Em co thoa man hay thanh cong trong viec hoc cac mon nay khong? Tai sao? Neu em co quyen chon lua, em co muon nhung mon nay day bang tieng Viet khong? Em co nghi la no co giup do gi khong trong viec hoc?

12. Nhan vien nha truong co lien lac voi em va gia dinh khong? Bang phuong tien nao va voi muc dich gi?

13. Gia dinh em co thay doi va tro ngai gi trong van de dieu chinh voi xa hoi moi hay khong? Vai tro cua em trong gia dinh nhu the nao? So sanh voi thoi gian o Viet Nam, vai tro cua em co gi thay doi khong?

14. Em co ban than nguoi My o truong khong? Em co ban than nguoi Viet o truong khong? Su lien he cua em voi nhung ban do nhu the nao?

15. Tu ngay qua My den gio, thaido va gia tri doi song co gi thay doi khong?

16. Em co biet nguoi ban nao bo hoc hay khong? Neu co, ly do vi sao?

17. Em nghi em la nguoi My hay la nguoi Viet? Tai sao?

18. Em co quan diem gi khong ve van de bao chi dang ve van de du dang A Dong va viec dung ma tuy, ruou va can sa trong hoc sinh A dong?

19. Neu em co mot ao uoc ve viec hoc hanh va tuong lai cua em, em ao uoc gi va tai sao?

20. Co van de gi khac ve cuoc doi cua em ma em muon chia se voi toi khong? 
APPENDIX E

SURVEY RESULTS 


\section{SURVEY RESULTS}

1. How long have you been in U.S. schools?

$\begin{array}{ll}\text { Less than two years } & 41.7 \% \\ \text { Three to four years } & 21.8 \% \\ \text { More than Four years } & 37.5 \%\end{array}$

2. How many people live in your house?

$\begin{array}{ll}\text { Three people or less } & 10.3 \% \\ \text { Four to Seven people } & 60.0 \% \\ \text { Seven or more } & 29.6 \%\end{array}$

3. Who do you live with?

$\begin{array}{ll}\text { With family } & 84.1 \% \\ \text { Without family } & 15.9 \%\end{array}$

4. Do you have a job where you earn money?

$\begin{array}{ll}\text { Yes } & 26.9 \% \\ \text { No } & 73.1 \%\end{array}$

5. Check the school subjects you do well in:

$\begin{array}{lr}\text { Math/Sciences } & 55.1 \% \\ \text { Social Studies } & 4.1 \% \\ \text { English } & 13.1 \% \\ \text { Other } & 27.7 \%\end{array}$


6. I prefer to have these above classes taught in Vietnamese.

$\begin{array}{ll}\text { Agree(1) } & 24.8 \% \\ \text { Somewhat(2) } & 14.3 \% \\ \text { Not sure(3) } & 30.1 \% \\ \text { Not much(4) } & 12.8 \% \\ \text { Disagree(5) } & 18.0 \%\end{array}$

7. I have close Vietnamese friends.

$\begin{array}{lr}\text { Agree(1) } & 77.1 \% \\ \text { Somewhat(2) } & 13.2 \% \\ \text { Not sure(3) } & 5.6 \% \\ \text { Not much(4) } & 0.8 \% \\ \text { Disagree(5) } & 4.2 \%\end{array}$

8. Teachers make me feel welcome.

$\begin{array}{lr}\text { Agree(1) } & 44.1 \% \\ \text { Somewhat(2) } & 38.5 \% \\ \text { Not sure(3) } & 11.9 \% \\ \text { Not much(4) } & 1.4 \% \\ \text { Disagree(5) } & 4.2 \%\end{array}$

9. My parents don't care if I do well at school.

$\begin{array}{lc}\text { Agree(1) } & 9.8 \% \\ \text { Somewhat(2) } & 6.3 \% \\ \text { Not sure(3) } & 7.7 \% \\ \text { Not much(4) } & 7.0 \% \\ \text { Disagree(5) } & 69.2 \%\end{array}$


10. Teachers, counselors, principal visit me at home.

$\begin{array}{lr}\text { Agree(1) } & 2.1 \% \\ \text { Somewhat(2) } & 2.8 \% \\ \text { Not sure(3) } & 9.0 \% \\ \text { Not much(4) } & 9.0 \% \\ \text { Disagree(5) } & 77.1 \%\end{array}$

11. My parents want very much for me to do well at school.

$\begin{array}{lr}\text { Agree(1) } & 84.8 \% \\ \text { Somewhat(2) } & 10.3 \% \\ \text { Not sure(3) } & 2.8 \% \\ \text { Not much(4) } & 1.4 \% \\ \text { Disagree(5) } & 0.7 \%\end{array}$

12. I do homework at home.

$\begin{array}{lr}\text { Agree(1) } & 57.2 \% \\ \text { Somewhat(2) } & 26.2 \% \\ \text { Not sure(3) } & 7.6 \% \\ \text { Not much(4) } & 5.5 \% \\ \text { Disagree(5) } & 3.4 \%\end{array}$

13. I try very hard to do well in school.

$\begin{array}{lr}\text { Agree(1) } & 61.3 \% \\ \text { Somewhat(2) } & 29.3 \% \\ \text { Not sure(3) } & 6.3 \% \\ \text { Not much(4) } & 1.4 \% \\ \text { Disagree(5) } & 1.4 \%\end{array}$


14. I do not belong to any clubs at school.

$\begin{array}{ll}\text { Agree(1) } & 11.2 \% \\ \text { Somewhat(2) } & 16.1 \% \\ \text { Not sure(3) } & 23.1 \% \\ \text { Not much(4) } & 23.8 \% \\ \text { Disagree(5) } & 25.9 \%\end{array}$

15. I play sports at school.

$\begin{array}{ll}\text { Agree(1) } & 23.9 \% \\ \text { Somewhat(2) } & 14.8 \% \\ \text { Not sure(3) } & 14.1 \% \\ \text { Not much(4) } & 12.7 \% \\ \text { Disagree(5) } & 34.5 \%\end{array}$

16. Vietnamese students don't belong to gangs.

$\begin{array}{ll}\text { Agree(1) } & 25.9 \% \\ \text { Somewhat(2) } & 6.3 \% \\ \text { Not sure(3) } & 17.5 \% \\ \text { Not much(4) } & 21.0 \% \\ \text { Disagree(5) } & 29.4 \%\end{array}$

17. My school makes me feel welcome.

$\begin{array}{lr}\text { Agree(1) } & 36.1 \% \\ \text { Somewhat(2) } & 33.3 \% \\ \text { Not sure(3) } & 24.3 \% \\ \text { Not much(4) } & 2.1 \% \\ \text { Disagree(5) } & 4.2 \%\end{array}$


18. I have close American friends at school.

$\begin{array}{ll}\text { Agree(1) } & 26.2 \% \\ \text { Somewhat(2) } & 19.1 \% \\ \text { Not sure(3) } & 20.6 \% \\ \text { Not much(4) } & 14.9 \% \\ \text { Disagree(5) } & 19.1 \%\end{array}$

19. Vietnamese students don't smoke or drink alcohol.

$\begin{array}{ll}\text { Agree(1) } & 20.3 \% \\ \text { Somewhat(2) } & 10.5 \% \\ \text { Not sure(3) } & 20.3 \% \\ \text { Not much(4) } & 20.3 \% \\ \text { Disagree(5) } & 28.7 \%\end{array}$

20. I learn a lot from my ESL teachers.

$\begin{array}{lr}\text { Agree(1) } & 36.2 \% \\ \text { Somewhat(2) } & 15.9 \% \\ \text { Not sure(3) } & 13.0 \% \\ \text { Not much(4) } & 5.8 \% \\ \text { Disagree(5) } & 29.0 \%\end{array}$

21. It is O.K. at my school to use Vietnamese language.

$\begin{array}{lr}\text { Agree(1) } & 39.4 \% \\ \text { Somewhat(2) } & 28.2 \% \\ \text { Not sure(3) } & 10.6 \% \\ \text { Not much(4) } & 6.3 \% \\ \text { Disagree(5) } & 15.5 \%\end{array}$


22. Vietnamese students don't drop-out of school.

$\begin{array}{ll}\text { Agree(1) } & 21.1 \% \\ \text { Somewhat(2) } & 16.2 \% \\ \text { Not sure(3) } & 22.5 \% \\ \text { Not much(4) } & 15.5 \% \\ \text { Disagree(5) } & 24.6 \%\end{array}$

23. I have plans for my career after high school.

$\begin{array}{lr}\text { Agree(1) } & 52.8 \% \\ \text { Somewhat(2) } & 20.4 \% \\ \text { Not sure(3) } & 16.2 \% \\ \text { Not much(4) } & 4.9 \% \\ \text { Disagree(5) } & 5.6 \%\end{array}$

24. I have been referred to the principal for discipline.

$\begin{array}{lr}\text { Agree(1) } & 9.2 \% \\ \text { Somewhat(2) } & 6.3 \% \\ \text { Not sure(3) } & 6.3 \% \\ \text { Not much(4) } & 7.0 \% \\ \text { Disagree(5) } & 71.1 \%\end{array}$

25. I am not worried about my future.

$\begin{array}{ll}\text { Agree(1) } & 8.4 \% \\ \text { Somewhat(2) } & 6.3 \% \\ \text { Not sure(3) } & 13.3 \% \\ \text { Not much(4) } & 11.9 \% \\ \text { Disagree(5) } & 60.1 \%\end{array}$


26. I understand the English spoken in my classes.

$\begin{array}{lr}\text { Agree(1) } & 31.7 \% \\ \text { Somewhat(2) } & 20.4 \% \\ \text { Not sure(3) } & 28.9 \% \\ \text { Not much(4) } & 11.3 \% \\ \text { Disagree(5) } & 7.7 \%\end{array}$

27. I am accepted and treated well by other students.

$\begin{array}{lr}\text { Agree(1) } & 31.5 \% \\ \text { Somewhat(2) } & 23.8 \% \\ \text { Not sure(3) } & 25.2 \% \\ \text { Not much(4) } & 14.7 \% \\ \text { Disagree(5) } & 4.9 \%\end{array}$

28. School counselors help me a lot.

$\begin{array}{lr}\text { Agree(1) } & 25.9 \% \\ \text { Somewhat(2) } & 31.5 \% \\ \text { Not sure(3) } & 25.9 \% \\ \text { Not much(4) } & 6.3 \% \\ \text { Disagree(5) } & 10.5 \%\end{array}$

29. Principal,teachers, counselors understand about my culture.

$\begin{array}{lr}\text { Agree(1) } & 22.5 \% \\ \text { Somewhat(2) } & 28.9 \% \\ \text { Not sure(3) } & 31.0 \% \\ \text { Not much(4) } & 7.7 \% \\ \text { Disagree(5) } & 9.9 \%\end{array}$

